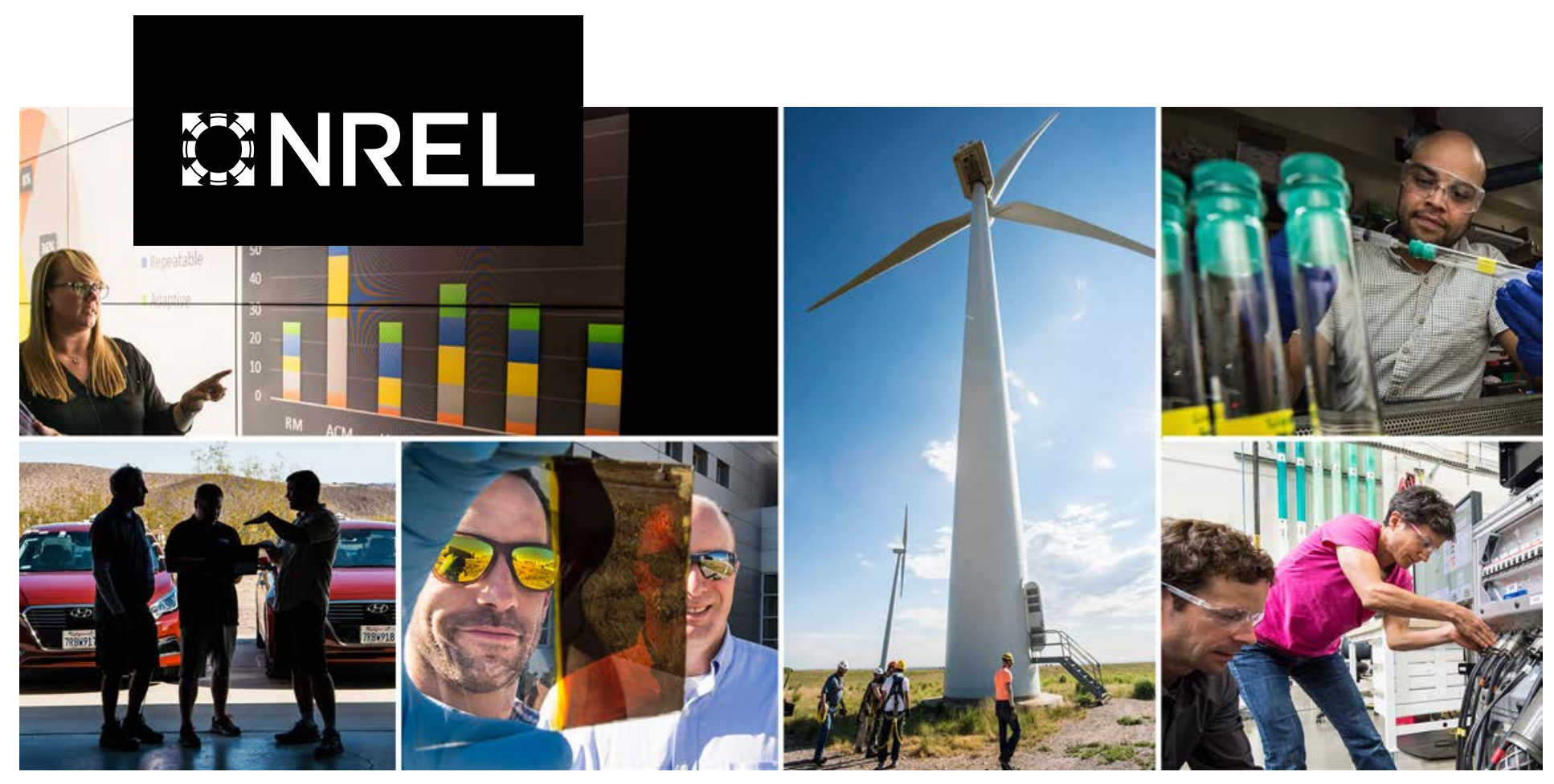

\title{
Impacts of Price Formation Efforts Considering High Renewable Penetration Levels and System Resource Adequacy Targets
}

Robin Broder Hytowitz, ${ }^{2}$ Bethany Frew, ${ }^{1}$ Gord Stephen, ${ }^{1}$ Erik Ela, ${ }^{2}$ Nikita Singhal, ${ }^{2}$ Aaron Bloom, ${ }^{1}$ and Jessica Lau ${ }^{1}$

${ }^{1}$ National Renewable Energy Laboratory

${ }^{2}$ Electric Power Research Institute

NREL is a national laboratory of the U.S. Department of Energy Office of Energy Efficiency \& Renewable Energy

Operated by the Alliance for Sustainable Energy, LLC

This report is available at no cost from the National Renewable Energy Laboratory (NREL) at www.nrel.gov/publications.
Technical Report

NREL/TP-6A20-74230

May 2020 


\title{
GNREL
}

\section{Impacts of Price Formation Efforts Considering High Renewable Penetration Levels and System Resource Adequacy Targets}

\author{
Robin Broder Hytowitz, ${ }^{2}$ Bethany Frew, ${ }^{1}$ Gord Stephen, ${ }^{1}$ \\ Erik Ela, ${ }^{2}$ Nikita Singhal, ${ }^{2}$ Aaron Bloom,${ }^{1}$ and Jessica Lau ${ }^{1}$ \\ ${ }^{1}$ National Renewable Energy Laboratory \\ ${ }^{2}$ Electric Power Research Institute
}

\section{Suggested Citation}

Hytowitz, Robin Broder, Bethany Frew, Gord Stephen, Erik Ela, Jessica Lau, Nikita Singhal, and Aaron Bloom. 2020. Impacts of Price Formation Efforts Considering High Renewable Penetration Levels and System Resource Adequacy Targets. Golden, CO: National Renewable Energy Laboratory. NREL/TP-6A20-74230.

https://www.nrel.gov/docs/fy20osti/74230.pdf.

NREL is a national laboratory of the U.S. Department of Energy Office of Energy Efficiency \& Renewable Energy Operated by the Alliance for Sustainable Energy, LLC

This report is available at no cost from the National Renewable Energy Laboratory (NREL) at www.nrel.gov/publications.

Contract No. DE-AC36-08GO28308
Technical Report

NREL/TP-6A20-74230

May 2020

National Renewable Energy Laboratory 15013 Denver West Parkway Golden, CO 80401

303-275-3000 • www.nrel.gov 


\section{NOTICE}

This work was authored in part by the National Renewable Energy Laboratory, operated by Alliance for Sustainable Energy, LLC, for the U.S. Department of Energy (DOE) under Contract No. DE-AC3608GO28308. Funding provided by U.S. Department of Energy Office of Energy Efficiency and Renewable Energy Wind Energy Technologies Office. The views expressed herein do not necessarily represent the views of the DOE or the U.S. Government. The authors especially thank Charlton Clark and Jian Fu for their guidance on this work, and Aaron Bloom and Dan Steinberg (NREL) for providing valuable feedback on the draft of this paper. The authors would like to thank Qingyu Xu who contributed to this project during his time as an intern at EPRI.

This report is available at no cost from the National

Renewable Energy Laboratory (NREL) at

www.nrel.gov/publications.

U.S. Department of Energy (DOE) reports produced after 1991 and a growing number of pre-1991

documents are available

free via www.OSTI.gov.

Cover Photos by Dennis Schroeder: (clockwise, left to right) NREL 51934, NREL 45897, NREL 42160, NREL 45891, NREL 48097, NREL 46526.

NREL prints on paper that contains recycled content. 


\section{Acknowledgements}

This work was authored in part by the National Renewable Energy Laboratory, operated by Alliance for Sustainable Energy, LLC, for the U.S. Department of Energy (DOE) under Contract No. DE-AC36-08GO28308. Funding provided by U.S. Department of Energy Office of Energy Efficiency and Renewable Energy Wind Energy Technologies Office. A portion of this research was performed using computational resources sponsored by the Department of Energy's Office of Energy Efficiency and Renewable Energy and located at the National Renewable Energy Laboratory. The authors especially thank Jian Fu for sponsoring this work and Paul Denholm, Greg Brinkman, Trieu Mai (NREL), Eamonn Lannoye, Aidan Tuohy, Jeffery Roark (EPRI), Francisco D. Munoz (Universidad Adolfo Ibáñez), Jonghwan Kwon (Argonne National Laboratory), and Richard O'Neill (FERC) for providing feedback on the draft of this paper. The views expressed in the article do not necessarily represent the views of the DOE or the U.S. Government. The U.S. Government retains and the publisher, by accepting the article for publication, acknowledges that the U.S. Government retains a nonexclusive, paid-up, irrevocable, worldwide license to publish or reproduce the published form of this work, or allow others to do so, for U.S. Government purposes. 


\section{List of Acronyms}

$\begin{array}{ll}\text { AESO } & \text { Alberta Electric System Operator } \\ \text { AGC } & \text { automatic generation control } \\ \text { AIC } & \text { average incremental costs } \\ \text { ATB } & \text { Annual Technology Baseline } \\ \text { CC } & \text { combined cycle } \\ \text { CT } & \text { combustion turbine } \\ \text { DA } & \text { day-ahead } \\ \text { ELMP } & \text { extended locational marginal price } \\ \text { ERCOT } & \text { Electric Reliability Council of Texas } \\ \text { EUE } & \text { expected unserved energy } \\ \text { FERC } & \text { Federal Energy Regulatory Commission } \\ \text { IESO } & \text { Independent Electricity System Operator } \\ \text { ISO } & \text { independent system operator } \\ \text { ISO-NE } & \text { ISO New England } \\ \text { LMP } & \text { locational marginal price } \\ \text { LOLE } & \text { loss of load expectation } \\ \text { MISO } & \text { Midcontinent Independent System Operator } \\ \text { MW } & \text { megawatt } \\ \text { MWh } & \text { megawatt-hour (MWh) } \\ \text { NPD } & \text { non-powered dam } \\ \text { NREL } & \text { National Renewable Energy Laboratory } \\ \text { NYISO } & \text { New York Independent System Operator } \\ \text { Pmax } & \text { maximum capacity of a generator } \\ \text { RT } & \text { real-time } \\ \text { RTO } & \text { regional transmission operator } \\ \text { SPP } & \text { Southwest Power Pool } \\ \text { ST } & \text { steam turbine }\end{array}$




\section{Executive Summary}

Electric energy prices in wholesale markets are formed to maximize market surplus for supply and demand and send signals to market participants to follow energy and reserve schedules that ensure short-term reliability. They also, sometimes in combination with other mechanisms, provide signals for resources that are needed for long-term resource adequacy to remain in place and for those not needed to retire. In recent years, expanded supply of low cost natural gas, increased energy efficiency, growing penetration levels of renewable energy, and substantial reserve margins have contributed to declining energy prices in wholesale electricity markets. Future markets with very high penetrations of renewable energy could have many more low- to zero-priced periods, which could impact energy revenues for the generation fleet. This can potentially affect the ability of resources that are needed for long-term reliability to recover both operating and capital costs. These revenue sufficiency and resource adequacy concerns have prompted much discussion over the importance of "getting prices right" in wholesale electricity markets.

Traditional electric energy pricing methods reflect the resource's marginal cost of providing energy. However, generators incur other operational costs, such as online commitment costs (\$/hour) and start-up costs (\$/start), which are nonconvex and not captured in this traditional pricing formulation. If revenue solely came from marginal cost pricing, resources that incur these other operational costs could earn less revenue than their total incurred costs for daily operations. Due to this characteristic, markets pay make-whole payments to ensure participants, at a minimum, recover their bid-in operating costs. Make-whole payments are included in the broader category of uplift payments, which can include lost-opportunity cost payments and other side payments. Unlike prices which are public, these individual payments are private and given to individual resources.

Since traditional prices do not capture all costs incurred while dispatching resources, alternative pricing methods have been proposed and implemented across the United States. Such methods can increase transparency by revealing more information in the public price and can send a price signal to existing and potential resources on opportunities for entry into the market. Though alternative pricing mechanisms do not reflect capital costs in pricing, they do reflect the additional operating costs (start-up and commitment/no-load costs) that systems incur during daily operations and they allow resources to set prices during time periods that otherwise would be ineligible. By incorporating online commitment costs in the price, many alternative pricing methods result in reduced need for uplift payments. While the methods can result in increased transparency and reduced uplift, they can also cause short-term incentive mismatches (e.g., prices higher than a resource's marginal costs, causing that resource to 'chase' the higher price) that must be addressed through market rules. This study explores the impact of one alternative pricing mechanism on revenue sufficiency metrics for existing and future resource mixes, including those with high penetrations of wind and solar.

Resource adequacy ensures that the planned resource mix can meet the future system capacity needs, with a very small probability of failing to do so. In fully deregulated markets, the investments that are needed to meet resource adequacy targets at lowest cost require sufficient revenue streams in order to sustain existing operations and/or plan for capital expenditures. The 
formation of energy spot prices does not directly aim to recover investment costs; the goal is rather to incentivize efficient operations and maintain reliability (FERC 2015a).

This study compares price, revenues, and cost outcomes with a traditional pricing mechanism against one alternative pricing mechanism. Each of these pricing mechanisms is evaluated across four sensitivity scenarios that encompass two categories: (1) high versus low renewable penetration levels, and (2) using a resource mix that has been adjusted to a preset resource adequacy target (adjusted) versus one that contains a full set of resources without retirements of unneeded resources (unadjusted). The sensitivity scenarios are tested on a modified version of the RTS-GMLC ${ }^{1}$, a 73-node test system with load, wind, and solar data, that are synchronized together in time, simulating a year of day-ahead and real-time markets operations. The alternative pricing mechanism analyzed is referred to as Relaxed Minimum, where prices incorporate fixed online commitment costs by relaxing a generator's minimum operating level to zero; the prices with this pricing design reflect that these costs can be viewed as incremental costs to operate the resource.

Results from different pricing methodologies under the developed scenarios show several key trends. First, renewable penetration has a greater impact on pricing and resulting net revenue than the resource mix adjusted for a resource adequacy target. While the resource adequacyadjusted cases have higher average prices than the unadjusted cases, the shape of the price duration curves and the average prices across hours and seasons are similar between these two cases. In contrast, the shapes and averages differ between the renewable penetration levels.

Second, the change in annual net revenue normalized by capacity between the traditional and Relaxed Minimum pricing method is modest; the range is between $+\$ 2.2 / \mathrm{kW}-\mathrm{yr}$ to $-\$ 3.6 / \mathrm{kW}-\mathrm{yr}$, representing $0.6 \%$ to $2.1 \%$ of average capital costs and the absolute difference (or mean absolute error) ranges between $\$ 3.5 / \mathrm{kW}$-yr to $\$ 9.9 / \mathrm{kW}$-yr. For the high renewable scenarios, the average net revenue is higher under traditional pricing, whereas the low renewable scenarios have higher net revenue for Relaxed Minimum pricing. There are more distinct trends when reviewing net revenue by fuel type. Those units which have average net revenue higher in the traditional pricing method are primarily non-renewable resources; across the four scenarios, $84 \%$ of nonrenewable units have higher net revenue under traditional pricing. Renewable units show opposite trends; $99 \%$ of renewable units make higher net revenue under Relaxed Minimum pricing compared to traditional. Solar resources are the only fuel type where all units have higher net revenue under Relaxed Minimum pricing. In the high renewable cases, wind resources can also make enough net revenue to surpass their annualized fixed capital costs. Few other units were able to make enough money from energy and make-whole payments alone to cover capital costs, and only the revenues from gas combined cycle units exceeded their capital costs on average.

Finally, prices under the higher renewable penetration were higher than the low renewable penetration, driven primarily by a higher frequency of scarcity pricing conditions. Similar to Independent System Operators (ISOs) today who assign administratively determined scarcity

${ }^{1}$ RTS-GMLC is Reliability Test System-Grid Modernization Lab Consortium. For more information, see (Barrows et al. 2019). 
prices that set prices during periods where system reserves are insufficient to meet needs, this analysis used an exogenous price for scarcity. The many periods of scarcity in the high renewables cases are not meant to indicate future conditions and are specific to the test system and operating procedure assumptions used in the study; they rather emphasize the importance of performing sensitivities to exogenously-determined scarcity prices. The result is counterintuitive to existing hypotheses that higher renewable penetration systems result in lower average energy prices. However, renewables also add uncertainty to markets, especially when considering the outcomes of both day-ahead and real-time markets. If averaging only the periods without price spikes, prices resulted in the intuitive trend that high renewable scenarios might have lower prices. However, the values on average covers fewer hours (because hours with spikes are removed), and they do not consider the scarcity which might occur due to renewables. While these simulations used a single set of modeling assumptions, a sensitivity analysis was conducted using different exogenous scarcity prices. These results highlight the importance of scarcity price assumptions; price results should be interpreted with an understanding of these assumptions.

These conclusions are not intended to be direct predictions for future outcomes but rather to lead to additional insight on the impacts of pricing on investment incentives and future resource adequacy targets. The analysis was performed for a single test system, and results and conclusions on pricing, net revenue, and impact may be different with other systems, resource mixes, and operating assumptions. Additional research should examine the impact of other alternative pricing mechanisms on prices and revenue, including further sensitivity analysis on the penetration of renewable energy. Future work can include simulations including price responsive demand, which might reduce the number of price spikes under every scenario, or multi-period pricing and dispatch, which can capture the impact of many system conditions in prices, including ramping. 


\section{Table of Contents}

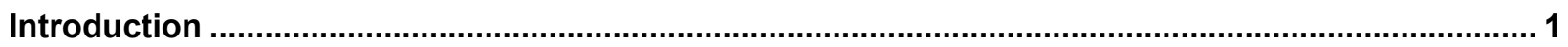

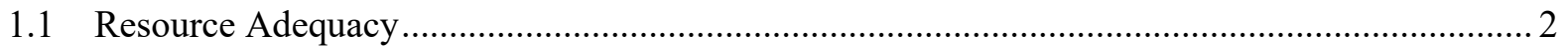

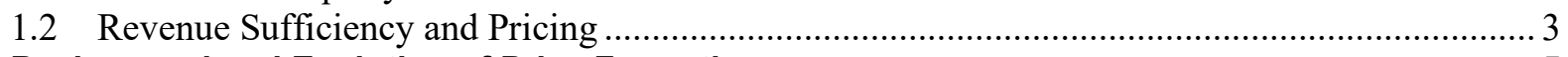

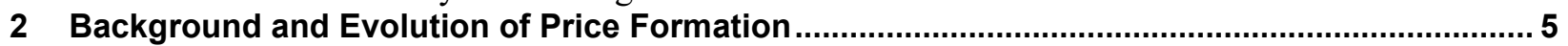

2.1 Proposed Methods to Determine Spot Market Prices............................................................ 6

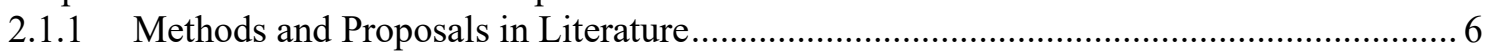

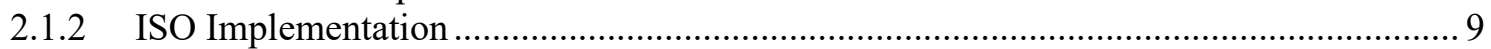

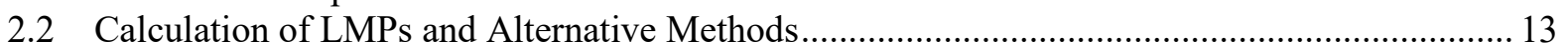

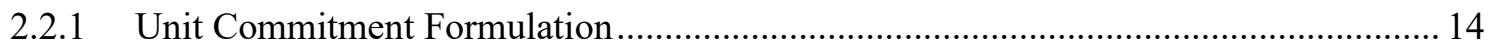

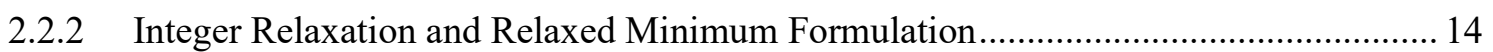

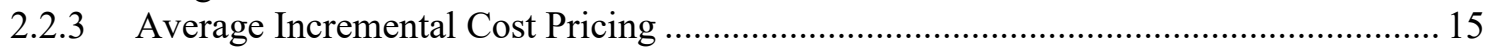

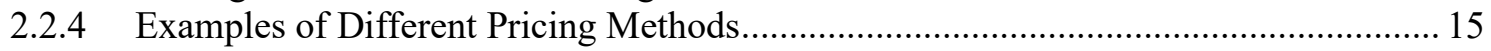

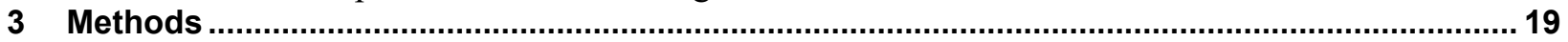

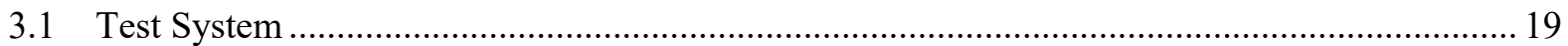

3.2 Generation Fleet Adjustment Process ............................................................................ 20

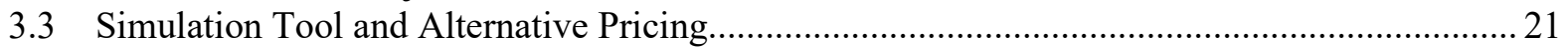

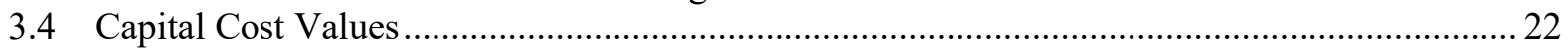

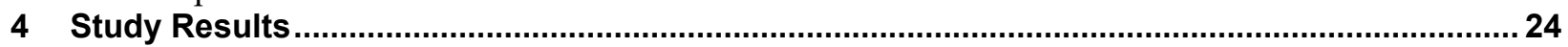

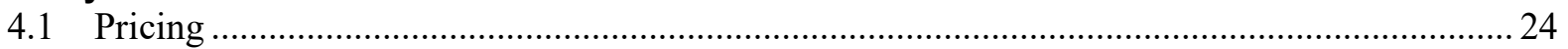

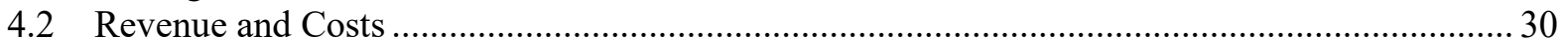

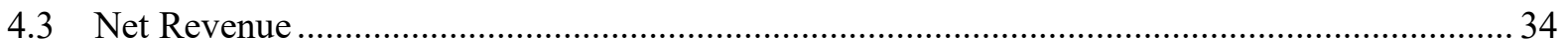

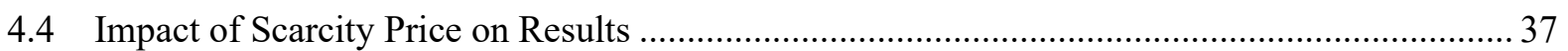

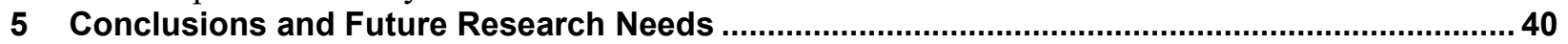

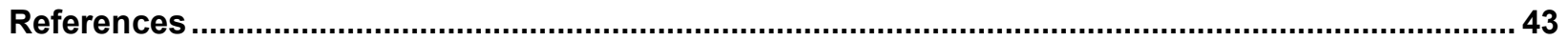

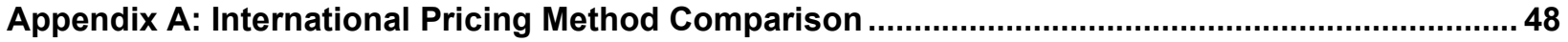

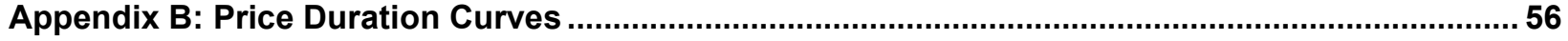

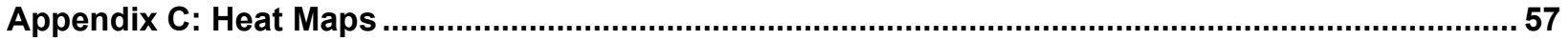




\section{List of Figures}

Figure 1. Different pricing methods across increasing demand levels ................................................. 18

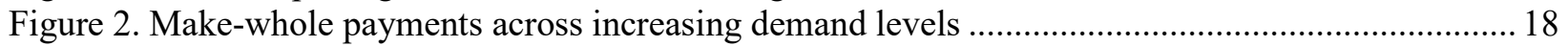

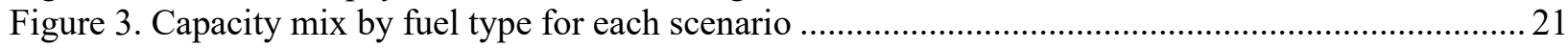

Figure 4. Price averages for each scenario .................................................................................... 26

Figure 5. Price duration curves for values under $\$ 200 / \mathrm{MWh}$ for each scenario: (a) high/adjusted, (b)

high/unadjusted, (c) low/adjusted, (d) low/unadjusted ......................................................... 27

Figure 6. Revenue, uplift, and operating costs ("Costs") compared to annualized capital costs ("Capital") for a) high/adjusted, b) high/unadjusted, c) low/adjusted, and d) low/unadjusted scenarios. 33

Figure 7. Box plot of net revenue (profits) per resource compared to annualized capital costs ( $\$ / \mathrm{kW}-\mathrm{yr})$ for a) high/adjusted, b) high/unadjusted, c) low/adjusted, and d) low/unadjusted scenarios. 36

Figure 8 Average yearly prices resulting from different scarcity prices for a) day-ahead and b) real-time, ranging from $\$ 500 / \mathrm{MWh}$ to $\$ 2000 / \mathrm{MWh}$. Numbers shown on the figure are the averages used in study results, \$1000/MWh. Alternative = Relaxed Minimum.................................. 38

Figure 9 Scarcity price sensitivity for average net revenue. Light colors show a price of $\$ 500 / \mathrm{MWh}$, darkest colors show \$1000/MWh, and medium colors show \$2000/MWh for both traditional and Relaxed Minimum pricing for a) high/adjusted, b) high/unadjusted, c) low/adjusted, and

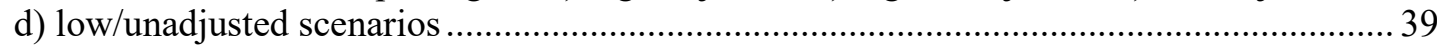

Figure B-1. Price duration curves for (a) high/adjusted, (b) high/unadjusted, (c) low/adjusted,

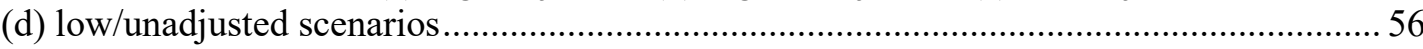

\section{List of Tables}

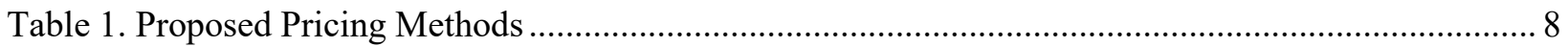

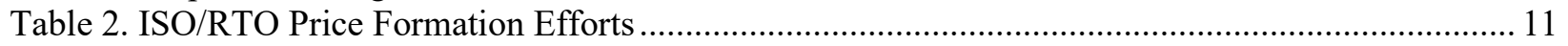

Table 3. Alternative Pricing Characteristics ..................................................................................... 13

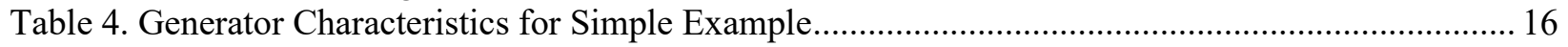

Table 5. Commitment and Dispatch Solution for Demand Value of 70 MW .......................................... 16

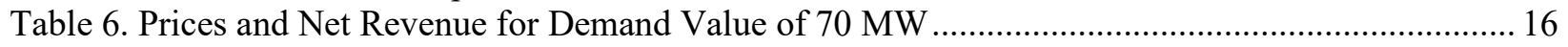

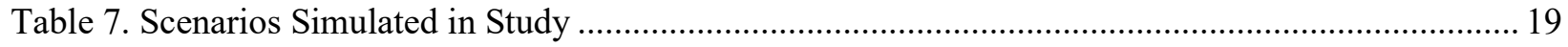

Table 8. Details About the Annual Technology Baseline (ATB) Values ................................................ 23

Table 9. Real-Time Price Statistics, Percentage Based on Number of Five-Minute Periods in the Year... 24

Table 10. Heat Map of Traditional Average Real-Time Prices for the High/Adjusted Scenario over the Course of a Day (24 hours) for Each Month of the Year in \$/MWh...............................2 29

Table 11. Heat Map of Relaxed Minimum Average Real-Time Prices for the High/Adjusted Scenario

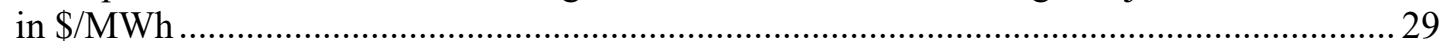

Table 12. Heat Map of Traditional Average Real-Time Prices for the Low/Adjusted Scenario in \$/MWh

Table 13. Heat Map of Relaxed Minimum Average Real-Time Prices for the Low/Adjusted Scenario

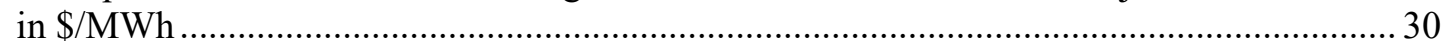

Table A-1. International Price Formation Efforts .............................................................................. 49

Table C-1. Heat Map of Traditional Average Real-Time Prices for the High/Unadjusted Scenario over the Course of a Day (24 hours) for Each Month of the Year in \$/MWh ................................... 57

Table C-2. Heat Map of Relaxed Minimum Average Real-Time Prices for the High/Unadjusted Scenario

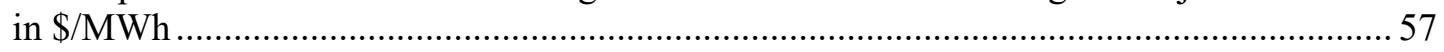

Table C-3. Heat Map of Traditional Average Real-Time Prices for the Low/Unadjusted Scenario

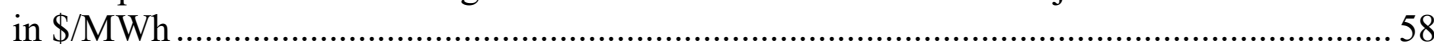

Table C-4. Heat Map of Relaxed Minimum Average Real-Time Prices for the Low/Unadjusted Scenario

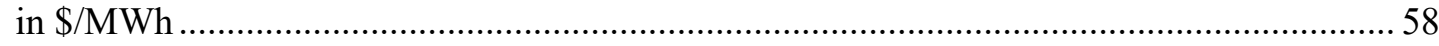




\section{Introduction}

This paper is focused on the details of alternative pricing formulations for energy prices in competitive wholesale electricity markets in the United States. We provide additional background on some international markets (see section A.1), as well as brief descriptions of resource adequacy and revenue sufficiency as it relates to the analysis here. However, we do not provide background materials on the basics of how competitive wholesale electricity markets operate. We refer readers to Stoft (2002), Kirschen and Strbac (2004), EPRI (2016), Ela et al. (2014), and FERC (2015b) for such background.

Traditional wholesale electricity markets consist of energy markets, ancillary services or essential reliability services markets, financial transmission rights, and capacity markets or resource adequacy requirements. This paper focuses on the energy markets, analyzing the pricing methodology behind day-ahead and real-time markets. Resources in U.S. electricity markets today are allowed to bid three-part offers: incremental $\operatorname{costs}^{2}$ (fuel and variable operations and maintenance), fixed hourly operating costs (often called commitment/no-load or minimum run costs), and start-up costs. Traditional energy-pricing formulations reflect the incremental cost of resources but do not reflect the commitment costs that are also incurred during operations. If revenue solely came from marginal cost pricing, marginal resources would recover only their incremental costs, meaning they would lose money (the commitment costs) by entering the market. Due to this characteristic, markets pay make-whole payments to ensure participants, at a minimum, recover bid-in costs. Make-whole payments are included in the broader category of uplift payments, which can include lost-opportunity cost payments and other side payments. Unlike prices which are public, these payments are private and given to individual resources, meaning they are not fully transparent. They are also often allocated widely, which can dull the locational or temporal price signals.

Due to the complexities of electricity markets, many pricing proposals have arisen over time, often referred to as price formation efforts. Alternative pricing methods aim to increase transparency in market prices, ensure resources follow their dispatch signals, and incentivize short- and long-term investment signals. Many alternative pricing methods capture the commitment costs in the price, which often reduces the need for uplift payments. While most agree that there is a need to "get the prices right," economists, mathematicians, and engineers do not agree on a single solution to this problem.

Price formation is also relevant to recent concerns over revenue sufficiency, driven by suppressed energy prices from low natural gas prices, lower-than-expected load growth, high reserve margins, and low- to zero-marginal-cost renewable resources. As low-incremental-cost renewable energy enters electricity markets, it shifts supply curves further to the right, often decreasing average wholesale energy spot prices (Seel et al. 2018). Future markets with high penetration levels of renewable energy could have many low to zero cost periods, which could

\footnotetext{
${ }^{2}$ In this paper, fuel and variable operations and maintenance costs that change with the output of a generator are called incremental costs. These costs can also be referred to as variable costs. When the term marginal cost is used, it refers to the cost of the marginal generator.
} 
reduce energy revenues for existing generation and could impact the ability of resources that are needed for long-term reliability to recover operating and capital costs. This revenue sufficiency challenge can reduce incentives for new entry of supply resources as well as the incentives of existing resources to refrain from retirement, which can in turn challenge long-term system resource adequacy. Many utilities and research organizations are examining these challenges and considering whether any changes to the way markets are operated and designed are needed to address these challenges.

This study explores the impact of alternative pricing mechanisms on revenue sufficiency for different resource mixes. The central questions the study addresses are:

- Does the method for calculating the auction price of energy impact overall revenue sufficiency?

- If so, how? How will different resource mixes impact prices?

- Are prices providing transparent signals for investment?

These questions will be addressed in the following sections. The rest of Section 1 describes the importance of resource adequacy, and how prices impact revenue sufficiency and resource adequacy. Section 2 provides background on wholesale spot market pricing for electricity, recent changes to the pricing formulations, and mathematical formulations and examples of traditional and alternative prices. Section 3 details the methods used in this study, including the test system, generation fleet adjustment, simulation software, and fixed capital costs. The study results are shown in Section 4 through resulting prices, revenue, and net revenue. Section 5 describes lessons learned from the study as well as future work. The appendices include additional price results, as well as a comparison of pricing methods from other countries and regions as context for ongoing pricing efforts in the United States.

\subsection{Resource Adequacy}

A key objective of power systems operations is to reliably supply electricity at the lowest reasonable cost to the end user. To help provide such reliable operations, system planners set resource (or capacity) adequacy targets to ensure sufficient energy supply resources exist to support a very small probability, magnitude, and duration of involuntary load shedding caused by shortfalls in supply capacity. This planning reliability target is distinct from operational reliability standards. Resource adequacy is typically estimated with planning reserve margins or, more ideally, with probability-based metrics such as expected unserved energy (EUE) or loss of load expectation (LOLE) that quantify the risk of a shortfall. A common resource adequacy target is an LOLE of 1 day/10 years; however, there is no universal resource adequacy target. Instead, each planning area sets its own target, which is often the result of an administrative action that establishes an acceptable level of reliability for long-term supply. In North America, the North American Electric Reliability Corporation annually assesses, but does not enforce, seasonal and long-term planning reserve margins (NERC 2017).

Whatever the resource adequacy target may be, it is fundamentally divorced from the market process and outcomes unless there is a resource adequacy component in electricity pricing (Ela et al. 2014; Cramton, Ockenfels, and Stoft 2013; Milligan et al. 2017). Because energy-only markets cannot explicitly take into account whether the target is 1 day/10 years, 1 day/2 years, or 1 day/20 years, there is no reason to expect the market will simultaneously deliver the targeted 
long-term reliability, balance supply and demand, and provide sufficient revenue to all resources so that all costs (fixed and incremental) are recovered. This means energy-only markets by themselves - without any connection between resource adequacy and prices - can but are not guaranteed to achieve an administered resource adequacy target.

\subsection{Revenue Sufficiency and Pricing}

Ensuring resource adequacy requires maintaining needed resources in the existing fleet and incentivizing investments that meet resource adequacy targets, which can either be set by a planning authority or through customer preference. Both future investments and existing resources are maintained by having enough revenue to recover costs (Pfeifenberger et al. 2013). However, in organized markets the formation of energy prices from an auction clearing mechanism does not directly incorporate investment or capital costs (Cochran et al. 2013). Energy prices are instead intended to help speculators or investors understand potential energy market revenue. Capacity markets are meant to address the 'missing money' problem in energy markets and capture the cost of investment. While each U.S. capacity market operates with different rules and many are presently undergoing changes, capacity market revenue can help both existing and future resources recover investment costs. Some regions do not operate capacity markets and one, ERCOT, is an energy-only market without direct payments for capacity.

The creation of spot market electricity prices serves many purposes. In a recent notice of proposed rulemaking, the Federal Energy Regulatory Commission (FERC 2015a) explained several main goals for price formation, paraphrased here:

- Maximization of market surplus for both suppliers and consumers

- Incentivization following dispatch instructions, efficient investments, and reliability

- Price transparency

- Bid-cost recovery.

The goals acknowledge that pricing for electricity is complex and there are many attributes for getting the price right. Capital costs are not directly included into the formation of prices, but incentivizing efficient investment is a direct aim of price formation. Potential investors might look to spot market electricity market outcomes to understand future revenue streams. These signals can be difficult to understand without transparency, as some payments to ensure bid cost recovery (e.g., make-whole payments) are generally known only by the individual market participant that receives them.

Many regional markets have several revenue streams available to generators. Many U.S. markets either run a capacity auction or use capacity payments to help generators recover capital costs. However, some markets are considered energy-only markets, where revenue is limited to payments from energy and ancillary services. The Electric Reliability Council of Texas (ERCOT) is the only market in the United States that does not pay some form of capacity 
payments $^{3}$; markets in Scandinavia, New Zealand, and Australia are examples of energy-only markets from abroad (Pfeifenberger 2014).

Traditional wholesale electricity prices reflect the incremental cost bids of suppliers (EPRI 2016). Many new resources entering markets have low or zero (and in cases of production-based subsidies, even negative) incremental costs and high capital costs. Future revenue streams in energy-only markets can decline if prices similarly decline (Seel et al. 2018). Though alternative pricing mechanisms do not reflect capital costs in pricing, they often reflect some level of the additional operating costs beyond incremental costs that systems incur during daily operations, including start-up and no-load or minimum generation operating costs. Incorporating these additional costs into prices may lead to greater transparency and clearer incentives for efficient investments for the reasons discussed in Section 2.

\footnotetext{
${ }^{3}$ SPP does not have a capacity market but requires market participants to have enough capacity to cover their obligations (FERC 2015b). CAISO supports the California Resource Adequacy program, and provides 'backstop' mechanisms through the Capacity Procurement Mechanism in addition to reliability must run contracts.
} 


\section{Background and Evolution of Price Formation}

Determining spot market pricing for electricity is a complex process compared to other commodities. First, electricity market designs in the United States include both physical and financial elements, where auction quantities and pricing are influenced by the physics of electricity delivery. Second, many generation resources have both incremental and commitment costs that are incurred every hour, creating a multipart non-convex supply curve. Pricing reflects both the locational and temporal aspects of the marginal cost of producing energy. Energy prices in the United States are thus called locational marginal prices (LMPs). Although the use of LMPs for electricity pricing is prevalent today in the United States, it has changed over time to reflect both computational advances and the evolution of electricity market design.

Electricity pricing has evolved from concepts originally presented by Schweppe, Caramanis, Tabors, and Bohn in Spot Pricing of Electricity (1988). Though they presented pricing that reflected nodal location, most electricity markets were founded using zonal prices (Lin and Magnago 2017). Similar to the current European system, these markets historically priced electricity starting with a large region or zone, and they then produced a uniform price for electricity without considering intraregional transmission congestion. While zonal pricing might have been simpler, it also obscured intraregional locational price signals. As zonal markets were observed to be less efficient and open to manipulation, all U.S. markets had moved to the use of nodal pricing as of 2010, with the latest implementation in ERCOT. Today, individual generator buses or nodes in a network have distinct prices that reflect congestion throughout the network and provide geographic information for future investment in generation and transmission. Implementation of LMP pricing varies between markets, and all make modifications to basic LMP theory (e.g., the price represents an increment of demand rather than theory in which prices (dual variables) can represent an increment or decrement of demand).

Pricing has also been impacted by computational and algorithmic advances. Independent system operators (ISOs) and regional transmission organizations (RTOs) originally used Lagrangian relaxation to determine generator schedules in markets solving the unit commitment problem. However, those results were less efficient than schedules determined using mixed-integer programming (Sioshansi, O'Neill, and Oren 2008). As computers and solution algorithms have become faster and more efficient, all U.S. ISOs/RTOs now use mixed-integer programming for their unit commitment solution, which results in more efficient solutions and prices.

The computational burden to solve electricity market schedules and pricing is high due to the non-convexities or "lumpiness" in electricity supply. Many resources have non-convex characteristics that are directly modeled in the scheduling problem; these include minimum economic operating levels, minimum run times, and commitment costs. In the United States, electricity market operators typically allow resources to submit a three-part bid that includes their fixed and incremental operating costs: step-wise incremental costs, no-load or minimum generation operating costs, and start-up costs. Together, these costs create a non-convex supply curve, meaning the prices are not monotonically nondecreasing with increasing demand. Resources that are dispatched to their minimum operating level or are block-loaded (i.e., their minimum capacity and maximum capacity levels are the same) are unable to set price, even though their dispatch impacts market efficiency. 
Alternative pricing proposals have been introduced to address the unique nature of electricity pricing. In Section 2.1, we characterize proposed methods to calculate electricity prices and detail implementation efforts by each ISO. In Section 2.2, we describe traditional and alternative pricing through formulations and simple examples.

\subsection{Proposed Methods to Determine Spot Market Prices}

While nodal pricing has not drastically changed since being introduced in each ISO, the formation of pricing and definition of marginal costs used to set prices has recently come under review. Most U.S. ISOs and RTOs have either modified or are proposing alternative pricing. Additionally, FERC released several orders and notices related to pricing over the last few years, including uplift allocation, scarcity pricing, price mitigation, and pricing for fast start resources (FERC 2018). These endeavors, commonly referred to as "price formation" efforts, have spurred renewed interest in both industry and academia.

\subsubsection{Methods and Proposals in Literature}

Although most implementations of alternative pricing have occurred recently, the ideas behind it originated decades ago. Economic and operations research literature have considered the problem of non-convex pricing, often applied to small electricity problems (Scarf 1990; Liberopoulos and Andrianesis 2016). This section describes a range of proposals that have not been adopted by the U.S. ISOs but which have notable properties; refer to Table 1 for the complete list.

Several key articles provide the foundation for current traditional and alternative pricing methods. Critical analysis of the electricity pricing problem, including formulations and economic justifications, was published by O'Neill et al. in 2005 and forms the groundwork for interpreting traditional LMPs. The first proposed method we highlight, often called Integer Pricing, determines prices from the dual variable of the node/load balance constraint in a typical unit commitment problem. Prices will reflect the marginal cost to produce an increment or decrement of demand. The make-whole payment is then determined from dual variables on constraints fixing commitment variables; since the price reflects the marginal costs, resources should not be incentivized to deviate above their optimal dispatch. This method reduces the computational complexity of the dispatch algorithm (mixed integer linear program to a linear program), and additionally requires minimal modifications for implementation (fixing the commitment variables to their optimal solution).

More recent alternative pricing methods are based on Convex Hull Pricing, originating from Hogan and Ring (2003) and Gribik, Hogan, and Pope (2007). Convex Hull Pricing results in a price that minimizes both make-whole payments and lost opportunity costs. Make-whole payments ensure bid-cost recovery, while lost opportunity cost payments ensure a participant is not incentivized to deviate from the dispatch signal sent by the operator. Since the scheduling and pricing run are decoupled, there is a chance a unit will be dispatched below its maximum and the price will be higher than its incremental cost. If this is the case, the participant would be incentivized to increase output to capture more revenue. In order to incentivize the resource to follow the dispatch signal, the operator can pay a lost opportunity cost equal to the potential profit higher profit. Convex Hull Pricing minimizes both payments, meaning the incentive to follow the dispatch signal is represented in the formulation. The resulting prices and payments 
only minimize the combination of make-whole payments and lost opportunity costs (i.e., they do not minimize make-whole payments alone) and are not guaranteed to be revenue adequate. After originally implementing an approximation to Convex Hull Pricing, Midcontinent ISO (MISO) has updated the formulation to include better approximations (Wang et al. 2013; Hua and Baldick 2017). Implementation of full Convex Hull Pricing is immensely computationally difficult (Schiro et al. 2016; Zheng et al. 2018), which is why ISOs have approximated the method for implementation. Another method, Modified Integer Programming (Bjørndal and Jörnsten 2008), alters the pricing formulation from the Integer Programming method to decrease volatility across increasing demand levels. As demand increases, both prices and uplift payments increase, reducing the volatility that can arise from both Integer Programming and Convex Hull pricing methods.

Unlike these first three methods, the Generalized Uplift (Motto and Galiana 2002; Galiana et al. 2003) method both pays and charges generators explicitly in order to maintain market equilibrium. The profit received determines if a charge or payment will be assigned to a particular generator. For instance, resources would receive payments if they would otherwise prefer to be dispatched off, i.e., if they are operating at a loss under the linear price; they could also provide a payment if they are making a profit in order to contribute to total compensation amongst resources. The total sum of all uplift payments and charges is zero. To contrast with the many side-payments of Generalized Uplift, the Semi-Lagrangean (Araoz and Jörnsten 2011) method determines a single price and provides no make-whole payments. The price is high enough that generators never operate at a loss from bid-in costs, which makes payments for bidcost recovery unnecessary. In between these methods is the Dual Pricing Algorithm (O'Neill et al. 2016). The method uses a conditioning constraint that allows the user to tune the method depending on preferences. On one side, the method can produce a single market clearing price that results in no make-whole payments. On the other, it can produce make-whole payments and charges that are allocated to all participants based on their bids and offers. The payments and charges, like Generalized Uplift, sum to zero.

Current ISO implementations are described in Section 2.1.2. For comparison with the peerreviewed proposals described in this section, a proposed method by PJM is shown in the table (PJM 2017). This method is similar to what other ISOs have implemented, which is based on Convex Hull pricing. Described in further detail in the next sections, the binary commitment variable would be relaxed between zero and one. Unlike other ISOs and similar to many proposed methods in this section, PJM's proposal extends eligibility to all resources rather than only fast-start or block-loaded resources. The commitment costs would be included in the price, allocated over the maximum capacity, and they propose to compensate units to incentivize them to stay on dispatch. Since the proposal was issued, the ISO has been looking at other options that are more in line with other ISOs and submitted a pricing proposal to FERC.

The proposals described above are compared in Table 1. Each column heading describes a characteristic of the pricing method listed by name in the first column. The second column indicates if the method considers commitment costs when determining the price or if the price only reflects incremental costs. Some proposals include an explicit variable while other algorithms include commitment costs as part of the price calculation. Column three describes treatment of make-whole payments within the proposal; some calculate an explicit payment internal to the algorithm, while others use output of the model to calculate payments. The next 
characteristic describes the approach, if any, that is used to incentivize resources to stay on dispatch. In simple models, prices that reflect marginal costs do not incentivize price chasing, defined as seeing a price higher than a resource's marginal cost and deviating from a dispatch setpoint to capture additional revenue. Methods that increase or decrease the price from the marginal cost might incentivize resources to deviate. Some methods explicitly consider this opportunity in the formulation through payments or calculation of prices, others provide penalties, and some do not directly discuss it. The fourth column compares these incentive opportunities. The fifth column puts each method into broad categories to classify the computational difficulty of the formulation: low, mid-range, or high difficulty. This does not necessarily correlate to implementation within ISO market software but provides a basis for assessing implementation at small scale. While the direct comparison necessarily simplifies each method, the last column differentiates the proposals by notable properties that are not shared with other proposals.

Table 1. Proposed Pricing Methods

\begin{tabular}{|c|c|c|c|c|c|}
\hline Method & $\begin{array}{l}\text { Commitment } \\
\text { Cost in Price }\end{array}$ & $\begin{array}{l}\text { Uplift } \\
\text { Payment } \\
\text { Calculation }\end{array}$ & $\begin{array}{l}\text { Incentive to } \\
\text { Stay on } \\
\text { Dispatch }\end{array}$ & $\begin{array}{l}\text { Computational } \\
\text { Difficulty }\end{array}$ & Notable Properties \\
\hline $\begin{array}{l}\text { Integer } \\
\text { Programming } \\
\text { (“Traditional”) }\end{array}$ & Not included & Outcome & N/A & Low & $\begin{array}{l}\text { Mathematical properties } \\
\text { of LMP pricing }\end{array}$ \\
\hline $\begin{array}{l}\text { Convex Hull } \\
\text { Pricing }\end{array}$ & Incorporated & Minimized & $\begin{array}{l}\text { Incorporated } \\
\text { into method }\end{array}$ & High & $\begin{array}{l}\text { Minimizes make-whole } \\
\text { payments and lost } \\
\text { opportunity costs }\end{array}$ \\
\hline $\begin{array}{l}\text { Modified Integer } \\
\text { Programming }\end{array}$ & Incorporated & $\begin{array}{l}\text { Volatility } \\
\text { reduced }\end{array}$ & Not explicit & Mid & Prices are less volatile \\
\hline $\begin{array}{l}\text { Generalized } \\
\text { Uplift }\end{array}$ & Incorporated & Internal & $\begin{array}{l}\text { Incorporated } \\
\text { into method }\end{array}$ & High & $\begin{array}{l}\text { All participants are } \\
\text { charged or receive } \\
\text { payments that sum to } \\
\text { zero }\end{array}$ \\
\hline $\begin{array}{l}\text { Semi- } \\
\text { Lagrangean } \\
\text { Relaxation }\end{array}$ & Incorporated & None & Not explicit & High & $\begin{array}{l}\text { Single price paid } \\
\text { without side-payments }\end{array}$ \\
\hline $\begin{array}{l}\text { Dual Pricing } \\
\text { Algorithm }\end{array}$ & Incorporated & Internal & Penalties & Low & $\begin{array}{l}\text { Make-whole payments } \\
\text { allocated to participants, } \\
\text { method conditioned } \\
\text { based on preferences }\end{array}$ \\
\hline PJM Proposal & Incorporated & Minimized & Compensated & Low & $\begin{array}{l}\text { All resources can set } \\
\text { price }\end{array}$ \\
\hline
\end{tabular}




\subsubsection{ISO Implementation}

Before publication of many of the proposals in Table 1, alternative pricing was introduced for block-loaded units in New York ISO (NYISO) since the peakers would otherwise not raise inframarginal rents or introduce price separation between New York City and the rest of the state. ISO implementation of alternative pricing has been diverse and highly dependent on the needs within the region. MISO and ISO New England (ISO-NE) based their price formation efforts on Convex Hull Pricing theory, using approximations to the full formulation because true Convex Hull Pricing is computationally burdensome (Gribik 2011; Schiro et al. 2016). Each $\mathrm{ISO}^{4}$ has implemented the method differently, reflecting stakeholder and regional differences. One consideration is the set of resources that qualify for alternative pricing. To demonstrate that the costs being incorporated into pricing are costs incurred in real time, some ISOs designate a set of fast-start resources that can trigger alternative prices. Others limit the set to block-loaded resources, as they will never set price under the traditional formulation.

The ISOs have different ways of allowing these resources to set price, even if physically operating at their minimum generation level. Pricing methods must also consider how the commitment costs are incorporated into pricing and how they are allocated. True Convex Hull pricing allows prices to be set by units not scheduled to be online; some ISOs allow these units to set price under certain conditions, while others limit pricing to online resources. It should be noted that ISOs can schedule offline resources as reserves as part of the optimal dispatch. Allocating fixed start-up costs also varies between ISOs. One option is to allocate the costs over the minimum run time; while this is an easy calculation, it might not allocate the cost to the period it was incurred. Meaning, if the resource is only truly needed in period one but its start-up costs are allocated across four periods, the price signal is muted for period one and raised for the other three periods. The length of the real-time market horizon can impact allocation of fixed costs.

There are also particular characteristics of the pricing process that differ between ISOs. Some ISOs separate the pricing and scheduling process, running each optimization separately, while others integrate the two processes. Each ISO must also determine how they will incentivize resources to follow dispatch instructions. Under alternative methods, prices in any period might be above a resource's incremental cost but they might not be dispatched up to gain maximum profit. In this case, the resource might want to increase its output to make additional revenue, defined as price chasing in the last section. The market operator can either pay the resource an opportunity cost equal to the additional revenue to stay on dispatch or penalize the resource in for deviating.

In addition to alternative prices, recent FERC orders have dealt with changes to scarcity pricing. When the market is unable to meet a reserve requirement, scarcity prices are administratively set, and they can exceed the highest generator bid (EPRI 2016; FERC 2015b). Scarcity pricing aims to enhance short-term incentives when there is a reserve shortage, additionally helping

\footnotetext{
${ }^{4}$ For the remainder of the paper, any time ISO is used, the shorthand term is meant to include RTOs as well.
} 
investment decisions. These prices can impact a resource's revenue sufficiency and range in price from $\$ 5,000$ to $\$ 9,000$.

The characteristics described above are shown for each ISO in Table 2 and described in further detail in EPRI (2019). Many ISOs have also presented or written extensively on price formation efforts. MISO staff produced technical and academic reports on their Extended LMP formulation (Gribik 2011; Wang et al. 2013). ISO-NE created a series of technical sessions on pricing (Schiro and White 2015), and PJM produced a similar set of detailed presentations as they explore an alternative pricing mechanism for their market (PJM 2018). Pricing in PJM, NYISO, and SPP is likely to change as the ISOs respond to FERC actions ${ }^{5}$ on pricing. Additional information for FERC regulated ISOs and RTOs can be found in the ISO/RTO response submissions to the FERC Docket AD14-14-000 Order Directing Reports (FERC 2015a).

\footnotetext{
${ }^{5}$ See New York Independent System Operator, Inc., 161 FERC 9 61,294; PJM Interconnection, L.L.C., 161 FERC 9
} 61,295; and Southwest Power Pool, Inc., 161 FERC \ 61,296, (2017) 
Table 2. ISO/RTO Price Formation Efforts

\begin{tabular}{|c|c|c|c|c|c|c|c|}
\hline Characteristic & ISO-NE & CAISO & NYISO\# & MISO & PJM $^{*}$ & SPP $\neq$ & ERCOT \\
\hline $\begin{array}{l}\text { Separation of } \\
\text { scheduling and } \\
\text { pricing }\end{array}$ & Separate & Integrated & Separate & Separate & Integrated & Integrated & Separate \\
\hline $\begin{array}{l}\text { Length of RT } \\
\text { Market horizon }\end{array}$ & $\begin{array}{l}\text { Single; } \\
\text { 15-minute } \\
\text { ahead }\end{array}$ & $\begin{array}{l}\text { Multiple; } \\
13 \text { intervals, } \\
\text { 1-hour ahead }\end{array}$ & $\begin{array}{l}\text { Multiple; } \\
5 \text { intervals, } \\
\text { 1-hour ahead }\end{array}$ & $\begin{array}{l}\text { Single; } \\
\text { 10-minutes ahead }\end{array}$ & $\begin{array}{l}\text { Single; } \\
\text { 10-minutes } \\
\text { ahead }\end{array}$ & $\begin{array}{l}\text { Single; } \\
\text { 5-minutes } \\
\text { ahead }\end{array}$ & $\begin{array}{l}\text { Single; } \\
\text { 5-min ahead }\end{array}$ \\
\hline $\begin{array}{l}\text { Set of } \\
\text { resources with } \\
\text { alternative } \\
\text { pricing applied }\end{array}$ & $\begin{array}{l}30 \text {-minute } \\
\text { and faster } \\
\text { start-up } \\
\text { resource }\end{array}$ & $\begin{array}{l}\text { Online } \\
\text { "constrained } \\
\text { output } \\
\text { generators" } \\
\text { (block-loaded) }\end{array}$ & $\begin{array}{l}30 \text {-minute and } \\
\text { faster block } \\
\text { loaded } \\
\text { resources }\end{array}$ & $\begin{array}{l}\text { 60-minute start-up } \\
\text { and faster } \\
\text { resources (ELMP } \\
\text { Ph. II) includes } \\
\text { demand response }\end{array}$ & $\begin{array}{l}\text { Block- } \\
\text { loaded } \\
\text { resources }\end{array}$ & $\begin{array}{l}\text { 10-minute } \\
\text { start-up, can } \\
\text { follow dispatch }\end{array}$ & $\begin{array}{l}\text { RUC committed } \\
\text { resources }\end{array}$ \\
\hline $\begin{array}{l}\text { Minimum } \\
\text { Output }\end{array}$ & $\begin{array}{l}\text { Relaxed to } \\
\text { zero }\end{array}$ & $\begin{array}{l}\text { Relaxed to } \\
\text { zero }\end{array}$ & Relaxed to zero & Relaxed to zero & $\begin{array}{l}\text { Relaxed } \\
\text { to } 80 \%\end{array}$ & $\begin{array}{l}\text { Relaxed for } \\
\text { screening run, } \\
\text { but not in } \\
\text { pricing* }\end{array}$ & $\begin{array}{l}\text { In pricing run, } \\
\text { relaxed to zero ** }\end{array}$ \\
\hline $\begin{array}{l}\text { Commitment } \\
\text { Cost }\end{array}$ & $\begin{array}{l}\text { No-load and } \\
\text { start-up } \\
\text { cost } \\
\text { allocated } \\
\text { over Pmax, } \\
\text { start-up } \\
\text { also over } \\
\text { min. run } \\
\text { time }\end{array}$ & $\begin{array}{l}\text { Minimum } \\
\text { generation } \\
\text { cost allocated } \\
\text { over Pmax }\end{array}$ & $\begin{array}{l}\text { Start-up costs } \\
\text { only included } \\
\text { for offline 10- } \\
\text { minute GTs }\end{array}$ & $\begin{array}{l}\text { No-load and start- } \\
\text { up cost } \\
\text { incorporated into } \\
\text { price based on "unit } \\
\text { status" }\end{array}$ & None & None $^{*}$ & None $^{* *}$ \\
\hline $\begin{array}{l}\text { Incentive to } \\
\text { stay on } \\
\text { dispatch }\end{array}$ & $\begin{array}{l}\text { Provision of } \\
\text { lost } \\
\text { opportunity } \\
\text { cost }\end{array}$ & $\begin{array}{l}\text { Proposed } \\
\text { penalties for } \\
\text { poor } \\
\text { performance }\end{array}$ & $\begin{array}{l}\text { Penalties for } \\
\text { poor } \\
\text { performance }\end{array}$ & $\begin{array}{l}\text { Penalties for poor } \\
\text { performance }\end{array}$ & $\begin{array}{l}\text { ACE } \\
\text { corrected } \\
\text { through } \\
\text { regulation }\end{array}$ & $\mathrm{N} / \mathrm{A}$ & $\begin{array}{l}\text { Penalties for poor } \\
\text { performance }\end{array}$ \\
\hline $\begin{array}{l}\text { Offline } \\
\text { resources }\end{array}$ & & & $\begin{array}{l}\text { Yes, 10-minute } \\
\text { GT's only }\end{array}$ & $\begin{array}{l}\text { Yes, if relieving } \\
\text { transmission/ } \\
\text { reserve shortage } \\
\text { condition }\end{array}$ & & & \\
\hline
\end{tabular}


${ }^{\ddagger}$ In response to FERC orders, these ISOs are updating aspects of their fast-start pricing designs which might cause information listed to change.

CAISO: As of this writing, no resources have voluntarily registered to be designed as constrained output generators.

SPP: *Registered quick-start resources can include adder to energy offer with start-up and no-load costs, which is allocated over the previous year's output, but not all quick-start resource commitment costs will set prices; minimum levels are relaxed to zero for a screening run but not the final dispatch or pricing run.

ERCOT: ** SCED Base Points are effective immediately upon posting and typically there is a SCED execution every 5 minutes. ERCOT also calculates and posts indicative pricing which is non-binding and provided for each 5-minute interval for 11 future intervals. Quick-start resources are relaxed to zero for dispatch

(SCED). RUC committed resource offer curves are the greater of $\$ 1,500 / \mathrm{MWh}$ and the resource's offer. For commitment costs, the exception is quick-start resources and other Resources with Voluntary Mitigation Plans (VMPs) may include start-up and no-load costs or other costs in their offers. For mitigation purposes, verifiable incremental costs are used. Quick-starts are allowed to include start-up and no-load costs in their verifiable incremental costs. For resources with VMPs, the verifiable incremental costs are based on a filed agreement with the PUCT. 
Few reports or papers have examined the direct impact of alternative pricing on long-term investments. Studying the effect of pricing on investments is difficult because both operational and investment models are computationally intensive. Herrero, Rodilla, and Batlle (2015) investigated investment signals from two pricing methods similar to those in this study and found the alternative method incentivized technologies with lower costs, therefore lowering prices. They caution that perceived benefits can be overstated depending on implementation. Mays, Morton, and O'Neill (2018) considered pricing impacts on investment and included active demand-side bidding. They found the traditional LMP produces the optimal long-term capacity mix, though they acknowledged the test case was stylized and could not predict the magnitude of impact on ISO markets. Additional research and large-scale test cases are needed to further explore impacts on future investments.

\subsection{Calculation of LMPs and Alternative Methods}

Although LMPs have a locational or congestion component, alternative pricing focuses on changes to the marginal or energy component of the LMP. The following formulations and examples show how the traditional LMP compares to alternatives. For ease of understanding, transmission constraints are excluded from the small examples; however, they are included in the year-long simulations in Section 4.

Table 3 summarizes the four pricing methods in Sections 2.2.1-2.2.3, along with the constraints, resulting prices, and considerations. The list of considerations for the methods is not exhaustive, but it provides insight into the amount of variation that can occur between operators. In addition to the model formulation summarized in this table, price formation rules must be put in place that define participation and incentive compatibility. For instance, it must be determined if the pricing run will occur before or after the scheduling run, i.e., ex-ante or ex-post respectively. Additionally, the different ways to formulate the pricing can result in the same primal solution but a different dual solution. The resulting prices can therefore differ depending on the formulation. Tradeoffs that come with these formulations - in addition to those proposed in literature - suggest no method is clearly dominant (Zheng et al. 2018). The simulations in Section 4 use the Relaxed Minimum method to establish the alternative price.

Table 3. Alternative Pricing Characteristics

\begin{tabular}{|c|c|c|c|}
\hline Method & Constraints & Price & Considerations \\
\hline $\begin{array}{l}\text { Traditional } \\
\text { LMP }\end{array}$ & $(1)-(5),(7)$ & $C_{g}$ & - Ex-ante or ex-post pricing run \\
\hline $\begin{array}{l}\text { Integer } \\
\text { Relaxationa }\end{array}$ & (1)-(5), (8) & \multirow{2}{*}{$C_{g}+\frac{C_{g}^{N L}}{P_{g}^{\max }}+\frac{C_{t}^{S U}}{T^{M R T} P_{g}^{\max }}$} & $\begin{array}{l}\text { - Subset of resources to include } \\
\text { (fast-start, all, etc.) }\end{array}$ \\
\hline $\begin{array}{l}\text { Relaxed } \\
\text { Minimuma }\end{array}$ & $(2),(5),(9),(10)$ & & $\begin{array}{l}\text { - Include start-up costs in price } \\
\text { - Allow offline units to set price }\end{array}$ \\
\hline $\begin{array}{l}\text { Average } \\
\text { Incremental } \\
\text { Cost }^{\mathrm{a}}\end{array}$ & $(2),(5),(11)-(13)$ & $C_{g}+\frac{C_{g}^{N L}}{p_{g t}^{*}}+\sum_{t} \frac{C_{g}^{S U}}{p_{g t}^{*}}$ & $\begin{array}{l}\text { - Incentives for staying on dispatch } \\
\text { (pay lost opportunity cost, impose } \\
\text { penalty) }\end{array}$ \\
\hline
\end{tabular}

a Representation of start-up costs in price can vary; $T^{M R T}$ is the unit's minimum run time. 


\subsubsection{Unit Commitment Formulation}

The core unit commitment problem can be seen in equations (1)-(6), where $p_{g t}$ is the dispatch variable; $u_{g t}$ is the binary commitment variable, which can only be 0 or $1 ; v_{g t}$ is the binary startup variable; $C_{g}, C_{g}^{N L}, C_{g}^{S U}$ are the incremental, commitment/no-load, and start-up costs; $P_{g}^{\max }, P_{g}^{\min }$ are maximum and minimum generator capacities; and $D_{t}$ is demand. The objective is to minimize operating costs, which is equivalent to maximizing surplus because there are no demand bids, shown in (1). The node balance constraint is in (2). The generator capacity constraints are in (3), and (4) is the start-up logic. Equation (5) ensures the dispatch variables are nonnegative, and (6) forces the start-up and commitment variables to be binary. Note this formulation does not include many constraints necessary for operations, such as ramp rates, and additionally does not include reserve. The formulation of those constraints can impact pricing.

$$
\min \sum_{g, t} C_{g} p_{g t}+C_{g}^{N L} u_{g t}+C_{g}^{S U} v_{g t}
$$

Subject to

$$
\begin{array}{lc}
\sum_{\forall g} p_{g t}=D_{t} & \forall t\left(\lambda_{t}\right) \\
P_{g}^{\text {min }} u_{g t} \leq p_{g t} \leq P_{g}^{\text {max }} u_{g t} & \forall g, t \\
u_{g t}-u_{g, t-1} \leq v_{g t} & \forall g, t \\
p_{g t} \geq 0 & \forall g, t \\
u_{g t}, v_{g t} \in\{0,1\} & \forall g, t
\end{array}
$$

The traditional price comes out of a linear program with commitment fixed, meaning (6) is replaced by (7), which fixes the start-up and commitment variables to their optimal solution from the unit commitment solution, $u_{g t}^{*}, v_{g t}^{*}$. The dual variables of (2), $\lambda_{t}$, are then the LMPs.

$$
\begin{aligned}
& u_{g t}=u_{g t}^{*} \\
& v_{g t}=v_{g t}^{*}
\end{aligned}
$$

$\forall g, t$

\subsubsection{Integer Relaxation and Relaxed Minimum Formulation}

In its most simplistic early form, the approximation to the convex hull used by MISO uses the same constraints in (1)-(5) and replaces (6) with (8). Relaxing the integrality of the commitment and start-up variables for each generator allows the minimum operating level of the generators to go to zero. This ensures generators physically dispatched to their minimum operating level can set the price. Typically, the start-up costs would then be allocated over the minimum run time and the maximum capacity ex post. We refer to this as Integer Relaxation pricing; prices are often called ELMP, referring to MISO's Extended LMP.

$$
\begin{aligned}
& 0 \leq u_{g t} \leq 1 \\
& 0 \leq v_{g t} \leq 1
\end{aligned}
$$

$\forall g, t$

Similar to relaxing the commitment and start-up variables, another formulation can exclude all commitment and start-up costs by changing the bid costs to include the commitment costs allocated over the maximum capacity, shown in (9) and similar to the method used by ISO-NE. Constraint (3) would then be replaced by (10), allowing the minimum operating level to drop to 
zero. The new model can include all or a subset of offline and online resources, or it can include all or a subset of online resources, as indicated by $G^{*}$ in (10). The pricing model, which we call Relaxed Minimum, would also include the objective in (9) and constraints (2), (5), and (10). In both the Integer Relaxation and Relaxed Minimum methods, start-up cost allocation over multiple periods must be considered. The methods can produce similar prices in the most simplistic formulations but diverge with additional constraints.

$$
\min \sum_{g, t}\left(C_{g}+\frac{C_{g}^{N L} u_{g t}^{*}}{P_{g}^{\max }}+\frac{C_{g}^{S U} v_{g t}^{*}}{P_{g}^{\max } T^{M R T}}\right) p_{g t}
$$

Subject to

$$
0 \leq p_{g t} \leq P_{g}^{\max } \quad \forall g \in G^{*}, t
$$

\subsubsection{Average Incremental Cost Pricing}

The previous methods minimize uplift payments more than in the traditional method. Pricing based on average costs, sometimes called Average Incremental Cost (AIC) Pricing, can further reduce or eliminate make-whole payments (Van Vyve 2011). However, prices are likely to be higher. A second defining feature of AIC pricing is that, unlike integer-relaxed prices, prices are not monotonically nondecreasing with demand. Prices reflect "quantity discounts" for generation, meaning that prices reflect that it is less expensive to operate a plant at maximum than at its minimum operating level per megawatt-hour (MWh).

The formulation fixes the optimal commitment and creates two subsets of generators, one that would have incurred a make-whole payment under traditional LMP pricing $\left(G^{M W P}\right)$ and one that would not have incurred a make-whole payment $\left(G^{N P}\right)$. The new objective is shown in (11), and slightly modified constraints for each subset are shown in (12) and (13). Constraints (2) and (5) remain unchanged. Similar to relaxed integer pricing, start-up costs can be included as an afterthe-fact calculation or in the bid. If start-up costs were included in the bid, the subset of

generators receiving a make-whole payment would include $\sum_{t} \frac{C_{g}^{S U} u_{g t}^{*}}{p_{g t}^{*}}$ as a third component of their costs as shown in (11).

$$
\min \sum_{t, g \in G^{M W P}}\left(C_{g}+\frac{C_{g}^{N L} u_{g t}^{*}}{p_{g t}^{*}}+\sum_{t} \frac{C_{g}^{S U}}{p_{g t}^{*}}\right) p_{g t}+\sum_{t, g \in G^{N P}} C_{g} p_{g t}
$$

Subject to

$$
\begin{array}{lc}
0 \leq p_{g t} \leq P_{g}^{\max } u_{g t}^{*} & \forall g \in G^{M W P}, t \\
P_{g}^{\text {min }} u_{g t}^{*} \leq p_{g t} \leq P_{g}^{\text {max }} u_{g t}^{*} & \forall g \in G^{N P}, t
\end{array}
$$

\subsubsection{Examples of Different Pricing Methods}

The following examples show the different pricing options discussed in the formulation section. The simple two-generator example has characteristics found in Table 4. 
Table 4. Generator Characteristics for Simple Example

\begin{tabular}{lllll}
\hline Gen & $\begin{array}{l}\text { Minimum } \\
\text { Capacity } \\
\text { (MW) }\end{array}$ & $\begin{array}{l}\text { Maximum } \\
\text { Capacity } \\
\text { (MW) }\end{array}$ & $\begin{array}{l}\text { Incremental } \\
\text { Cost } \\
\text { (\$/MWh) }\end{array}$ & $\begin{array}{l}\text { No-Load Cost } \\
(\$ / h)\end{array}$ \\
\hline$A$ & 0 & 40 & 40 & 500 \\
$B$ & 20 & 100 & 60 & 500 \\
\hline
\end{tabular}

By solving the unit commitment formulation in (1)-(6), the optimal commitment and dispatch decisions can be determined. Table 5 shows the solution if demand is $70 \mathrm{MW}$ and both generators are online, with Gen A at its maximum capacity and Gen B at $30 \mathrm{MW}$. The resulting prices, revenue, and net revenue for three methods discussed in Section 2.2.1 are shown in

Table 6. Note the net revenue column shows revenue less costs from energy and does not include make-whole payments. The costs are the same for each method because the dispatch does not change, only the price. The net revenue shows how each method impacts generators. In the traditional LMP method, Gen B loses \$500, meaning the make-whole payment to Gen B will be $\$ 500$. In the Integer Relaxation method, prices are slightly higher and Gen B only needs a \$350 payment for bid cost recovery. The Average Incremental Cost method increases the price to the average incremental cost of Gen $\mathrm{B}$, meaning no make-whole payment is needed.

Table 5. Commitment and Dispatch Solution for Demand Value of 70 MW

\begin{tabular}{llcl}
\hline Gen & Commitment & Dispatch $(\mathbf{M W})$ & Cost $(\$)$ \\
\hline A & Online & 40 & $(40 \mathrm{MW})^{*}(\$ 40 / \mathrm{MWh})+\$ 500 / \mathrm{h}$ \\
B & Online & 30 & $(30 \mathrm{MW})^{*}(\$ 60 / \mathrm{MWh})+\$ 500 / \mathrm{h}$ \\
\hline
\end{tabular}

Table 6. Prices and Net Revenue for Demand Value of 70 MW

\begin{tabular}{lccccc}
\hline Pricing Method & $\begin{array}{l}\text { Price } \\
\text { (\$/MWh) }\end{array}$ & Gen & Revenue (\$) & Cost (\$) & $\begin{array}{l}\text { Net } \\
\text { Revenue } \\
\mathbf{( \$ )}\end{array}$ \\
\hline Traditional LMP & 60.00 & A & 2,400 & 2,100 & 300 \\
& & B & 1,800 & 2,300 & -500 \\
\hline \multirow{2}{*}{ Integer Relaxation } & 65.00 & A & 2,600 & 2,100 & 500 \\
& & B & 1,950 & 2,300 & -350 \\
Average Incremental Cost & 76.67 & A & 3,067 & 2,100 & 967 \\
& & B & 2,300 & 2,300 & 0 \\
\hline
\end{tabular}

At a demand level of $70 \mathrm{MW}$, both generators are online and operating above their minimum operating levels. The solution changes for other demand levels. If the demand is under the maximum capacity of the less-expensive generator, or $40 \mathrm{MW}$, the solution is to dispatch Gen A; if it is over $60 \mathrm{MW}$, both generators are needed to meet demand. In between these two demand levels, the dispatch is less straightforward. Once the demand exceeds the maximum capacity of the less expensive generator (Gen A), it might be logical to assume Gen B would turn on at minimum and Gen A would produce as much as possible. However, if the demand is $42 \mathrm{MW}$, dispatching both Gen A and Gen B is more expensive than dispatching Gen B alone. As seen in 
the sums below, this is due to the added commitment costs and the requirement to dispatch Gen $\mathrm{B}$ to a minimum of $20 \mathrm{MW}$.

Cost to dispatch Gen B:

$$
(42 \mathrm{MW}) *(\$ 60 / \mathrm{MWh})+\$ 500 / \mathrm{h}=\$ 3,020
$$

Cost to dispatch Gen A and Gen B at minimum:

$$
(22 \mathrm{MW}) *(\$ 40 / \mathrm{MWh})+\$ 500 / \mathrm{h}+(20 \mathrm{MW}) *(\$ 60 / \mathrm{MWh})+\$ 500 / \mathrm{h}=\$ 3,080
$$

Once demand reaches $45 \mathrm{MW}$, it is less expensive if both generators are dispatched. Gen B will be dispatched to its minimum operating level until Gen A's capacity is exhausted. The prices that result from each demand level are shown in Figure 1. Under traditional LMP, the prices are based simply on the incremental cost of the marginal generator. Below $40 \mathrm{MW}$, the price is the incremental cost of Gen $\mathrm{A}(\$ 40 / \mathrm{MWh})$. Between $40 \mathrm{MW}$ and $45 \mathrm{MW}$, the price is the incremental cost of Gen B (\$60/MWh). Between $45 \mathrm{MW}$ and $60 \mathrm{MW}$, although both generators are online, Gen A sets the price because Gen B is at its minimum operating level. Over $60 \mathrm{MW}$, Gen B sets the price because Gen A its operating at its maximum.

Under Integer Relaxation, the price starts at Gen A's average cost at maximum $(\$ 40 / \mathrm{MWh}+$ $(\$ 500 / \mathrm{h}) / 40 \mathrm{MW}=\$ 52.50 / \mathrm{MWh})$ and increases to Gen B's average cost at maximum $(\$ 60 / \mathrm{MWh}$ $+(\$ 500 / \mathrm{h}) / 100 \mathrm{MW}=\$ 65 / \mathrm{MWh})$. Above $40 \mathrm{MW}$, the relaxed problem is able to set Gen B's minimum operating level to zero and dispatch it to the level needed, allowing Gen B to set the price. The Average Incremental Cost method produces prices that reflect the marginal generator's average incremental cost, which declines from a resource's minimum operating level to its maximum. This means that as the dispatch of the marginal resource approaches its maximum capacity, both the Average Incremental Cost method and the Integer Relaxation method will converge to the same price. The declining curves show quantity discount that occurs for generators with commitment costs; it is less expensive to operate at maximum than at minimum capacity.

The prices are only part of the settlement; the make-whole payments owed to the generators are shown in Figure 2. The Traditional LMP method has a consistent $\$ 500$ make-whole payment, except for demand levels between $45 \mathrm{MW}$ and $60 \mathrm{MW}$, where it increases to $\$ 1,400$ due to Gen B operating at minimum capacity and Gen A setting the price. The make-whole payment for Integer Relaxation decreases as demand increases as each generator moves from its minimum to maximum capacity. Only at maximum capacity is the make-whole payment zero. As expected, there is no make-whole payment for the Average Incremental Cost method, because the price is high enough to cover all the generator's operating costs. 


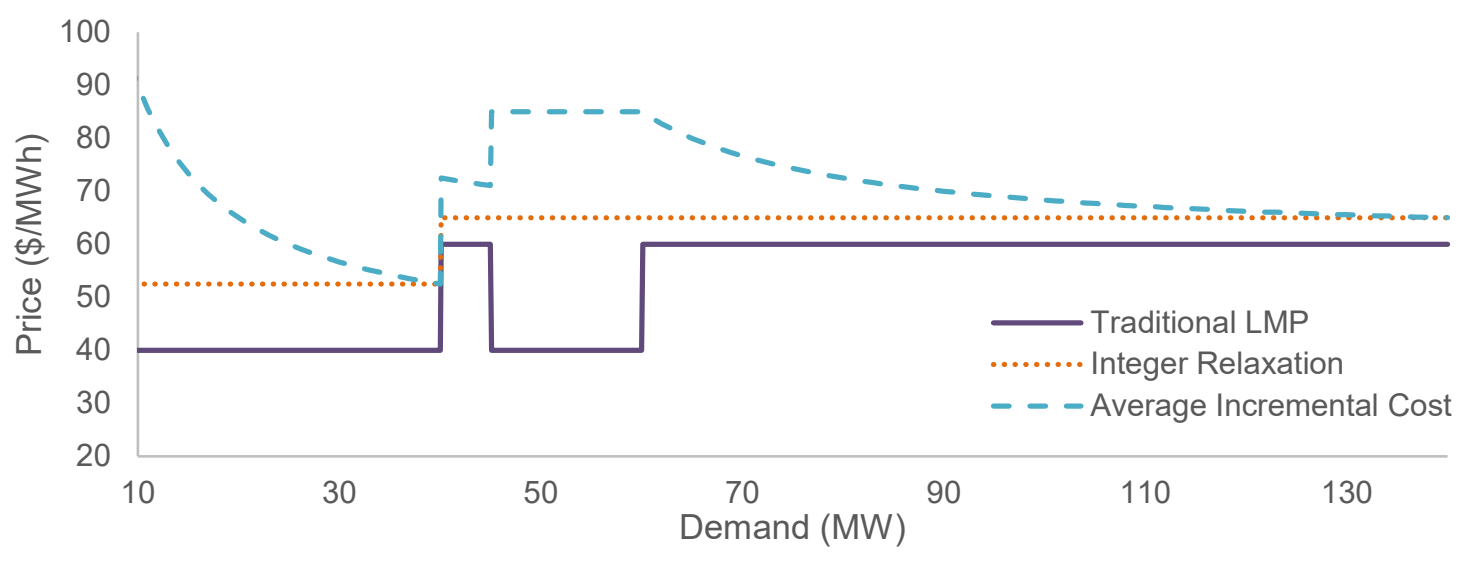

Figure 1. Different pricing methods across increasing demand levels

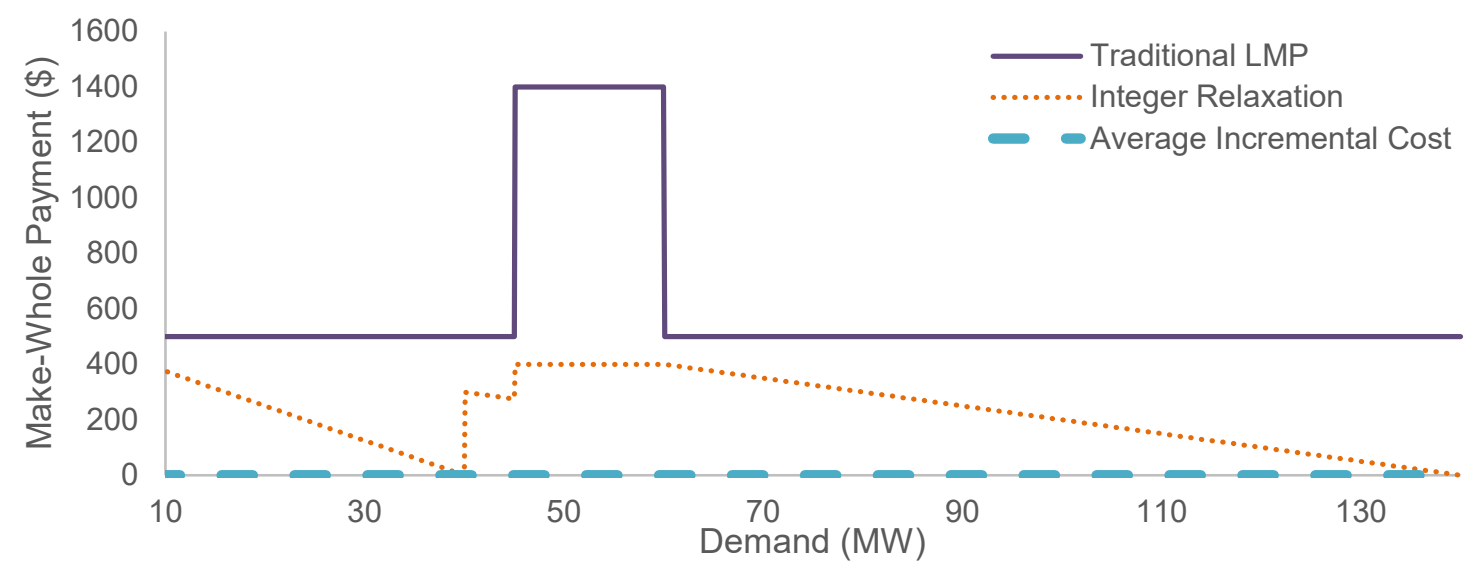

Figure 2. Make-whole payments across increasing demand levels 


\section{Methods}

This study provides several annual simulations of day-ahead and real-time markets to evaluate the revenue, net revenue, and prices that result from different scenarios. It contrasts a traditional pricing mechanism against one alternative pricing mechanism, and each is evaluated across four sensitivity scenarios that encompass two categories: (1) renewable penetration levels, and (2) resource mix. The eight simulation characteristics are shown in Table 7 . The renewable penetration was divided into high and low levels; information about the penetration and test system can be found in Section 3.1. The resource mix refers to the quantity of installed capacity used in the scenario. The adjusted mix meets a specific resource adequacy target. Conversely, the unadjusted mix uses all available resources and exceeds the specific resource adequacy target that was used for the adjusted mix (i.e., the unadjusted mix does not retire resources with addition of renewables, and the system is overbuilt). Details about the generation fleet adjustment process are in Section 3.2. The pricing type refers to the traditional LMP used by most market studies, and alternative pricing (Relaxed Minimum), of which details can be found in Section 3.3. Finally, the net revenue is compared against capital costs described in Section 3.4.

Table 7. Scenarios Simulated in Study

\begin{tabular}{|c|c|c|c|}
\hline & Renewable Level & Resource Mix & Pricing Type \\
\hline $1 \mathrm{a}$ & High & Adjusted & Traditional Pricing \\
\hline $1 b$ & High & Adjusted & Alternative Pricing \\
\hline $2 a$ & High & Unadjusted & Traditional Pricing \\
\hline $2 b$ & High & Unadjusted & Alternative Pricing \\
\hline $3 a$ & Low & Adjusted & Traditional Pricing \\
\hline $3 b$ & Low & Adjusted & Alternative Pricing \\
\hline $4 a$ & Low & Unadjusted & Traditional Pricing \\
\hline $4 b$ & Low & Unadjusted & Alternative Pricing \\
\hline
\end{tabular}

\subsection{Test System}

The generator fleet and transmission network properties for this analysis are from a modified version of the Reliability Test System - Grid Modernization Lab Consortium (RTS-GMLC) (Barrows et al. 2019), which is an updated version of the RTS-96 test system (Grigg et al. 1999). The RTS-GMLC model consists of 3 regions with 73 buses and includes an extensive set of operational properties for each generator and line limits for the transmission network.

The primary modification to the base RTS-GMLC model was a much larger set of wind and solar photovoltaic (PV) generators time-synchronized with load data to allow for a Low VRE scenario with about $13 \%$ variable renewable energy (VRE) (of which $45 \%$ is wind and $55 \%$ is PV) and a High VRE scenario with about $68 \%$ VRE (of which $33 \%$ is wind and $67 \%$ is PV); both are on a pre-curtailment energy basis. The wind and PV sites were selected from NREL's Western Wind and Solar Integration Study Phase 2 (Lew et al. 2013) database based on distance to nodes in the RTS-GMLC test system. The second, and final, modification was a different set 
of reserve requirement inputs resulting from (and corresponding to) these two VRE penetration levels; this modification was based on the same methodology used in the base RTS-GMLC database, as originally defined by Lew et al. (2013). The fuel costs are assumed to be \$2.11/MMBtu for coal, \$3.89/MMBtu for natural gas, \$0.81/MMBtu for nuclear, and \$10.35/MMBtu for oil.

\subsection{Generation Fleet Adjustment Process}

When studying future systems, new capacity, such as renewable resources, is often added without adjusting the generation fleet. Adjusting the generation fleet is intended to create a study system without large amounts of excess generation capacity. This process considers economics of different unit types and their associated resource adequacy implications. In this study, the "adjusted" study systems had a goal of $2.4 \mathrm{hr} /$ year LOLE target, which corresponds approximately to the 1 day in 10 years LOLE commonly used in the industry as a reliability target. The adjustments were accomplished by connecting a capacity expansion model and resource adequacy assessment model: the capacity expansion model (CEM) prescribed a system buildout and passed that information to the resource adequacy assessment model, which assessed whether the system was overbuilt or underbuilt relative to a $2.4 \mathrm{~h} /$ year LOLE target. This process was iterated for "adjusted" systems to reach the $2.4 \mathrm{hr} /$ year LOLE target.

Details about the adjustment process are provided in Frew et al. (2019); a short description is included in this section. If the system deviated too far from its target resource adequacy level, the CEM was run again with an adjusted planning reserve margin to achieve a more desirable level of resource adequacy. The CEM selected a subset of available coal, oil, and natural gas units to include in the system to minimize total capital investment and operating costs, subject to the planning reserve margin constraint. Some plants associated with the desired VRE scenario were preselected: hydropower, concentrating-solar power, nuclear units, and the subset of wind and solar PV plants. This iteration process was repeated until the CEM's system buildout was neither overbuilt nor underbuilt, within some specified tolerance.

The resulting set of resources is called "adjusted" in the simulation results, while the full set of resources is called "unadjusted" in the results. Figure 3 shows the resource mix for each scenario. Although the total capacity varies, the thermal generation fleets are identical in the unadjusted cases, and the renewable penetration is identical within each of the different VRE levels (high and low penetrations). 


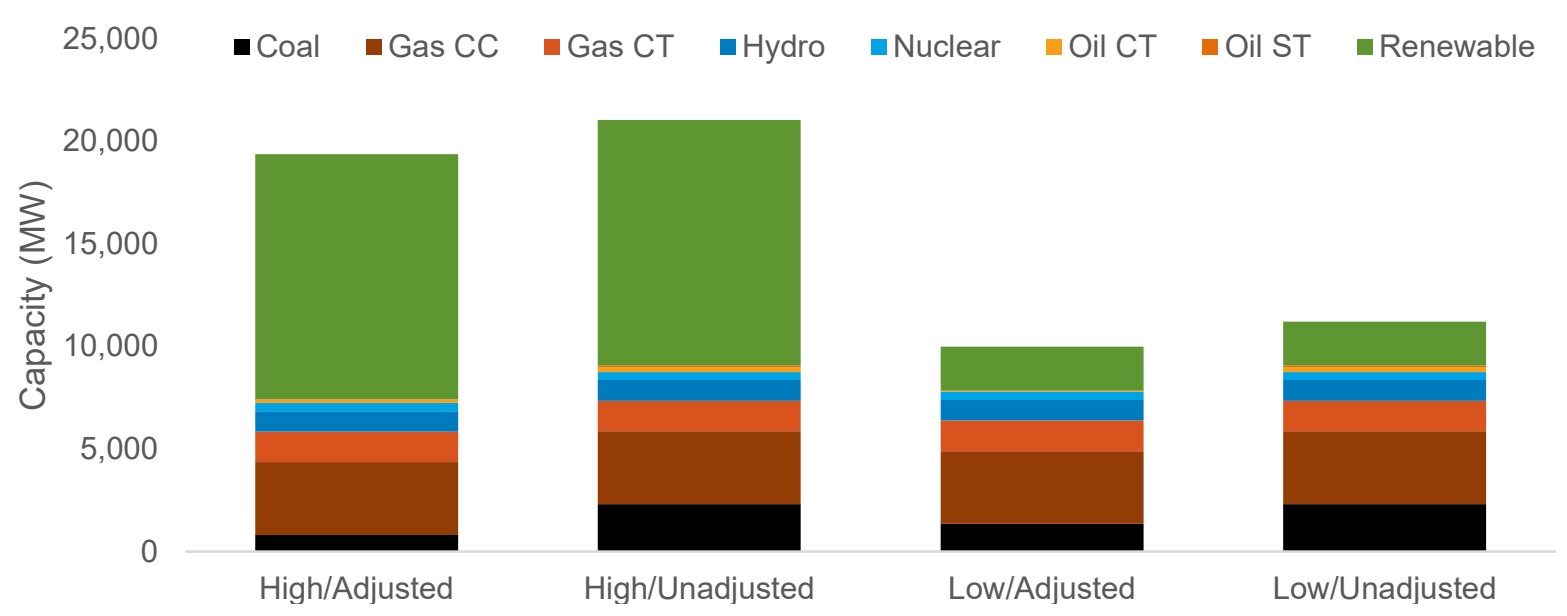

Figure 3. Capacity mix by fuel type for each scenario $\mathrm{CC}=$ Combined cycle; $\mathrm{CT}=$ Combustion turbine; $\mathrm{ST}=$ Steam turbine

\subsection{Simulation Tool and Alternative Pricing}

To run the annual simulations, Polaris' Power System Optimizer ${ }^{6}$ is used. It is a production cost model that can be customized for multiple time horizons and used to mimic specific markets' rules. For this study, three optimization problems are run sequentially: day-ahead unit commitment, real-time unit commitment and dispatch, and in the case of the alternative pricing simulations, a pricing run. The day-ahead commitment runs for 24 hours and commits units that have more than an hour of start-up time. The real-time, five-minute unit commitment and dispatch for the same day runs using the commitments of slow-start units from the day-ahead and further committing units with less than an hour start-up time. Each five-minute, real-time commitment and dispatch run is followed by the five-minute pricing run. The pricing run does not commit any additional resources and is used solely for pricing purposes in the alternative pricing simulations. Both the day-ahead and real-time commitment and dispatch runs include a short look-ahead period that produces non-binding commitment, dispatch, and prices. These are not included in price or revenue calculations. The day-ahead look-ahead period is 12 hours.

The day-ahead market optimizes energy and ancillary services together for 24 hours. Regulating reserves up and down, spinning reserves, and flexibility reserves are scheduled in day-ahead to ensure enough capacity is online to reduce impacts from forecast error. All reserves are released in the real-time market, allowing redispatch of online slow units, and commitment of units with an hour or less start-up time. No additional reserves are scheduled in real-time. The real-time commitment and dispatch run also includes a look-ahead period of one hour, which allows faststart units to come online. Although ancillary services are procured, the prices and payments are not included in the study results to focus on the energy revenue (which is significantly larger in ISOs today).

The pricing run does not commit additional units; it redispatches only the units committed in the day-ahead and real-time runs. The minimum operating level of all online generators is relaxed to zero, making this a linear program. The incremental-cost bids of the generators are then replaced

\footnotetext{
${ }^{6}$ For more information, see “PSO: Power System Optimizer," http://psopt.com/pso/.
} 
with new bids reflecting both incremental energy and their hourly commitment costs, or no-load costs. Unlike the pricing logic used in MISO and ISO-NE, a generator's start-up costs, while considered as part of the commitment decisions, are not included in this pricing method in order to simplify resulting prices for better comprehension. The pricing that results follows the logic below, referred to as the Relaxed Minimum method described in Section 2.2.1. This method incorporates fixed hourly operating costs into prices, similar to the method used by MISO and ISO-NE. Note that although the traditional and alternative prices both consider incremental costs, the marginal unit in each case might be different.

$$
\begin{array}{ll}
\text { Traditional: } & \text { MarginalCost } \\
\text { Relaxed Minimum: } & \text { MarginalCost }+\frac{\text { NoLoad }}{\text { MaxCapacity }}
\end{array}
$$

Several assumptions made in the simulations can result in prices that are inconsistent with current electricity market prices:

- Renewable resources are bid in at zero rather than bidding negative due to subsidies or other contracts.

- All generators are assumed to bid their true costs, and no bid mitigation is needed.

- There are no virtual players to arbitrage day-ahead and real-time prices.

- No storage devices or bidders are in the market.

- The model does not capture operator actions or out-of-market corrections, including resources that might be dispatched during an ISO's Reliability Unit Commitment.

- The value of lost load (the penalty for load shedding) is set to $\$ 5,000 / \mathrm{MWh}$ in the model simulation. However, the calculations in the results use a value of $\$ 1,000 / \mathrm{MWh}$ for periods when the penalty sets the price. First, this is done because the simulations cannot fully capture the impact of operator actions or adjustments made by AGC; there is no recourse decision making that might occur in actual operations. Second, the value in the simulation was chosen to emulate scarcity pricing, which can range from $\$ 5,000$ to $\$ 9,000$ depending on the product. The reduction is an acknowledgement that other forces impact dispatch after the five-minute real-time market is cleared that are difficult to model accurately in simulations.

\subsection{Capital Cost Values}

Investment costs for the CEM were approximated as the annualized (assuming a capital recovery factor of $6.6 \%$ ) total capital costs required to achieve commercial operation of a plant, by technology type, from NREL's 2017 Annual Technology Baseline (ATB) (NREL 2017). 
Table 8. Details About the Annual Technology Baseline (ATB) Values

\begin{tabular}{|c|c|c|}
\hline $\begin{array}{l}\text { Technology Type in } \\
\text { This Study }\end{array}$ & Technology Type from ATB & $\begin{array}{l}2015 \text { Amortized Capital } \\
\text { Costs (\$/MW-yr) }\end{array}$ \\
\hline Hydro & Hydropower NPDa 2 & 370,751 \\
\hline PV & Utility PV: $20 \%$ CF & 132,982 \\
\hline Wind & Land-Based Wind TRG 5 & 106,702 \\
\hline Coal ST & Coal-new-AvgCFc & 254,801 \\
\hline Gas CC & Natural Gas-CC-AvgCF & 68,076 \\
\hline Gas CT & Natural Gas-CT-AvgCF & 58,237 \\
\hline Gas STd & Natural Gas-CC-AvgCF & 68,076 \\
\hline Nuclear ST & Nuclear & 394,785 \\
\hline Solid Biofuel ST & Biopower Dedicated & 256,785 \\
\hline \multicolumn{3}{|c|}{$\begin{array}{l}\text { a NPD = non-powered dam } \\
\text { b TRG = techno-resource group } \\
\text { c CF = capacity factor } \\
\text { d } S T=\text { steam turbine }\end{array}$} \\
\hline
\end{tabular}




\section{Study Results}

Section 3 described the two pricing mechanisms and four sensitivity scenarios that are included in this study (see Table 7), which combine different system resource adequacy states, renewable energy penetration, and pricing methods. Each simulation was run using Polaris' Power System Optimizer for a year, with the day-ahead market using hourly intervals and the real-time market using five-minute intervals. The revenues, costs, net revenue, and prices that result from each simulation are analyzed in this section.

\subsection{Pricing}

The simulations, described in Section 2.2, compare two primary pricing methods. The "traditional" method uses the shadow price of the node-balance constraint for the price "as is," and an alternative ${ }^{7}$ method incorporates commitment costs through the Relaxed Minimum approach. Table 9 shows the mean annual price and standard deviation for each of the scenarios, along with the percentage of periods with price spikes and periods where the price was zero. Similar to EPRI (2017), spikes are defined as any price over $\$ 500 / \mathrm{MWh}$, which can reflect shortage conditions. All average prices shown in this paper are simple (not load-weighted) averages.

Table 9. Real-Time Price Statistics, Percentage Based on Number of Five-Minute Periods in the Year

\begin{tabular}{|c|c|c|c|c|c|}
\hline Scenario & Simulation & $\begin{array}{l}\text { Mean } \\
\text { (\$/MWh) }\end{array}$ & $\begin{array}{l}\text { Standard } \\
\text { Deviation }\end{array}$ & $\begin{array}{l}\text { Price } \\
\text { Spikes (\%) }\end{array}$ & $\begin{array}{l}\text { Zero } \\
\text { Prices (\%) }\end{array}$ \\
\hline \multirow{2}{*}{$\begin{array}{l}\text { High Renewable } \\
\text { /Adjusted }\end{array}$} & Traditional & 68.39 & 215.58 & 4.9 & 44.4 \\
\hline & Relaxed Minimum & 67.79 & 192.80 & 4.0 & 25.8 \\
\hline \multirow{2}{*}{$\begin{array}{l}\text { High Renewable } \\
\text { /Unadjusted }\end{array}$} & Traditional & 57.40 & 193.85 & 3.9 & 45.1 \\
\hline & Relaxed Minimum & 59.24 & 174.30 & 3.2 & 25.8 \\
\hline \multirow{2}{*}{$\begin{array}{l}\text { Low Renewable } \\
\text { /Adjusted }\end{array}$} & Traditional & 34.56 & 87.08 & 0.8 & 0.4 \\
\hline & Relaxed Minimum & 43.09 & 80.98 & 0.7 & 0.0 \\
\hline \multirow{2}{*}{$\begin{array}{l}\text { Low Renewable } \\
\text { /Unadjusted }\end{array}$} & Traditional & 27.08 & 46.59 & 0.2 & 0.3 \\
\hline & Relaxed Minimum & 35.19 & 39.34 & 0.2 & 0.0 \\
\hline
\end{tabular}

Pricing results are distinguished between the scenarios by the renewable penetration level more than the adjusted or unadjusted resource mix. For the traditional and Relaxed Minimum pricing methods, average prices decline in the same order as the scenarios listed in the table. The high renewable case with an adjusted system fuel mix has the highest average prices with the widest standard deviation, but the high unadjusted case shows only slight reduction across the four statistics. The standard deviation for both of the high renewable cases (adjusted and unadjusted) is wider than the low renewable cases, due in part to the high percentage of zero-priced and price-spike periods. With the high renewable penetration, around $45 \%$ of the hours are zero-

\footnotetext{
${ }^{7}$ The alternative method, or the Relaxed Minimum method, is sometimes referred to as "Alt" or "Alternative" in figures for brevity.
} 
priced for the traditional pricing method. For the same renewable penetration level, the Relaxed Minimum method produces significantly fewer zero priced hours, just over $25 \%$ for both the adjusted and unadjusted resource mixes. The reduction in zero-priced hours is due to the relaxation of the minimum operating level for online generation. During periods when renewables are setting the price under the traditional LMP pricing method, thermal generation will either be at its minimum or maximum and unable to set prices. The Relaxed Minimum method relaxes the minimums, allowing renewables to inject their full capability (for purposes of pricing only) and other online generation to set price. In the high/adjusted case, the Relaxed Minimum average price is slightly lower than the traditional price.

In theory, the Relaxed Minimum price includes allocated commitment costs and should be higher than the traditional price. This trend is generally, but not fully, observed in the results here, influenced in part by modeling artifacts. Namely, start-up and shutdown ramping in both the traditional and Relaxed Minimum pricing runs can cause infeasibilities, triggering price spikes. These infeasibilities or price spikes generally result when a slower unit is committed in dayahead and needed either a few periods before it starts up or after it shuts down in real-time. An operator would have the ability to commit the unit, but the model does not initiate out-of-market corrections and no additional ancillary services are procured in the real-time simulation. In some cases, the price spike occurs in the traditional but not Relaxed Minimum case. This modeling artifact occurs because the Relaxed Minimum simulation positions the slow unit to shut down from a higher dispatch point by relaxing the minimums of fast-start units several periods prior to shut down, and then shutting down the slow unit faster. In practice, the number of spikes, and therefore the average price, would likely decrease. The addition of price responsive demand would also be able to alleviate many of these spikes and prevent shortages.

The low-renewable-penetration cases have lower average prices (which is counterintuitive to most other studies and predictions), fewer price spikes, and fewer zero-priced periods. With less zero-cost generation, it follows that zero-priced periods would decrease. Less renewable energy also reduces the uncertainty between day-ahead and real-time net load, meaning prescheduled generation might be better able to meet changes in net load and thereby reduce the amount of price spikes that result in infeasibilities (which typically result in ramp or reserve shortages in practice). Though the traditional and Relaxed Minimum simulations show similar trends, average prices are much higher for the Relaxed Minimum pricing method in the low renewable cases.

Figure 4 shows averages for prices under \$500/MWh in dark colors (labeled "No Spikes") and overall annual averages are shown in light colors (labeled "Avg"). The "No Spikes" results, which remove the impact of price spikes, reveal the intuitive results: the high renewable cases have lower average prices than the low renewable cases, and the Relaxed Minimum cases have higher average prices than traditional cases. While these prices now result in the intuitive trend that high renewable scenarios might have lower prices, the values average over fewer hours (because hours with spikes are removed), and do not consider the scarcity which might occur due to renewables. 


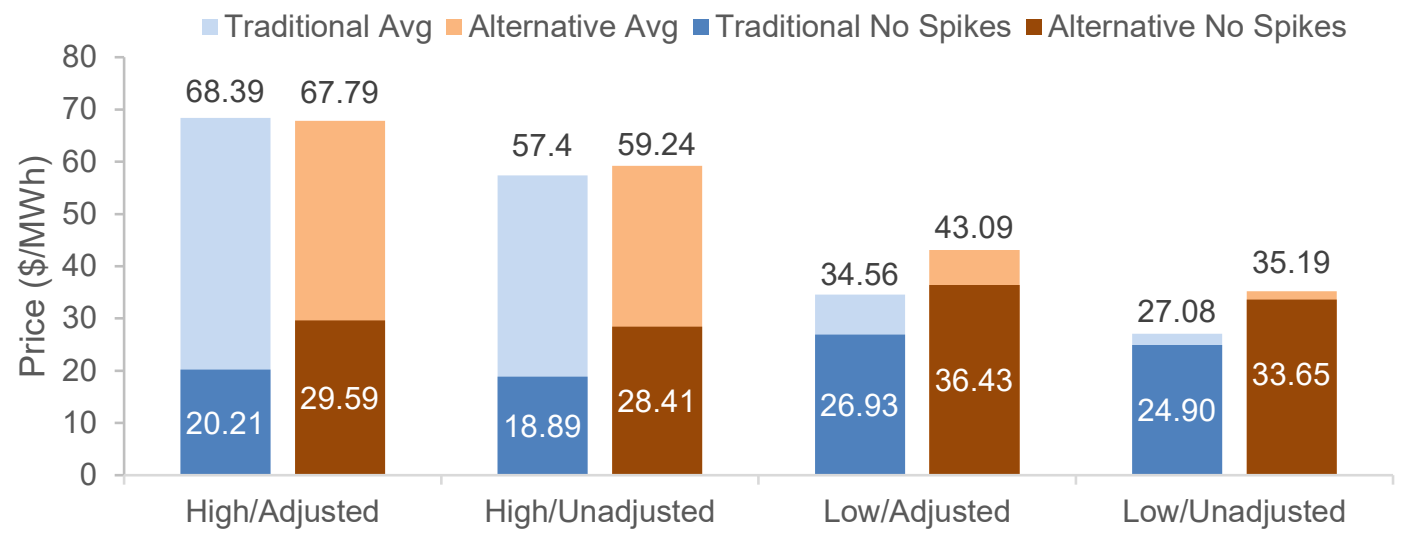

Figure 4. Price averages for each scenario

The No Spikes values show averages for hours without price spikes (under \$500/MWh). Alternative = Relaxed Minimum

Price duration curves provide a means to examine broad trends. These curves order five-minute real-time prices from high to low, similar to the sorting applied to load data for load duration curves. The full graphs are shown in Figure 5 for prices below $\$ 200 / \mathrm{MWh} .{ }^{8}$ The shape of these curves is most dependent on the amount of renewables in the system. The high renewable cases show similar trends, with many zero-price periods, while the low renewables cases steadily trend toward lower-priced hours with minimal number of zero-price periods. Another clear trend from these graphs is the increase in prices between the traditional and Relaxed Minimum pricing methods.

${ }^{8}$ Figure B-1 (in Appendix B) shows the full range of prices, which are more difficult to see. 


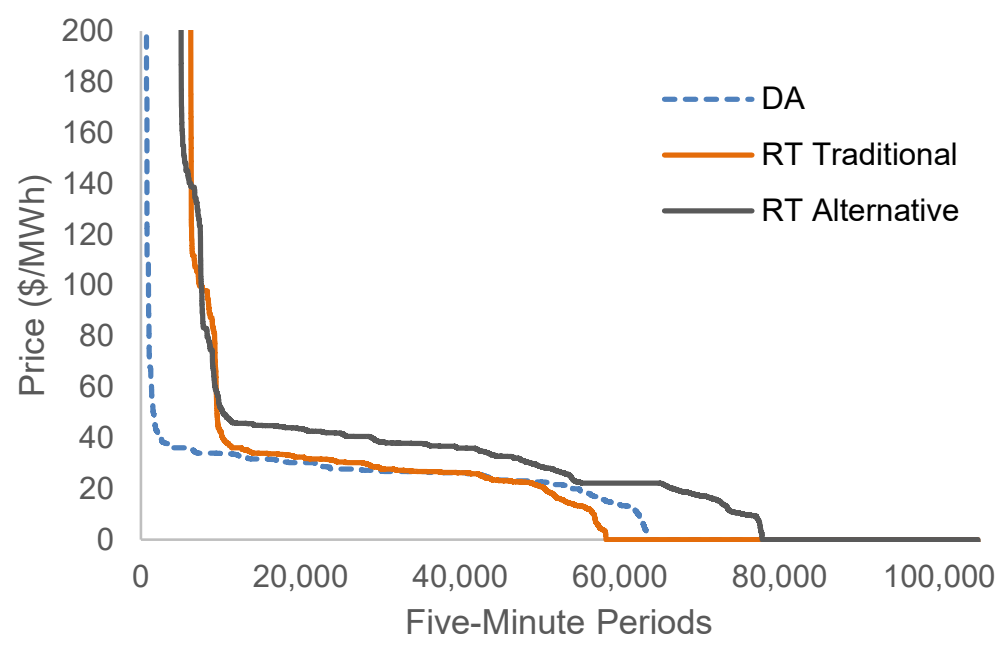

a)

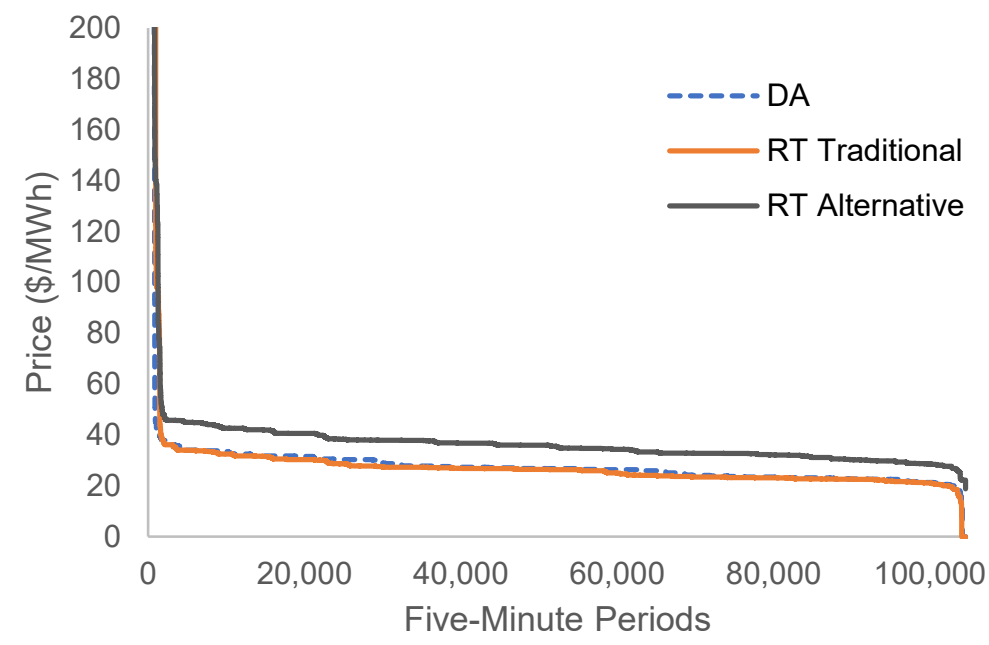

c)

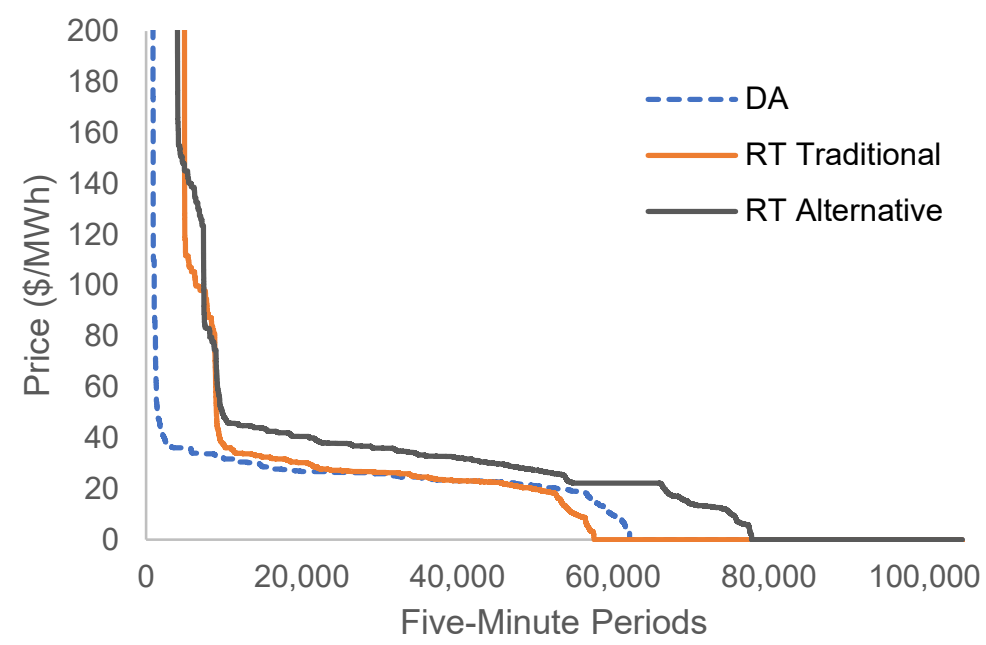

b)

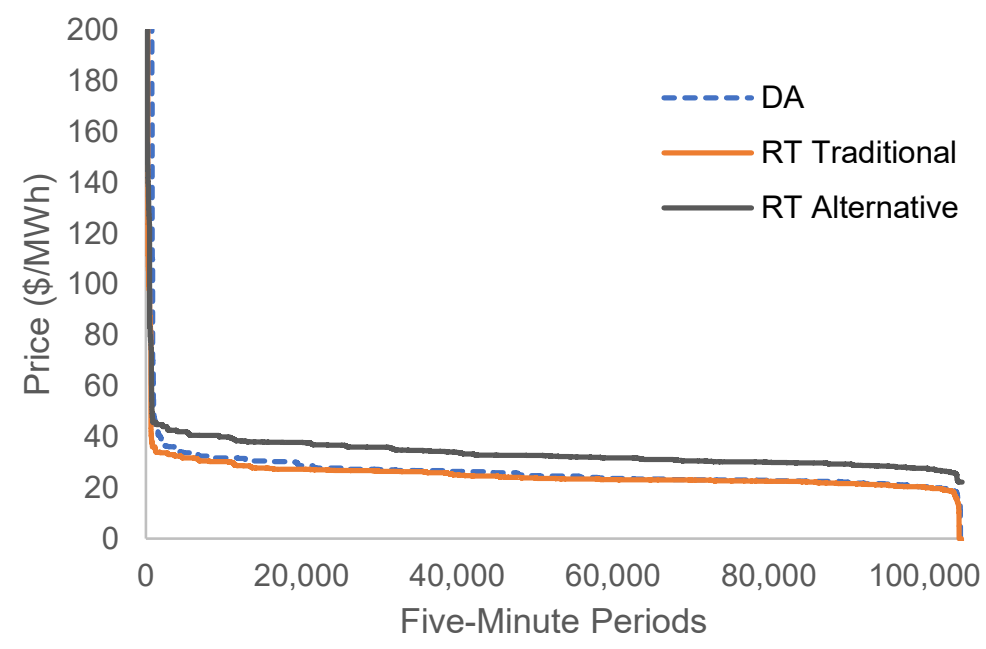

d)

Figure 5. Price duration curves for values under $\$ 200 / \mathrm{MWh}$ for each scenario: (a) high/adjusted, (b) high/unadjusted, (c) low/adjusted, (d) low/unadjusted

$\mathrm{RT}=$ real time; $\mathrm{DA}=$ day ahead; Alternative = Relaxed Minimum 
While the figure does not show intertemporal relationships, the graphs do show a similar result as the averages from Table 9: Relaxed Minimum prices are consistently higher than traditional prices. The graphs also confirm that renewable penetration impacts price outcomes more than the resource mix. This is driven by higher prices and greater volatility between hours of the day and months of the year in the higher renewable cases compared to the low renewable cases. These intertemporal outcomes are revealed in Table 10-Table 13, where the heat map values show averages across each hour of the day for every month of the year. Table 10 and Table 11 show traditional and Relaxed Minimum pricing for the high renewable case and Table 12 and Table 13 show the low renewable case. Because the adjusted and unadjusted averages are similar, the values for the unadjusted case are shown in Appendix C.

Prices in the high renewable case are highest in the shoulder hours, between 5 a.m. and 7 a.m., and between 5 p.m. and 8 p.m., depending on the season. Though the traditional prices are lower than the Relaxed Minimum prices for most hours, the shape of the heat map is the same. However, the difference between shoulder average prices and midday prices is greater for traditional pricing than Relaxed Minimum pricing. In July, the peak hour (5 a.m.) reaches a price of $\$ 481 / \mathrm{MWh}$ in the Traditional simulation and a midday average of $\$ 6.67 / \mathrm{MWh}$, whereas the Relaxed Minimum pricing reaches a lower peak of $\$ 278 / \mathrm{MWh}$ at $5 \mathrm{a} . \mathrm{m}$. and a midday average of \$18/MWh. Looking across the year, the morning peak hour averages \$527/MWh for traditional pricing and \$398/MWh for Relaxed Minimum pricing, while the midday average (8 a.m.- 4 p.m.) is $\$ 4.80 / \mathrm{MWh}$ for traditional pricing and $\$ 9.02 / \mathrm{MWh}$ for Relaxed Minimum pricing. While both methods have significantly higher morning peak prices, the difference is greater for traditional pricing than Relaxed Minimum pricing. The high prices on the heat map show scarcity issues that persist on some days during the entire hour, where scarcity is set at $\$ 1000 / \mathrm{MWh}$. Some of these issues arise from generator shutdowns or start-ups committed in day-ahead, a type of modeling artifact we would not expect to see in actual operations.

The significant difference between shoulder and midday periods also suggests demand shifting or price responsive demand might have a stronger incentive to participate in markets to take advantage of consumption during low midday periods and avoid high charges during the morning and evening ramps. The incentive would depend partially on the magnitude of the difference between hours, which could be altered with active price responsive demand.

Unlike the high renewable case, there are no extremely high morning peaks in the low renewable case. There are afternoon peaks during the summer, as is typical in most regions today, but prices remain lower during winter and the shoulder months. The price differences between the peaks in the traditional and Relaxed Minimum cases are much smaller, often within a few dollars of each other. However, the midday prices are much higher for Relaxed Minimum pricing, averaging around $\$ 30 / \mathrm{MWh}$ in winter and shoulder months while traditional pricing averages around $\$ 20 / \mathrm{MWh}$. The average volatility of prices across the day reduced in the low renewable case, with midday prices rarely reaching zero. 
Table 10. Heat Map of Traditional Average Real-Time Prices for the High/Adjusted Scenario over the Course of a Day (24 hours) for Each Month of the Year in \$/MWh

$\begin{array}{lrrrrrrrrrrrrrrrrrrrrrrrrrrrrrr}\text { Hour } & 1 & 2 & 3 & 4 & 5 & 6 & 7 & 8 & 9 & 10 & 11 & 12 & 13 & 14 & 15 & 16 & 17 & 18 & 19 & 20 & 21 & 22 & 23 & 24 \\ \text { Jan } & 38 & 25 & 57 & 41 & 56 & 108 & 468 & 58 & 0 & 0 & 0 & 0 & 0 & 0 & 0 & 0 & 26 & 164 & 56 & 45 & 39 & 26 & 103 & 44 \\ \text { Feb } & 39 & 51 & 44 & 25 & 97 & 297 & 548 & 31 & 0 & 0 & 0 & 0 & 0 & 3 & 3 & 4 & 12 & 148 & 141 & 32 & 78 & 30 & 92 & 58 \\ \text { Mar } & 63 & 86 & 54 & 29 & 150 & 528 & 181 & 7 & 0 & 0 & 0 & 0 & 0 & 2 & 2 & 25 & 3 & 136 & 185 & 39 & 27 & 48 & 95 & 89 \\ \text { Apr } & 105 & 185 & 88 & 151 & 296 & 494 & 13 & 1 & 1 & 1 & 1 & 1 & 0 & 0 & 0 & 0 & 2 & 122 & 220 & 162 & 62 & 63 & 85 & 88 \\ \text { May } & 77 & 64 & 62 & 91 & 496 & 69 & 7 & 2 & 0 & 0 & 0 & 0 & 0 & 1 & 23 & 2 & 3 & 29 & 152 & 139 & 32 & 28 & 25 & 96 \\ \text { Jun } & 51 & 29 & 65 & 83 & 573 & 20 & 5 & 3 & 2 & 1 & 2 & 3 & 18 & 48 & 34 & 10 & 12 & 20 & 196 & 64 & 58 & 54 & 32 & 126 \\ \text { Jul } & 88 & 100 & 88 & 120 & 481 & 69 & 20 & 6 & 0 & 0 & 2 & 5 & 9 & 11 & 12 & 15 & 17 & 126 & 484 & 106 & 79 & 35 & 67 & 116 \\ \text { Aug } & 54 & 37 & 71 & 58 & 257 & 355 & 18 & 5 & 1 & 0 & 0 & 1 & 4 & 7 & 10 & 11 & 14 & 100 & 378 & 132 & 48 & 41 & 76 & 50 \\ \text { Sep } & 35 & 39 & 23 & 41 & 78 & 678 & 21 & 1 & 0 & 0 & 0 & 0 & 0 & 2 & 4 & 7 & 11 & 189 & 68 & 56 & 28 & 27 & 77 & 53 \\ \text { Oct } & 25 & 39 & 34 & 42 & 77 & 562 & 43 & 2 & 0 & 0 & 0 & 0 & 0 & 0 & 0 & 0 & 18 & 45 & 60 & 33 & 41 & 35 & 33 & 54 \\ \text { Nov } & 63 & 101 & 38 & 24 & 153 & 36 & 227 & 2 & 0 & 0 & 0 & 0 & 0 & 0 & 0 & 0 & 181 & 107 & 28 & 50 & 22 & 39 & 56 & 114 \\ \text { Dec } & 32 & 56 & 49 & 69 & 93 & 191 & 608 & 89 & 0 & 0 & 0 & 0 & 1 & 15 & 3 & 4 & 185 & 202 & 33 & 44 & 56 & 65 & 60 & 52\end{array}$

Table 11. Heat Map of Relaxed Minimum Average Real-Time Prices for the High/Adjusted Scenario in $\$ / M W h$

\begin{tabular}{lrrrrrrrrrrrrrrrrrrrrrrrrrrrrrrrrr} 
Hour & 1 & 2 & 3 & 4 & \multicolumn{1}{c}{5} & 6 & 7 & 8 & 9 & 10 & 11 & 12 & 13 & 14 & 15 & 16 & 17 & 18 & 19 & 20 & 21 & 22 & 23 & 24 \\
Jan & 55 & 43 & 71 & 60 & 68 & 97 & 376 & 65 & 2 & 0 & 0 & 0 & 0 & 0 & 0 & 1 & 205 & 236 & 65 & 54 & 50 & 36 & 87 & 50 \\
Feb & 51 & 64 & 42 & 39 & 100 & 245 & 385 & 36 & 4 & 0 & 0 & 0 & 0 & 3 & 5 & 4 & 48 & 216 & 145 & 45 & 73 & 42 & 53 & 54 \\
Mar & 68 & 73 & 65 & 43 & 145 & 413 & 137 & 16 & 3 & 2 & 1 & 1 & 1 & 3 & 5 & 28 & 13 & 240 & 193 & 50 & 37 & 36 & 56 & 76 \\
Apr & 116 & 149 & 102 & 137 & 194 & 425 & 25 & 4 & 3 & 2 & 2 & 2 & 1 & 1 & 2 & 3 & 12 & 227 & 259 & 169 & 74 & 70 & 86 & 87 \\
May & 80 & 63 & 74 & 79 & 38 & 66 & 18 & 7 & 1 & 0 & 1 & 2 & 3 & 6 & 28 & 9 & 15 & 60 & 174 & 145 & 43 & 37 & 34 & 58 \\
Jun & 62 & 37 & 57 & 76 & 426 & 32 & 19 & 11 & 7 & 7 & 9 & 11 & 28 & 57 & 44 & 21 & 24 & 33 & 199 & 77 & 63 & 43 & 38 & 79 \\
Jul & 68 & 86 & 90 & 93 & 278 & 43 & 31 & 19 & 13 & 13 & 14 & 17 & 19 & 20 & 21 & 26 & 30 & 121 & 479 & 117 & 84 & 47 & 53 & 44 \\
Aug & 63 & 39 & 76 & 43 & 14 & 229 & 34 & 18 & 12 & 11 & 11 & 13 & 16 & 18 & 20 & 21 & 27 & 89 & 381 & 137 & 53 & 42 & 61 & 40 \\
Sep & 41 & 50 & 35 & 50 & 74 & 585 & 27 & 10 & 4 & 3 & 4 & 5 & 7 & 10 & 12 & 16 & 24 & 190 & 77 & 68 & 42 & 37 & 45 & 42 \\
Oct & 33 & 49 & 45 & 50 & 76 & 481 & 43 & 8 & 1 & 0 & 0 & 1 & 2 & 3 & 4 & 10 & 110 & 76 & 70 & 42 & 44 & 33 & 37 & 54 \\
Nov & 66 & 103 & 50 & 35 & 138 & 294 & 163 & 7 & 0 & 0 & 0 & 0 & 0 & 0 & 0 & 2 & 286 & 116 & 40 & 60 & 36 & 44 & 54 & 87 \\
Dec & 38 & 57 & 44 & 80 & 96 & 160 & 498 & 73 & 5 & 2 & 2 & 2 & 2 & 16 & 5 & 4 & 227 & 195 & 46 & 53 & 64 & 65 & 53 & 47
\end{tabular}


Table 12. Heat Map of Traditional Average Real-Time Prices for the Low/Adjusted Scenario in $\$ / M W h$

\begin{tabular}{llllllllllllllllllllllllllllll} 
Hour & 1 & 2 & 3 & 4 & 5 & 6 & 7 & 8 & 9 & 10 & 11 & 12 & 13 & 14 & 15 & 16 & 17 & 18 & 19 & 20 & 21 & 22 & 23 & 24 \\
\hline Jan & 25 & 24 & 24 & 24 & 25 & 27 & 40 & 27 & 24 & 23 & 22 & 22 & 22 & 22 & 22 & 22 & 25 & 38 & 37 & 40 & 29 & 32 & 33 & 26 \\
Feb & 25 & 24 & 24 & 24 & 24 & 26 & 28 & 25 & 23 & 23 & 23 & 22 & 22 & 22 & 22 & 23 & 24 & 28 & 36 & 31 & 37 & 35 & 26 & 26 \\
Mar & 24 & 24 & 23 & 24 & 24 & 26 & 32 & 24 & 22 & 22 & 22 & 22 & 21 & 21 & 21 & 22 & 23 & 26 & 55 & 33 & 29 & 28 & 26 & 25 \\
Apr & 25 & 25 & 25 & 30 & 47 & 25 & 23 & 22 & 22 & 22 & 20 & 20 & 21 & 21 & 22 & 23 & 24 & 25 & 62 & 142 & 29 & 27 & 50 & 26 \\
May & 25 & 24 & 24 & 23 & 24 & 23 & 22 & 22 & 23 & 24 & 24 & 25 & 25 & 26 & 26 & 27 & 27 & 28 & 30 & 31 & 29 & 27 & 27 & 26 \\
Jun & 26 & 25 & 24 & 24 & 24 & 23 & 23 & 25 & 26 & 27 & 27 & 28 & 28 & 29 & 76 & 56 & 59 & 31 & 40 & 31 & 31 & 85 & 48 & 28 \\
Jul & 27 & 26 & 25 & 25 & 24 & 24 & 24 & 25 & 26 & 28 & 29 & 88 & 90 & 237 & 230 & 159 & 127 & 51 & 66 & 78 & 37 & 31 & 30 & 29 \\
Aug & 27 & 26 & 26 & 25 & 26 & 26 & 25 & 25 & 26 & 27 & 28 & 50 & 81 & 201 & 130 & 204 & 81 & 41 & 71 & 53 & 33 & 31 & 29 & 28 \\
Sep & 25 & 24 & 24 & 24 & 25 & 26 & 25 & 25 & 25 & 26 & 26 & 27 & 28 & 88 & 123 & 125 & 43 & 48 & 42 & 32 & 52 & 30 & 29 & 27 \\
Oct & 25 & 24 & 24 & 24 & 25 & 26 & 25 & 24 & 23 & 23 & 24 & 23 & 24 & 24 & 24 & 25 & 27 & 30 & 37 & 29 & 49 & 27 & 27 & 26 \\
Nov & 24 & 23 & 23 & 23 & 24 & 48 & 43 & 23 & 22 & 21 & 22 & 21 & 22 & 22 & 22 & 24 & 27 & 35 & 30 & 29 & 28 & 27 & 26 & 25 \\
Dec & 37 & 26 & 30 & 27 & 49 & 51 & 66 & 26 & 23 & 22 & 22 & 21 & 19 & 19 & 21 & 22 & 46 & 60 & 34 & 33 & 30 & 29 & 33 & 26
\end{tabular}

Table 13. Heat Map of Relaxed Minimum Average Real-Time Prices for the Low/Adjusted Scenario in $\$ / M W h$

\begin{tabular}{l|llllllllllllllllllllllllllll} 
Hour 1 & 2 & 3 & 4 & 5 & 6 & 7 & 8 & 9 & 10 & 11 & 12 & 13 & 14 & 15 & 16 & 17 & 18 & 19 & 20 & 21 & 22 & 23 & 24 \\
Jan & 34 & 33 & 33 & 33 & 34 & 36 & 49 & 36 & 33 & 31 & 31 & 30 & 30 & 30 & 30 & 31 & 35 & 45 & 47 & 46 & 39 & 39 & 38 & 35 \\
Feb & 34 & 33 & 32 & 32 & 33 & 35 & 38 & 34 & 32 & 31 & 31 & 31 & 30 & 30 & 30 & 31 & 33 & 38 & 41 & 40 & 42 & 37 & 36 & 35 \\
Mar & 33 & 32 & 32 & 32 & 33 & 35 & 41 & 32 & 31 & 31 & 30 & 30 & 30 & 30 & 30 & 31 & 32 & 36 & 60 & 41 & 39 & 38 & 35 & 34 \\
Apr & 34 & 34 & 34 & 36 & 55 & 34 & 32 & 31 & 30 & 30 & 30 & 30 & 31 & 31 & 31 & 32 & 32 & 34 & 72 & 146 & 38 & 36 & 54 & 35 \\
May & 34 & 33 & 33 & 32 & 32 & 34 & 31 & 31 & 32 & 33 & 33 & 34 & 34 & 35 & 36 & 36 & 37 & 38 & 40 & 41 & 39 & 37 & 36 & 36 \\
Jun & 36 & 35 & 33 & 33 & 33 & 32 & 32 & 34 & 35 & 37 & 37 & 38 & 39 & 40 & 84 & 67 & 68 & 42 & 48 & 42 & 41 & 51 & 53 & 39 \\
Jul & 37 & 36 & 35 & 34 & 34 & 33 & 34 & 35 & 36 & 38 & 39 & 95 & 95 & 236 & 238 & 160 & 127 & 63 & 73 & 84 & 44 & 42 & 41 & 39 \\
Aug & 37 & 36 & 35 & 35 & 35 & 35 & 35 & 35 & 36 & 37 & 39 & 61 & 87 & 206 & 139 & 204 & 94 & 50 & 82 & 63 & 43 & 41 & 40 & 38 \\
Sep & 35 & 34 & 33 & 33 & 34 & 36 & 34 & 34 & 35 & 36 & 36 & 37 & 38 & 90 & 128 & 128 & 51 & 58 & 46 & 42 & 41 & 39 & 38 & 37 \\
Oct & 34 & 33 & 32 & 33 & 34 & 36 & 35 & 33 & 32 & 33 & 33 & 33 & 33 & 33 & 33 & 34 & 36 & 40 & 47 & 39 & 38 & 37 & 36 & 35 \\
Nov & 33 & 32 & 32 & 32 & 32 & 57 & 53 & 32 & 31 & 30 & 31 & 31 & 31 & 31 & 31 & 32 & 37 & 45 & 40 & 39 & 38 & 37 & 36 & 34 \\
Dec & 39 & 37 & 40 & 38 & 55 & 56 & 73 & 36 & 32 & 30 & 30 & 29 & 28 & 28 & 29 & 30 & 56 & 65 & 46 & 43 & 40 & 39 & 41 & 36
\end{tabular}

\subsection{Revenue and Costs}

Calculation of revenue and operating costs can help inform how each scenario impacts revenue sufficiency. These simulations only consider revenue from the energy market; depending on the region, market revenues would also include ancillary services and capacity payments. In the figures provided in this section, the first component of a unit's energy revenue is calculated using either the traditional or Relaxed Minimum price, and these revenues are shown by fuel type. In the day-ahead market, revenue is determined by day-ahead energy schedule and price, whereas in real time, revenue is determined based on the deviation in dispatch from the day-ahead schedule. This means revenues from real-time can be negative, as units must buy back their position at real-time prices if dispatched below their day-ahead schedule. Slow-start units can be redispatched in real-time, but not decommitted. Only the deviations above the day-ahead 
schedule receive positive revenue from the real-time price. Operating costs are determined based on the unit's bid-in cost curve including fixed hourly operating and start-up costs.

The uplift or make-whole payment is the second component of revenue ${ }^{9}$. Resources are guaranteed to recover their bid-in costs, typically across a specific period (e.g., one day). If a resource would lose money in a single day ( 24 hours), the market will pay a side-payment to ensure bid cost recovery. In this study, make-whole payments are calculated separately for both the day-ahead and real-time markets based on bid costs. All resources are eligible to receive make-whole payments, including nuclear units. Although many slow-start or inflexible units self-schedule in energy markets today, all units are assumed to be dispatchable and committed by the system operator, thereby being eligible to receive payments. In these simulations, hydro units are not dispatchable, which may underestimate their flexibility and potential revenue.

Several options exist for calculating make-whole payments for renewable resources based on bidding and operating assumptions. A renewable unit can have a lower dispatch in real-time due to forecast error or curtailment. If the resource is treated similar to a fully dispatchable resource, it would be responsible for buying back its position from day-ahead if dispatched down in realtime. Even though we assume no bid-in costs for renewables, a resource might still end the day with negative net revenue, or revenue less bid-in operating costs, if it is required to buy back energy due to downward forecast error. This option might assume the renewable resource is bidding in its day-ahead and real-time forecast, making it responsible for any discrepancies. Alternatively, if the operator provides the renewable forecast, the discrepancies are not due to the unit's bids. In that case, the operator can settle the renewable resource solely on the real-time schedule, which reflects a better forecast. These results show the latter option, settling the renewable resources based on their real-time schedules, while all other resources remain the use of a two-part settlement.

Figure 6 shows the average energy revenue, make-whole payments, and operating costs by fuel type for each scenario. Note that these fuel types and the data associated with their operations are somewhat stylized based on the RTS-GMLC system, although both the RTS-GMLC operations data and NREL's ATB investment costs are derived from real-world generator data. Operating costs are the same for both pricing formulations because the Relaxed Minimum pricing logic does not impact a unit's dispatch point. Relaxed Minimum revenue and make-whole payments are shown in solid colors in the figure for traditional pricing and in hatched bars for Relaxed Minimum pricing. The gray bars for each fuel type show the annualized capital costs from NREL's ATB values (NREL 2017). These capital costs values provide a point of comparison for what it would cost, on an annualized basis, to build a representative new generator for each technology type. While this provides an estimate of revenue adequacy, precise revenue adequacy calculations would require understanding the investment costs for specific projects, both for new and existing generators. Note also that the discussion of revenue by fuel type in this report is not meant to indicate future outcomes for the resource types. The test case has a set of specific units

\footnotetext{
${ }^{9}$ In Section 4, uplift payments only consist of make-whole payments. In actual operations uplift has additional components.
} 
and assumptions in each category that will impact results; other test cases and actual systems are likely to find different results.

Revenue from renewable resources differ mainly due to the renewable penetration level, with wind receiving more revenue in the high renewable case and solar receiving more in the low renewable case. The high renewable scenarios had low or zero prices during midday and high prices during shoulder hours. It follows that solar would make little revenue in these cases because it is producing the least amount of energy when prices are high. In the low penetration cases, the midday prices are significantly higher, meaning solar is able to make a higher net revenue.

Thermal generation revenue varies between both the renewable penetration levels and the adjusted or unadjusted scenarios. Coal units make more revenue per installed capacity in the low/adjusted case than in the high/unadjusted case. This discrepancy is partially due to the installed capacity of coal, which is reduced in the adjusted case. The total revenue for coal is much closer between the two scenarios, using traditional pricing revenue is $\$ 382$ million for low/adjusted, compared to $\$ 376$ million in the high/unadjusted case.

Gas CT units make enough revenue to cover annualized capital costs in the high renewable cases, but they are unable to cover these costs in the low renewable cases. For both the adjusted and unadjusted case, most gas CTs only had positive net revenue due to make-whole payments with either traditional or Relaxed Minimum pricing. In the low/unadjusted case (which is difficult to read on the graph), gas CTs are not turned on frequently. Their average energy revenue is negative due to a large number of periods when the units buy back power at real-time prices. Make-whole payments make them net positive but with very low total revenue. Similar to gas CTs, oil CTs make most revenue in the high renewable cases, and they just barely cover annualized capital costs in the low/adjusted case due to make-whole payments. In the low/unadjusted case, oil CTs cannot make enough to cover annualized capital costs. Many of the oil CTs make more profit than individual gas CTs, even though the marginal cost of oil is much higher than gas. This occurs due to the characteristics of units for each fuel type; oil CTs in the test system have lower minimum dispatch levels and lower minimum run times, in addition to lower commitment costs. Due to these factors, the units are turned on more frequently even though they have higher marginal costs, thereby gaining higher revenue.

Though the per-MW revenue that hydro and nuclear earn varies, neither can make enough revenue to cover annualized capital costs. As mentioned in Section 3, these costs consider a new installation rather than going-forward costs for existing resources, which may be lower than costs for a new installation. Both fuel types make more in the low-renewable case, partly because most of the revenue comes from the day-ahead market, and because the flexibility to capture higher real-time prices in the high renewable cases is lacking.

Combined-cycle gas units are the only resources to make enough revenue to exceed their annualized capital costs in all scenarios, including with both traditional pricing and Relaxed Minimum pricing. Gas CC units also make a small amount of revenue from make-whole payments, although energy revenue alone covers annualized capital costs for all cases. These graphs show average revenue for each fuel type, but not all generators make enough revenue to cover annualized capital costs. Section 4.3, in contrast, looks at the net revenue by fuel type of these individual generators. 


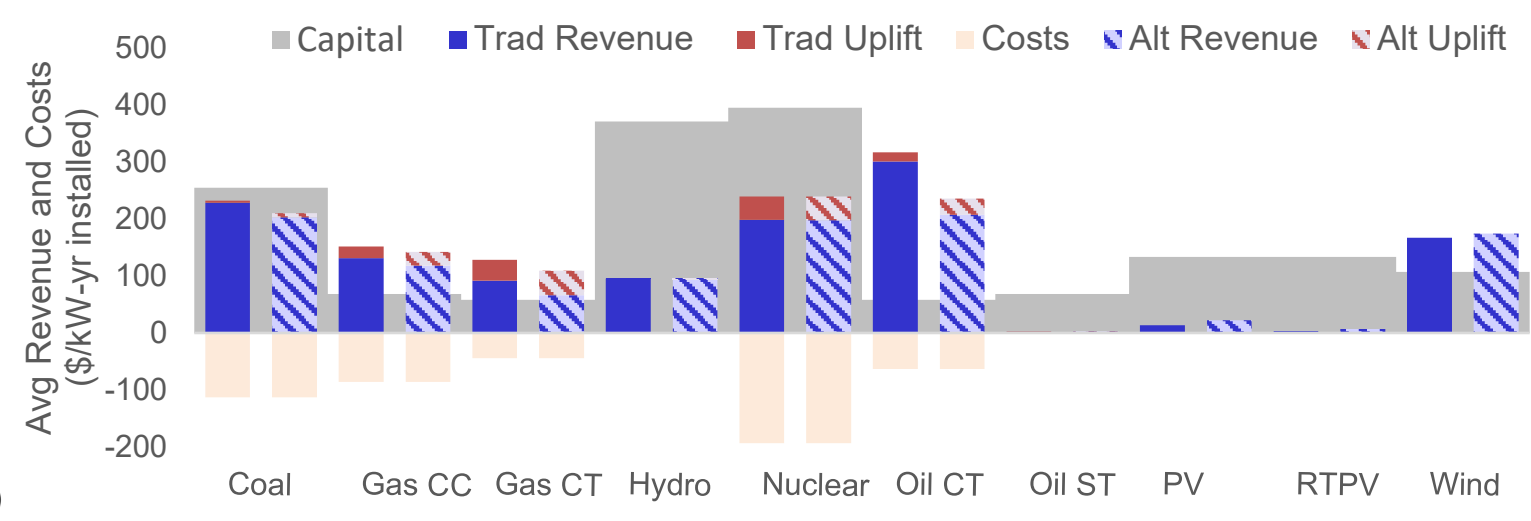

a)

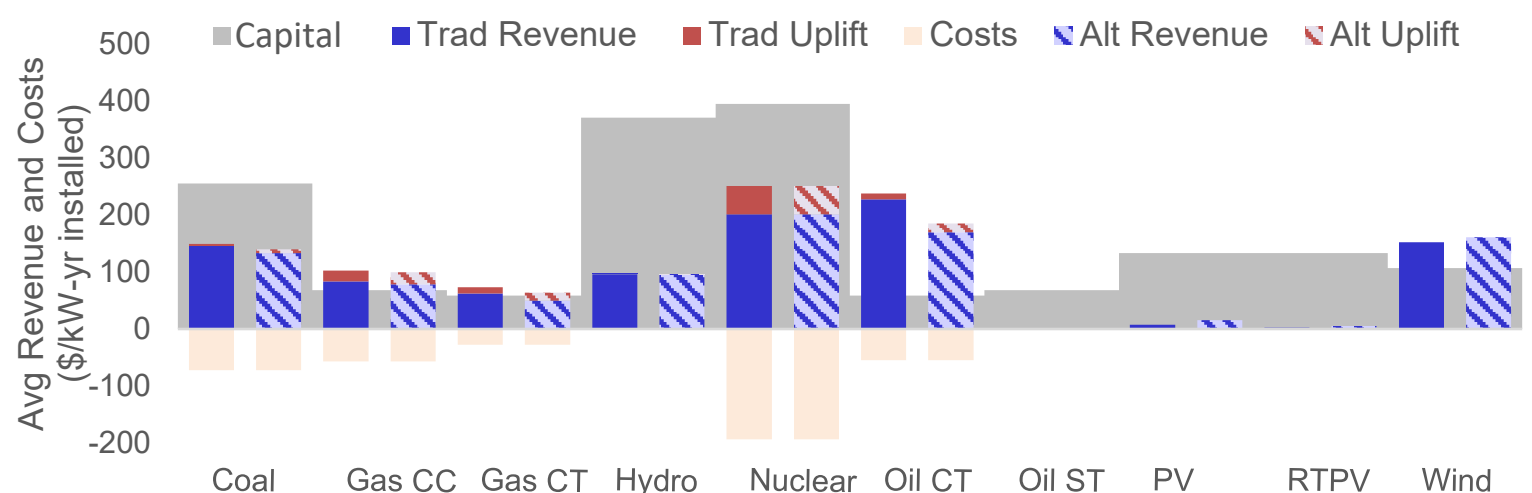

b)

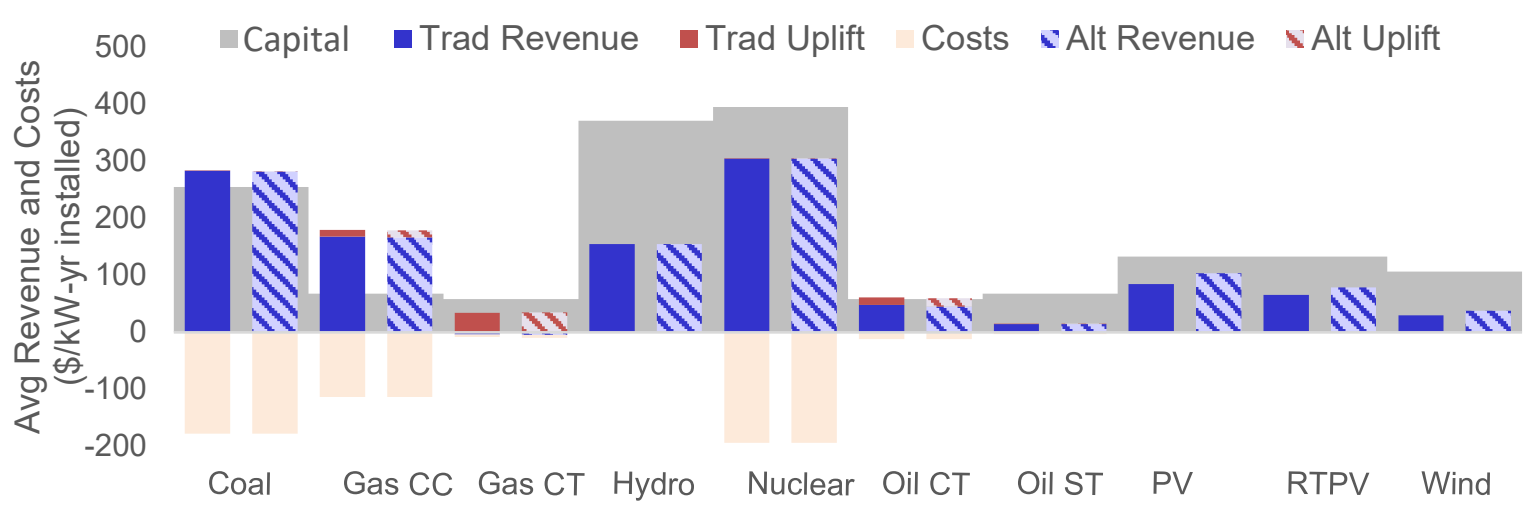

c)

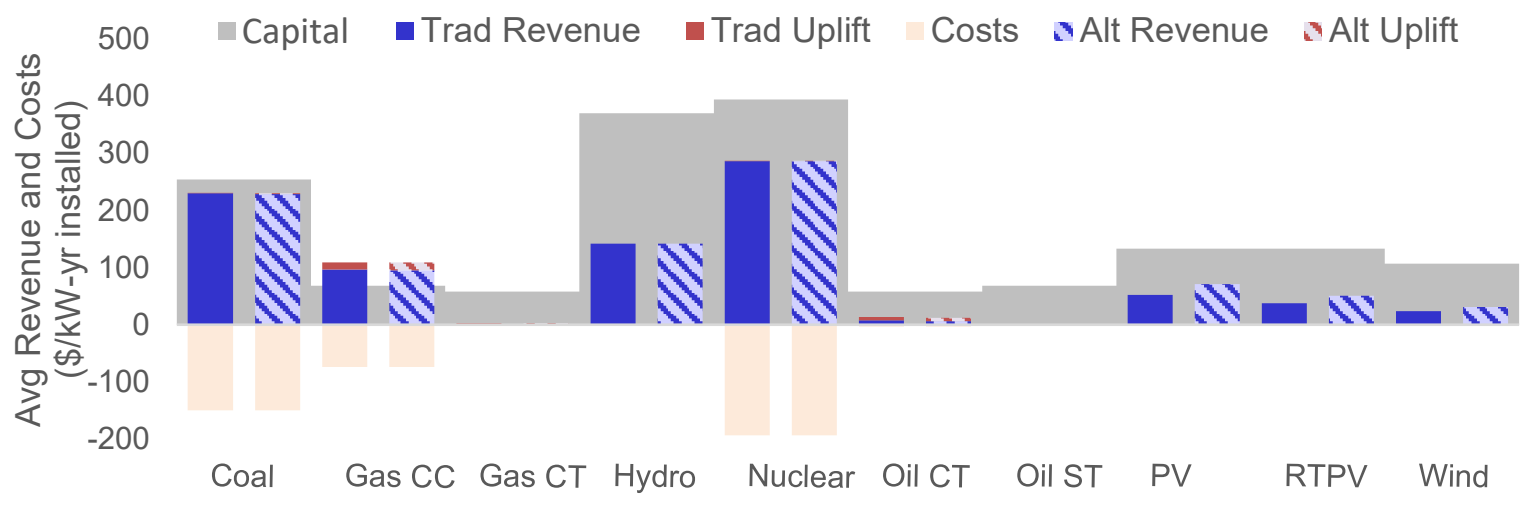

Figure 6. Revenue, uplift, and operating costs ("Costs") compared to annualized capital costs (“Capital”) for a) high/adjusted, b) high/unadjusted, c) low/adjusted, and d) low/unadjusted scenarios

Alternative $=$ Relaxed Minimum 


\subsection{Net Revenue}

Net revenue is defined as the difference between revenue from energy and make-whole payments less operating costs. It is often used as an approximation of the portion of revenues that can contribute to paying off any annual fixed costs, going forward costs, and/or upfront capital costs. However, these results do not consider revenue that generators gain from other markets and sources. For instance, ancillary services revenue, capacity market payments, bilateral contracts, or other side payments are not shown. Therefore, it is important to note that when comparing the net revenue to annualized capital costs, most generators have opportunities to recover costs through other revenue streams.

Figure 7 shows a box plot of each generator's net revenue per MW installed. The mean is shown with the darker line in the box and outliers are shown with multicolor dots. Similar to Figure 6, the gray bars for each fuel type show the annualized capital costs from NREL's ATB values. There are a different number of units for each fuel type, and the figure shows the range of net revenues across each unit with the exception of nuclear, since there is only one unit in the test system.

Similar to the pricing results, renewable penetration impacts net revenue more than the adjusted or unadjusted resource mix. The high renewable cases show higher net revenue for most thermal units, with many units making enough in the energy market to cover their annualized capital costs. Some thermal resources have low net revenue, in the tens of thousands of dollars per MW, but all oil CTs and wind plants can earn a higher net revenue across the year, exceeding their annualized capital costs.

Renewable revenue and net revenue are the same in this study because their bid in costs (and therefore operating costs as we define them here) are zero. For wind, the range of net revenue is much greater in the high renewable cases than in the low renewable cases. In contrast, solar net revenue is similar for all units across all scenarios. As mentioned in Section 4.2, solar net revenues in the high renewable cases are low due to low energy prices during the middle of the day when solar produces the most energy. Although there are a large number of solar generators, their net revenue does not vary among the units.

As with the solar resources across all scenarios and with the exception of gas $\mathrm{CC}$ units, the range of net revenue in the low renewable case is narrow. Given the lower volatility of prices in these cases, it can be expected that net revenue does not have a large range because prices are similar throughout the year. Gas and oil CTs make less net revenue in the low renewable cases, averaging $\$ 80 / \mathrm{kW}$-yr less, where the units did slightly better in the low/adjusted case than in the unadjusted case. Unlike in the high renewable case, the CTs never make enough net revenue to cover annualized capital costs.

The difference between average net revenue - aggregated across all fuel types - for the traditional and Relaxed Minimum pricing methods is $+\$ 2.16 / \mathrm{kW}-\mathrm{yr},+\$ .88 / \mathrm{kW}-\mathrm{yr},-\$ 3.56 / \mathrm{kW}$ $\mathrm{yr}$, and $-\$ 2.87 / \mathrm{kW}-\mathrm{yr}$ for the high/adjusted, high/unadjusted, low/adjusted, and low/unadjusted cases, respectively. This represents $0.6 \%$ to $2.1 \%$ of average annualized capital costs values for each scenario or a percent change between $+5 \%$ and $-5 \%$. For the high renewable scenarios, the average net revenue is higher under traditional pricing, whereas the low renewable scenarios have higher net revenue in the Relaxed Minimum pricing method. The absolute difference (or 
mean absolute error) ranges between $\$ 3.5 / \mathrm{kW}$-yr to $9.9 / \mathrm{kW}$-yr for each scenario, or between $2 \%$ to $7 \%$ of annualized capital costs.

The above ranges capture the averages aggregated across all fuel types; the difference between net revenue is greater when examining average net revenue between fuel types. Averages fluctuate between $\$ 6 / \mathrm{MW}$-yr for nuclear units in the low/unadjusted scenario to $\$ 81,000 / \mathrm{MW}$-yr for oil CTs in the high/adjusted scenario; keeping in mind both fuel types have less capacity compared to other fuel types. Units that have average net revenue higher in the traditional pricing method are primarily non-renewable; across the four scenarios, $84 \%$ of non-renewable units have higher net revenue under traditional pricing. Renewable units show opposite trends; $99 \%$ of renewable units have higher net revenue under Relaxed Minimum pricing compared to traditional. Across all scenarios, solar net revenue under Relaxed Minimum pricing increases between 20\% and 55\%. Relaxed Minimum prices are on average 14\% higher, and because solar does not have bid in costs to recover, they can capture higher net revenue. 
a)
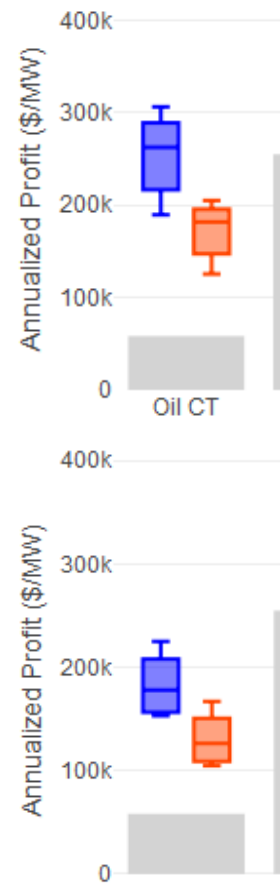

b)
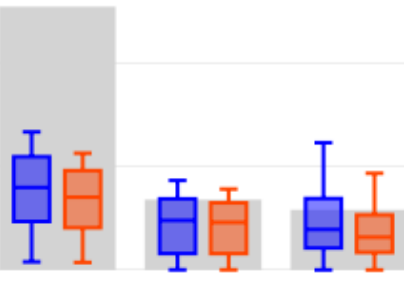

Gas CC

Gas CT

Oil ST
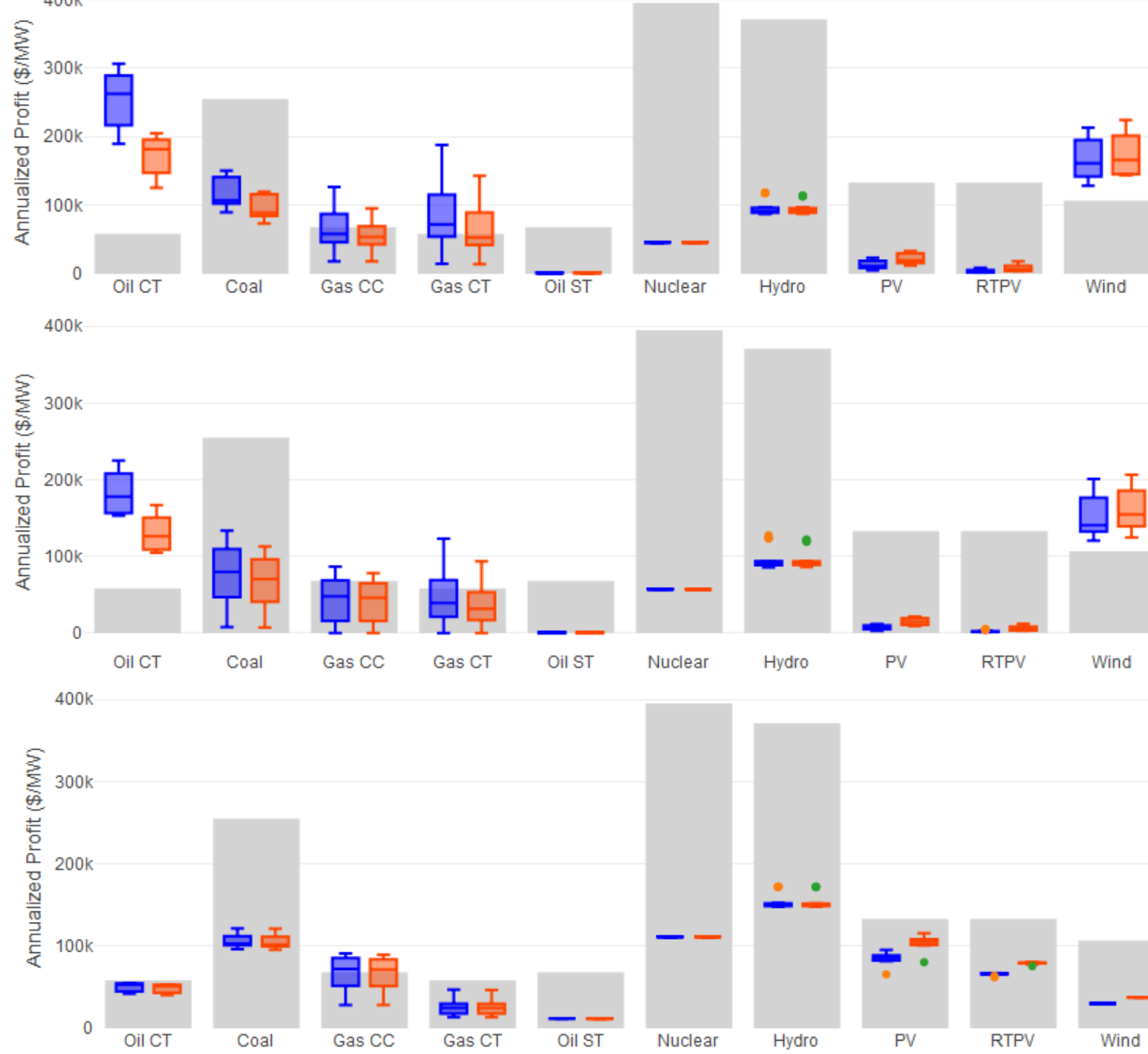

Nuclear

Hydro

PV

RTPV

Wind

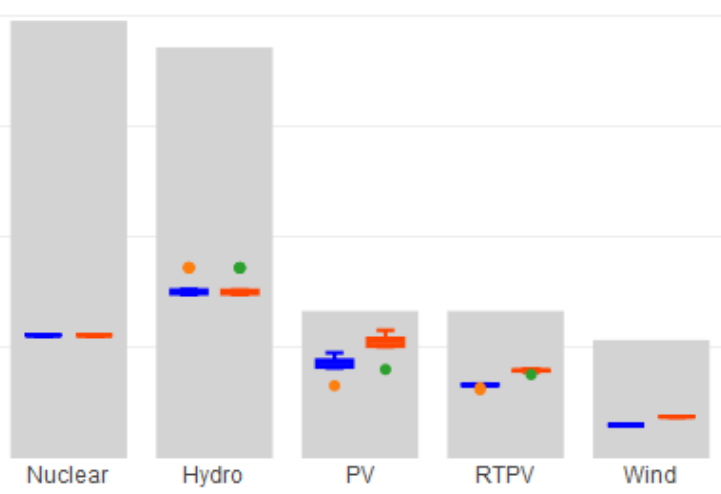

c)

$\square$ Traditiona

Alternative Capital

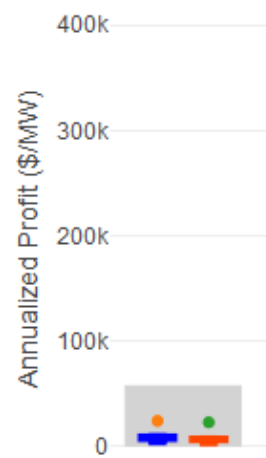

d)

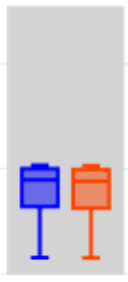

Coal

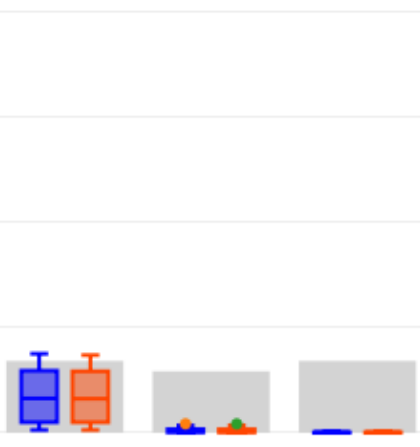

Gas CC

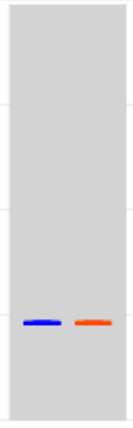

Nuclear

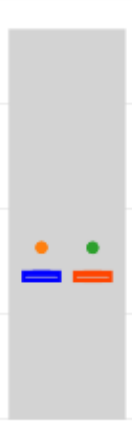

Hydro

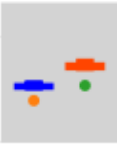

PV

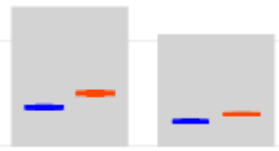

RTPV

Wind

Figure 7. Box plot of net revenue (profits) per resource compared to annualized capital costs (\$/kW-yr) for a) high/adjusted, b) high/unadjusted, c) low/adjusted, and d) low/unadjusted scenarios

Alternative $=$ Relaxed Minimum 


\subsection{Impact of Scarcity Price on Results}

The use of production cost simulation tools to simulate wholesale energy prices has several challenges. For example, the behavior of offer strategies is difficult to capture in these tools. When using high temporal resolution models with multiple stages of decision-making and forecast error, infeasibilities result which cause spikes in that period's prices. Periods when this occurs can be considered times of scarcity or reserve shortages in the system. In this study, many periods of scarcity occurred because a unit that was committed in day-ahead was needed a few periods prior to its actual start-up or a few periods after it shut down. In actual operations, an operator would see this issue and can opt to commit the unit for several additional periods or make other out-of-market decisions. Since the model has no reflection of human intervention and no options for out-of-market corrections, it is possible that the results in this study reflect more periods of scarcity than may occur in practice. The number of periods of scarcity in the different scenarios are not meant to be future predictions, rather they can aid in understanding of system scheduling and model development.

The study uses a scarcity price of $\$ 1000 / \mathrm{MWh}$ when calculating revenue and net revenue, as described in Section 3.3. The choice of scarcity price will impact the average prices shown in Table 9-Table 13 and the revenue and net revenue shown in Figure 6 and Figure 7. This section explores different scarcity price sensitivities. The sensitives are post-simulation adjustments and not the result of new simulations. These results show calculations if the scarcity price was replaced with either a higher or lower price to reflect changes that might exist in individual regions. The following figures show which simulations are most sensitive to the choice of scarcity price.

The average prices for day-ahead and real-time are shown in Figure 8 for scarcity prices ranging from $\$ 500 / \mathrm{MWh}$ to $\$ 2000 / \mathrm{MWh}$. The day-ahead averages are shown in (a), where only the low adjusted scenario had a single period of scarcity and all others did not hit the scarcity price during day-ahead. The real-time prices are shown in (b) where the high renewable scenarios hit many periods of scarcity.

The choice of price in these cases not only impacts the average, but also the relative hierarchy of traditional and Relaxed Minimum averages. With a price of $\$ 1000 / \mathrm{MWh}$, the high adjusted traditional average price is slightly higher than the Relaxed Minimum case. As discussed in Section 4.1, this is an unexpected result compared to the theory of alternative pricing in which the price would always be higher. With a lower scarcity price, the average of the Relaxed Minimum case is higher than the traditional case, which follows the intuitive pricing hierarchy. However, with a higher scarcity price, the traditional case is higher due to it having greater number of periods of scarcity. Predictably, the averages increment linearly with the change in scarcity price within each scenario. With fewer periods of scarcity, the low renewable cases show lower averages even with a very high scarcity price. 


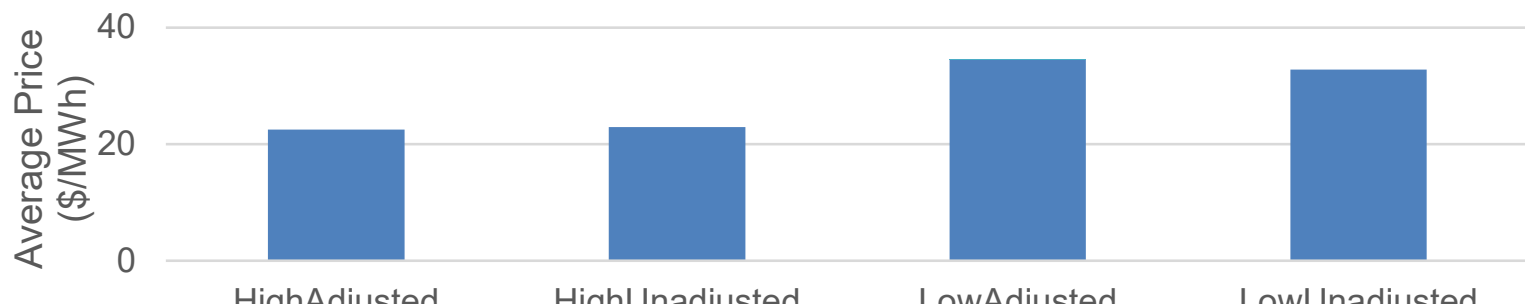

a)
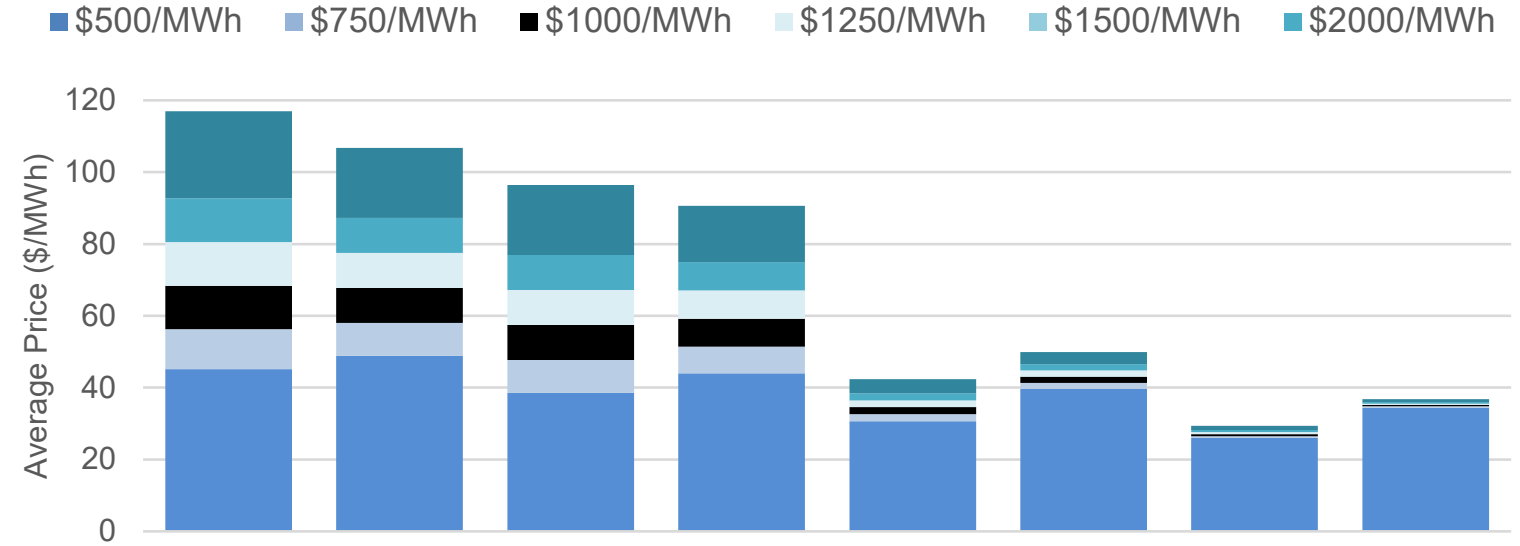

b)

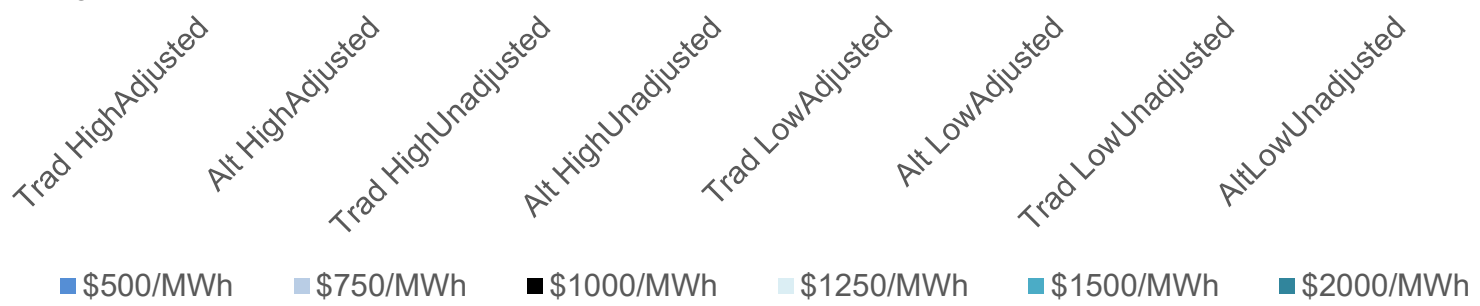

Figure 8 Average yearly prices resulting from different scarcity prices for a) day-ahead and b) realtime, ranging from $\$ 500 / \mathrm{MWh}$ to $\$ 2000 / \mathrm{MWh}$. Numbers shown on the figure are the averages used in study results, $\$ 1000 / \mathrm{MWh}$

Alternative $=$ Relaxed Minimum

Figure 9 shows the change in average net revenue per MW of installed capacity by fuel type for scarcity prices of $\$ 500 / \mathrm{MWh}, \$ 1000 / \mathrm{MWh}$, and $\$ 2000 / \mathrm{MWh}$ for each simulated scenario. The darkest colors show the results for $\$ 1000 / \mathrm{MWh}$, the same averages shown in Figure 7 . Similar to the average prices, the high renewable case has a greater range of average net revenue than the low renewable cases. Resources that gain more net revenue from periods of scarcity also have greater ranges compared to units that are slow or non-dispatchable, like nuclear and hydro. Net revenue from both gas and oil CTs, and wind units can increase greatly with a greater scarcity price.

The low renewable unadjusted case had very little deviation with different prices due to the minimal number of periods where a scarcity price is invoked. The low adjusted case had some deviations, especially for renewable resources and oil CTs. Gas CTs are an exception in this case; the $\$ 2000 / \mathrm{MWh}$ scarcity price slightly reduced their net revenue since they were required to buy back more in real-time. The $\$ 500 / \mathrm{MWh}$ scarcity price increased average net revenue by $\$ 1581 / \mathrm{MW}$ for the year. 


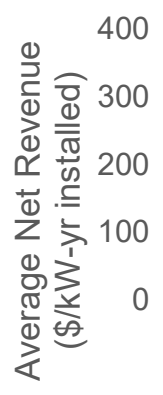

a)
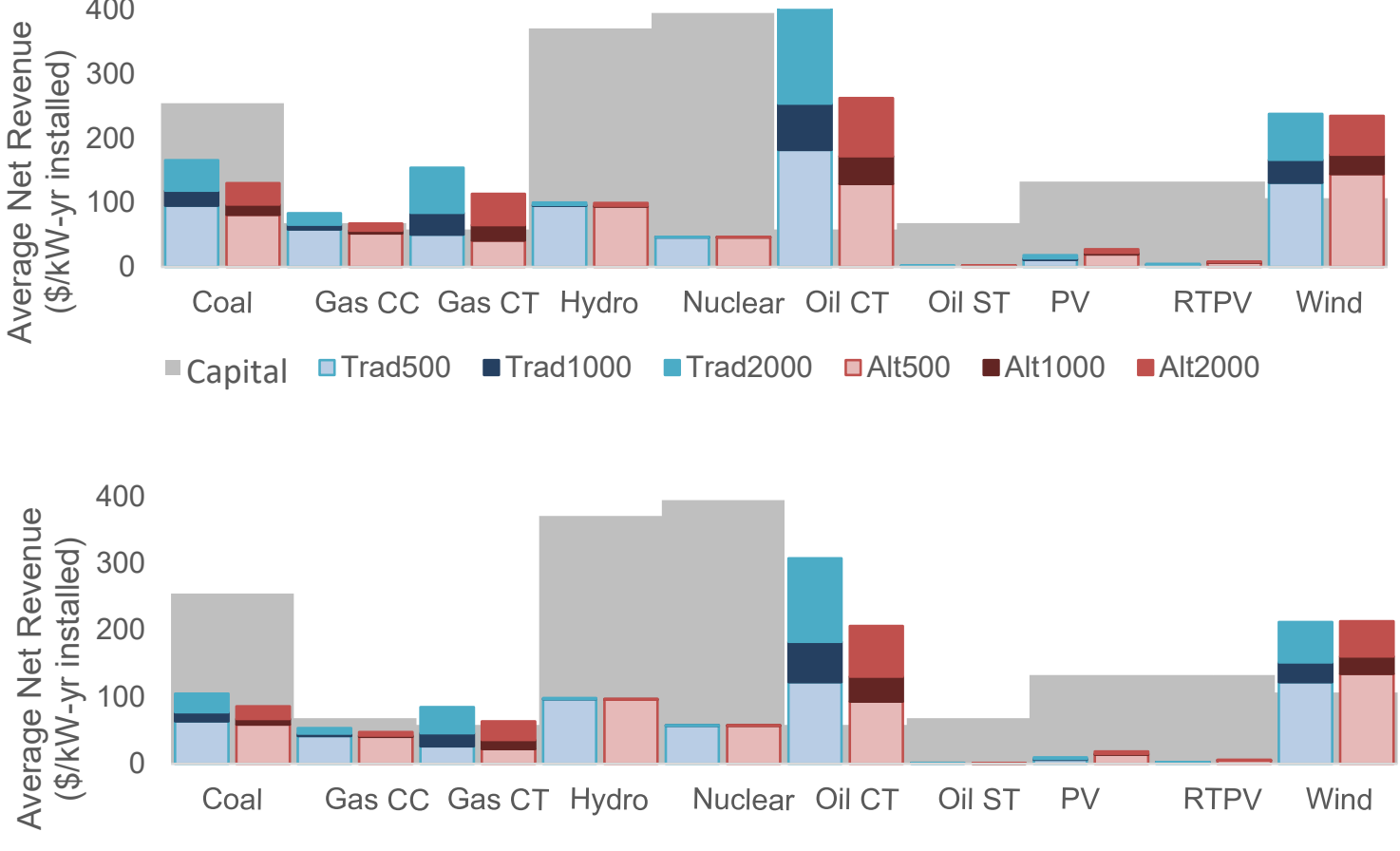

b)

- Capital $\quad$ Trad500 $\quad$ Trad1000 $\quad$ Trad2000 $\square$ Alt500 $\quad$ Alt1000 Alt2000

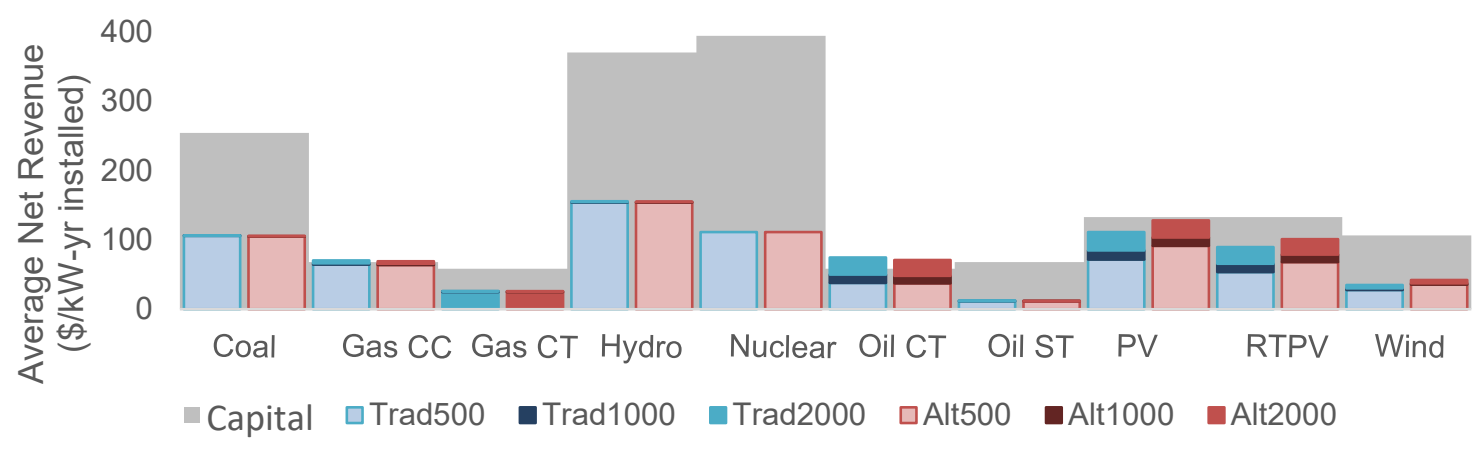

c)

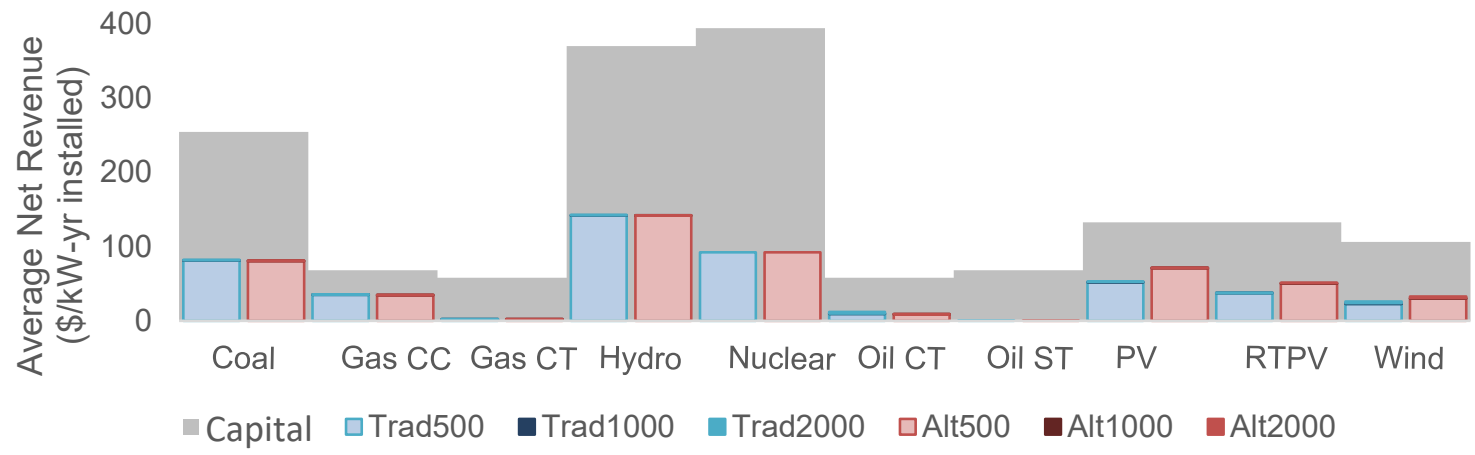

d)

Figure 9 Scarcity price sensitivity for average net revenue. Light colors show a price of $\$ 500 / \mathrm{MWh}$, darkest colors show $\$ 1000 / \mathrm{MWh}$, and medium colors show $\$ 2000 / \mathrm{MWh}$ for both traditional and

Relaxed Minimum pricing for a) high/adjusted, b) high/unadjusted, c) low/adjusted, and d) low/unadjusted scenarios

Alternative $=$ Relaxed Minimum 


\section{Conclusions and Future Research Needs}

Examining alternative price formation becomes increasingly important as revenue adequacy uncertainty arises from larger penetrations of weather-driven, zero-incremental-cost energy resources, such as wind and solar. Most ISOs and RTOs currently use different alternative pricing for a subset of resources in their market auctions. Alternative pricing attempts to capture aspects of electricity markets that are unusual compared with most commodities. Setting the "right price" in electricity markets is complex because of physical and financial auctions, minimum operating levels, and commitment costs. Although there have been many proposals for alternative pricing mechanisms, many experts agree that no one method dominates the rest.

This study compares one alternative pricing mechanism to traditional pricing under different renewable penetration and resource adequacy assumptions. The alternative pricing method incorporates commitment costs (also called no-load costs) into prices by relaxing the minimum operating level to zero; the prices reflect these costs as incremental costs to operate the resource. The results discussed in Section 4 and the conclusions below result from yearlong simulations using a single test case. The conclusions cannot necessarily be generalized for any one region or particular future year. The trends should be interpreted as possible outcomes, which can be compared against detailed simulations using different systems and data years. The study conducted here provides a process and set of analytics for utilities and ISOs to study in their specific regions.

The results from each of the four developed scenarios (eight simulations total) show several key trends. First, renewable penetration has a greater impact on pricing and resulting net revenue than the resource mix adjusted for a resource adequacy target. While the price duration curves and the heat maps (Tables 9-13) show minor price changes between the adjusted and unadjusted resource mix scenarios, the primary distinction and trends between the scenarios are driven by how much renewable capacity is available. For example, prices ranged between $\$ 20 / \mathrm{MWh}$ and $\$ 45 / \mathrm{MWh}$ over $95 \%$ of the year for the low renewable cases and less than $50 \%$ of the year for the high renewable cases. While major trends could be distinguished by renewable penetration level, in both the high and low renewables cases, the adjusted system mix has average higher prices than the unadjusted cases.

Second, net revenue is higher for some resources under traditional pricing, while others are higher under Relaxed Minimum pricing. Across the four scenarios, over $99 \%$ of renewable resources had higher average net revenue per MW of installed capacity under Relaxed Minimum pricing, while $84 \%$ of non-renewable resources had higher net revenue under traditional pricing. The difference between average net revenue under traditional compared to Relaxed Minimum pricing ranged between $0.6 \%$ to $2.1 \%$ of average annualized capital costs values for each scenario or a percent change between $+5 \%$ and $-5 \%$. Solar resources are the only fuel type where net revenue is consistently higher across all scenarios under Relaxed Minimum pricing; this is primarily due to prices during the day being set at values above $\$ 0 / \mathrm{MWh}$ under Relaxed Minimum pricing. Under the high renewable cases, wind resources can make enough net revenue to surpass their annualized capital costs. For all other fuel types, net revenue showed only small changes between the two pricing methods, with traditional pricing producing marginally higher net revenue for non-renewable resources. 
Finally, average prices were higher under the high renewable penetration scenarios than under the low renewable penetration scenarios. This result is counterintuitive to existing hypotheses and is driven by price spikes from more frequent shortage conditions in the high renewable cases. By looking at new supply stacks, it is intuitive that, all else equal, prices will decrease when renewable energy increases because the supply stack is pushed to the right by lower-cost renewables. However, renewables also add variability and uncertainty, which can lead to more challenging operating paradigms. These challenges can manifest as shortage conditions that come with administratively set prices that are typically much higher than any resource's operating cost. Although average prices in this study increased under the high renewable case, average prices excluding periods with price spikes are lower in the high renewables cases compared to the low ones, which follows intuition. The heat maps comparing monthly and hourly averages show that there are many periods of low- to no-cost prices, but they are countered with very high peaks in the shoulder hours, especially just before and during sunrise. The sensitivity analysis on different scarcity prices showed that average prices and net revenue in the high renewable cases increase as scarcity prices increase, but low renewable cases are affected less from increasing scarcity prices. The result emphasizes the need to assess modeling assumptions that might cause scarcity and highlights the importance of doing sensitivity on an exogenously determined scarcity or shortage price.

Some of these impacts might not be seen today in high renewable markets for several reasons. First, this is a test system that captures many but not all the intricacies of an ISO or RTO market. Second, operator action can impact very high prices. For example, seeing the possible need for a generator in a later period, an operator might turn on a plant outside the dispatch algorithm. Although prices in that period might not be impacted, prices in the later period that might have spiked can now be set by the additional online resources. Though this might not happen often, the look-ahead period used in the simulations cannot fully capture such behavior, and modeling artifacts may have worsened the impact. Many systems also have capacities beyond their resource adequacy requirements, which is equivalized in this study as "unadjusted." Finally, this study does not model AGC (automatic generation control) or any other near real-time adjustments that can reduce possible periods when spikes occur and sets one particular shortage price.

Many features of traditional and alternative prices could be studied in the future. During some parts of the day, prices under the high renewable cases were zero or near zero. In future scenarios when renewable resources are the marginal generator, thermal generation might be turned on at minimum to maintain adequate reserves. In this case, the reserve price might be higher than the traditional LMP, which would be set by the renewable resource. However, Relaxed Minimum pricing would set the price from the thermal resource dispatched at minimum operating level, rather than from a zero-marginal cost resource. Future work can evaluate formulations of reserve and alternative pricing to ensure the pricing mechanisms capture the full costs of procuring reserve and any relaxation supports co-optimized energy and reserve prices. It can also evaluate the relative differences between total revenue from energy compared to reserve; while reserve is often a small part of total revenue today, future prices might shift compensation.

This study focused on comparing two pricing methods; future studies could compare other proposed pricing methods, including the AIC method, or those specific to implementations or proposals by the ISOs or RTOs. Future research can also examine allowing offline generators to 
set prices and modifying the set of resources that are eligible to set prices under alternative methods. Also, this study could be extended to ISO system models to compare multiple pricing methods on a realistic test case.

Current pricing methods - both those that have been proposed and those that are implementedfocus on single-period pricing with extensions that accommodate the multiperiod auctions, such as allocation methods for start-up costs. Future research on multiperiod pricing could produce prices that signal need in particular periods. For example, if a fast-start unit is turned on for use in one period and has a two-period minimum run time, the start-up cost for the unit could be used to send a price signal in the first period rather than being allocated over its minimum run time.

Many studies, including this one, also do not include price responsive demand. While there is currently a very small amount of demand that actively bids into markets, future consumers might increase the amount of price responsive demand. The number of price spikes in any given scenario could decrease as demand is able to set prices and replace shortages with decreased consumption. Futures studies can evaluate the impact of different penetration levels and bidding strategies for price responsive demand.

Although many proposals for alternative pricing methods exist, industry and academics have not yet agreed upon a single method that dominates all others in meeting pricing goals, ease of implementation, or proved to produce efficient investments for a variety of system conditions and resource build-outs. Additional studies are needed to continue comparisons, and new metrics are likely needed to accurately compare results. 


\section{References}

Araoz, Veronica, and Kurt Jörnsten. 2011. "Semi-Lagrangean Approach for Price Discovery in Markets with Non-Convexities." European Journal of Operational Research 214 (2): 411-17. https://doi.org/http://dx.doi.org/10.1016/j.ejor.2011.05.009.

Andrianesis, Panagiotis, George Liberopoulos, George Kozanidis, and Alex D. Papalexopoulos. 2013. "Recovery Mechanisms in Day-Ahead Electricity Markets with Non-Convexities - Part I: Design and Evaluation Methodology." IEEE Transactions on Power Systems. https://doi.org/10.1109/TPWRS.2012.2207920.

Barrows, Clayton, Aaron Bloom, Ali Ehlen, Jussi Ikaheimo, Jennie Jorgenson, Dheepak Krishnamurthy, Jessica Lau, Brendan McBennett, et al. 2019. "The IEEE Reliability Test System: A Proposed 2019 Update.” IEEE Transactions on Power Systems. https://doi.org/10.1109/TPWRS.2019.2925557.

Bjørndal, Mette, and Kurt Jörnsten. 2008. "Equilibrium Prices Supported by Dual Price Functions in Markets with Non-Convexities." European Journal of Operational Research 190 (3): 768-89. https://doi.org/http://dx.doi.org/10.1016/j.ejor.2007.06.050.

Cochran, Jaquelin, Mackay Miller, Michael Milligan, Erik Ela, Douglas Arent, Aaron Bloom, Matthew Futch, et al. 2013. Market Evolution: Wholesale Electricity Market Design for $21^{\text {st }}$ Century Power Systems. Golden, CO: National Renewable Energy Laboratory. NREL/TP-6A2057477. https://www.nrel.gov/docs/fy14osti/57477.pdf.

Cramton, Peter, Axel Ockenfels, and Steven Stoft. 2013. "Capacity Market Fundamentals." Economics of Energy \& Environmental Policy 2 (2). https://doi.org/10.5547/2160-5890.2.2.2.

Ela, E., M. Milligan, A. Bloom, A. Botterud, A. Townsend, and T. Levin. 2014. Evolution of Wholesale Electricity Market Design with Increasing Levels of Renewable Generation. Golden, CO: National Renewable Energy Laboratory. NREL/TP-5D00-61765. https://www.nrel.gov/docs/fy14osti/61765.pdf.

EPRI (Electric Power Research Institute). 2019. Independent System Operator and Regional Transmission Organization Price Formation Working Group White Paper: Current Practice and Research Gaps in Alternative (Fast-Start) Price Formation Modeling. Palo Alto, CA: EPRI. EPRI Report 3002013724.

- 2017. Evaluation of Wholesale Energy Price Spikes in U.S. Electricity Markets. Palo Alto, CA: EPRI. EPRI Report 3002011828.

2016. Wholesale Electricity Market Design Initiatives in the United States: Survey and Research Needs. Palo Alto, CA: EPRI.

FERC (Federal Energy Regulatory Commission). 2015a. Price Formation in Energy and Ancillary Services Markets Operated by Regional Transmission Organizations and Independent System Operators: Order Directing Reports. FERC Docket No. AD14-14-000. Washington D.C.: FERC. https://elibrary.ferc.gov/idmws/file_list.asp?document_id=14400898. 
- 2015b. Energy Primer: A Handbook of Energy Market Basics. Washington D.C.: FERC Division of Energy Market Oversight. https://www.ferc.gov/market-oversight/guide/energyprimer.pdf.

.2018. "Energy Price Formation.” Last modified April 19, 2018.
https://www.ferc.gov/industries/electric/indus-act/rto/energy-price-formation.asp.

Frew, Bethany, Gord Stephen, Devon Sigler, Jessica Lau, Wesley Jones, and Aaron Bloom. 2019. "Evaluating Resource Adequacy Impacts on Energy Market Prices Across Wind and Solar Penetration Levels." The Electricity Journal 32 (8). https://doi.org/10.1016/j.tej.2019.106629.

Frontier Economics. 2009. International Transmission Pricing Review. Technical Report. Australia: Prepared for The New Zealand Electricity Commission. https://www.ea.govt.nz/dmsdocument/2539-report-by-frontier-economics-internationaltransmission-pricing-review.

Galiana, Francisco D., Alexis L. Motto, and François Bouffard. 2003. "Reconciling Social Welfare, Agent Profits, and Consumer Payments in Electricity Pools," IEEE Transactions on Power Systems 18 (2): 452-459. https://ieeexplore.ieee.org/stamp/stamp.jsp?arnumber=1198272

Gribik, Paul R. 2011. Direct Testimony of Dr. Paul R. Gribik Filed on Behalf of the Midwest Independent Transmission System Operator, Inc. Washington D.C.: FERC.

https://elibrary.ferc.gov/idmws/file_list.asp?document_id=13982501.

Gribik, Paul R., William W. Hogan, and Susan L. Pope. 2007. Market-Clearing Electricity Prices and Energy Uplift. Cambridge, MA. Working Paper.

https://hepg.hks.harvard.edu/publications/market-clearing-electricity-prices-and-energy-uplift.

Grigg, C., P. Wong, P. Albrecht, R. Allan, M. Bhavaraju, R. Billinton, Q. Chen, et al. 1999. “The IEEE Reliability Test System-1996: A Report Prepared by the Reliability Test System Task Force of the Application of Probability Methods Subcommittee." IEEE Transactions on Power Systems 14 (3): 1010-20. https://doi.org/10.1109/59.780914.

Herrero, Ignacio, Pablo Rodilla, and Carlos Batlle. 2015. "Electricity Market-Clearing Prices and Investment Incentives: The Role of Pricing Rules.” Energy Economics 47: 42-51. https://doi.org/10.1016/j.eneco.2014.10.024.

Hogan, William W., and Brendan J. Ring. 2003. On Minimum-Uplift Pricing for Electricity Markets. Cambridge, MA. Working Paper. https://sites.hks.harvard.edu/fs/whogan/minuplift 031903.pdf.

Hua, Bowen and Ross Baldick. 2017. "A Convex Primal Formulation for Convex Hull Pricing," IEEE Transactions on Power Systems 32 (5): 3814-3823.

https://ieeexplore.iee.org/stamp/stamp.jsp?tp=\&arnumber $=7778217$

Huppmann, Daniel, and Sauleh Siddiqui. 2018. “An Exact Solution Method for Binary Equilibrium Problems with Compensation and the Power Market Uplift Problem.” European Journal of Operational Research 266 (2): 622-638. https://doi.org/10.1016/j.ejor.2017.09.032. 
Kirschen, Daniel and Goran Strbac. 2004. Fundamentals of Power System Economics. West Sussex, England: John Wiley \& Sons.

Lew, D., G. Brinkman, E. Ibanez, A. Florita, M. Heaney, B.-M. Hodge, M. Hummon, et al. 2013. The Western Wind and Solar Integration Study Phase 2. Golden, CO: National Renewable Energy Laboratory. NREL/TP-5500-55588. https://www.nrel.gov/docs/fy13osti/55588.pdf.

Liberopoulos, George, and Panagiotis Andrianesis. 2016. "Critical Review of Pricing Schemes in Markets with Non-Convex Costs." Operations Research 64 (1): 17-31.

https://doi.org/10.1287/opre.2015.1451.

Lin, Jeremy, and Fernando H Magnago. 2017. "Pricing, Modeling, and Simulation of an Electricity Market." In Electricity Markets: Theories and Applications, 211-38. Piscataway, NJ: IEEE Press. https://doi.org/10.1002/9781119179382.ch8.

Madani, Mehdi, and Mathieu Van Vyve. 2017. "A MIP Framework for Non-Convex Uniform Price Day-Ahead Electricity Auctions." EURO Journal on Computational Optimization 5 (1-2): 263-84. https://doi.org/10.1007/s13675-015-0047-6.

Mays, Jacob, David Morton, and Richard O’Neill. 2018. Investment Effects of Pricing Schemes for Non-Convex Markets. USAEE Working Paper No. 18-348.

https://ssrn.com/abstract=3198423.

Milligan, Michael, Bethany A. Frew, Kara Clark, and Aaron P. Bloom. 2017. Marginal Cost Pricing in a World without Perfect Competition: Implications for Electricity Markets with High Shares of Low Marginal Cost Resources. Golden, CO: National Renewable Energy Laboratory. NREL/TP-6A20-69076. https://www.nrel.gov/docs/fy180sti/69076.pdf.

Motto, Alexis L., and Francisco D. Galiana. 2002. "Equilibrium of Auction Markets with Unit Commitment: The Need for Augmented Pricing." IEEE Transactions on Power Systems. https://doi.org/10.1109/TPWRS.2002.800947.

NERC (North American Electric Reliability Corporation). 2017. 2017 Long-Term Reliability Assessment. https://www.nerc.com/pa/RAPA/ra/Reliability\%20Assessments\%20DL/NERC LTRA 1213201 7 Final.pdf

NREL (National Renewable Energy Laboratory). 2017. "NREL ATB and Standard Scenarios 2017.” NREL Annual Technology Baseline. https://atb.nrel.gov/electricity/archives.html.

O’Neill, Richard P., Paul M. Sotkiewicz, Benjamin F. Hobbs, Michael H. Rothkopf, and William R. Stewart, Jr. 2005. "Efficient Market-Clearing Prices in Markets with Nonconvexities." European Journal of Operational Research 164 (1): 269-85. https://doi.org/10.1016/j.ejor.2003.12.011.

O’Neill, Richard P., Anya Castillo, Brent Eldridge, and Robin Broder Hytowitz. 2017. "Dual Pricing Algorithm in ISO Markets." IEEE Transactions on Power Systems 32 (4): 3301-3310. https://doi.org/10.1109/TPWRS.2016.2614891. 
Pfeifenberger, Johannes, Kathleen Spees, Kevin Carden, and Nick Wintermantel. 2013. Resource Adequacy Requirements: Reliability and Economic Implications. Prepared for FERC. https://www.ferc.gov/legal/staff-reports/2014/02-07-14-consultant-report.pdf.

Pfeifenberger, Johannes. 2014. "Resource Adequacy Requirements, Scarcity Pricing, and Electricity Market Design Implications." Presented for IEA Electricity Security Advisory Panel. Paris, France. https://www.iea.org/media/workshops/2014/esapworskhopi/Hannes Pfeifenberger.pdf.

PJM Interconnection. 2017. "Proposed Enhancements to Energy Price Formation." https://www.pjm.com/-/media/library/reports-notices/special-reports/20171115-proposedenhancements-to-energy-price-formation.ashx.

PJM Interconnection. 2018. "Price Formation Education Sessions." https://www.pim.com/committees-and-groups/stakeholder-meetings/price-formation.aspx.

Scarf, Herbert E. 1990. "Mathematical Programming and Economic Theory." Operations Research 38 (3): 377-85. https://doi.org/10.1287/opre.38.3.377.

Schiro, Dane, and Matthew White. 2015. Real-Time Price Formation: Energy Market Offer Design. ISO-NE Technical Session. Sturbridge, MA. https://www.iso-ne.com/staticassets/documents/2015/06/price_information_technical_session11.pdf.

Schiro, Dane A., Tongxin Zheng, Feng Zhao, and Eugene Litvinov. 2016. "Convex Hull Pricing in Electricity Markets: Formulation, Analysis, and Implementation Challenges." IEEE Transactions on Power Systems 31(5): 4068-75. https://ieeexplore.ieee.org/stamp/stamp.jsp?arnumber=7310885

Schweppe, Fred C., Michael C. Caramanis, Richard D. Tabors, and Roger E. Bohn. 1988. Spot Pricing of Electricity. Boston, MA: Kluwer Academic Publisher.

Seel, Joachim, Andrew Mills, Ryan Wiser, Sidart Deb, Aarthi Asokkumar, Mohammad Hassanzadeh, and Amirsaman Aarabali. 2018. Impacts of High Variable Renewable Energy Futures on Wholesale Electricity Prices, and on Electric-Sector Decision Making. Berkeley, CA: Lawrence Berkeley National Laboratory. https://emp.lbl.gov/publications/impacts-high-variablerenewable.

Sioshansi, Ramteen, Richard O’Neill, and Shmuel S. Oren. 2008. "Economic Consequences of Alternative Solution Methods for Centralized Unit Commitment in Day-Ahead Electricity Markets." IEEE Transactions on Power Systems. https://doi.org/10.1109/TPWRS.2008.919246.

Stoft, Steven. 2002. Power System Economics: Designing Markets for Electricity. Piscataway, NJ: IEEE Press.

Van Vyve, Mathieu. 2011. Linear Prices for Non-Convex Electricity Markets: Models and Algorithms. Center for Operations Research and Econometrics Discussion Paper. http://www.ulouvain.be/cps/ucl/doc/core/documents/coredp2011_50web.pdf. 
Wang, Congcong, Tengshun Peng, Peter B. Luh, Paul Gribik, and Li Zhang. 2013. "The Subgradient Simplex Cutting Plane Method for Extended Locational Marginal Prices." IEEE

Transactions on Power Systems 28 (3): 2758-67. https://doi.org/10.1109/TPWRS.2013.2243173.

Zheng, Tongxin, Feng Zhao, Dane Schiro, and Eugene Litvinov. 2018. "The Hidden Properties of Fast Start Pricing." In Increasing Market and Planning Efficiency and Enhancing Resilience through Improved Software. Washington D.C.: FERC.

https://www.ferc.gov/CalendarFiles/20180626080613-T1 - 3 - HiddenPropertiesOfFSP-

TZheng ISONE.pdf. 


\section{Appendix A: International Pricing Method Comparison}

This section describes pricing methods from around the world, comparing mechanisms for market clearing and price determination. Wholesale electricity markets across the world share some similarities with U.S. markets, but varying regional and political factors result in different designs, participants, and functionality. This section discusses several of these markets, focusing on the pricing method and formulation rather than the market as a whole. The section does not discuss the broader political landscape or set of reforms that lead to the market design, or the long-term contracts for power that often surround spot markets. The comparison is meant to provide a high-level overview of algorithmic pricing attributes of a market. The section first shows a comparison table, followed by brief descriptions for each country. The resources used to construct the comparison are found in the individual country sections, and a detailed transmission pricing review that includes a discussion of wholesale markets is available from Frontier Economics (2009).

Table A-1 compares a range of countries that have implemented a wholesale market for electricity. The first three columns list the country or region name, the system operator name, and basic characteristics of the system. Some operators have a similar role to U.S. ISOs, such as Ontario's IESO, while others split ISO functionality between several organizations, such as the European power exchanges and transmission system operators. The basic system characteristics are provided in rounded numbers based on available public information.

The next three columns describe characteristics of the pricing method in the region. Since the discussion of price formation in the United States has focused on the incorporation of commitment costs that units are allowed to offer into the market, the fourth column briefly describes the bid and offer parameters accepted by the market. The fifth column focuses on the method used to determine prices. While the country specific text following the table provides further detail, this column differentiates between methods that exclusively use price/quantity pairs to clear the market (merit order clearing), those which involve other constraints but still clear based on the marginal unit (marginal cost pricing), and other multi-step methods. The last column lists how many prices arise from the market (single, zonal, nodal), and the time frame for market clearing (day-ahead, real-time, etc.). Terms that might not be evident in the table will be further described in the country specific text. 
Table A-1. International Price Formation Efforts

\begin{tabular}{|c|c|c|c|c|c|}
\hline Region & Operator & Basic Characteristics & Bid \& Offer Parameters & Pricing Method & Prices and Market Timing \\
\hline Australia & $\begin{array}{l}\text { Australian } \\
\text { Energy Market } \\
\text { Operator }\end{array}$ & $\begin{array}{l}54 \text { GW capacity; } \\
197 \text { TWh generated (2017); } \\
9 \text { million customers; } \\
\text { Energy-only market }\end{array}$ & $\begin{array}{l}\text { Single-part bidding; } \\
\text { Resources allowed to bid, re-bid or } \\
\text { use default bids with } 10 \\
\text { price/quantity }(p / q) \text { pairs }\end{array}$ & Merit order clearing & $\begin{array}{l}\text { Zonal pricing, } 5 \text { zones; } \\
\text { Real-time 5-minute spot market }\end{array}$ \\
\hline $\begin{array}{c}\text { New } \\
\text { Zealand }\end{array}$ & $\begin{array}{l}\text { Electricity } \\
\text { Authority }\end{array}$ & $\begin{array}{l}10 \text { GW capacity; } \\
38 \text { TWh consumed }(2016 / 7) ; \\
2 \text { million customers; } \\
\text { Energy-only market }\end{array}$ & $\begin{array}{l}\text { Single-part bidding; } \\
\text { Resources allowed to offer } 5 \\
\text { increasing p/q pairs and must offer } \\
71 \text { periods prior }\end{array}$ & Marginal cost pricing & $\begin{array}{l}\text { Nodal pricing; } \\
\text { Real-time } 30 \text {-minute spot } \\
\text { market }\end{array}$ \\
\hline Argentina & $\begin{array}{l}\text { Compañía } \\
\text { Administradora } \\
\text { del Mercado } \\
\text { Mayorista } \\
\text { Eléctrico }\end{array}$ & $\begin{array}{l}36 \text { GW capacity; } \\
132 \text { TWh generated (2016); } \\
15 \text { million customers; } \\
\text { Energy-only market }\end{array}$ & $\begin{array}{l}\text { Single-part bidding; } \\
\text { Resources offer no more than } 115 \% \\
\text { of their fuel costs }\end{array}$ & $\begin{array}{l}\text { Marginal cost pricing; } \\
\text { Generators receive a fixed } \\
\text { capacity charge }(\$ 10 / \mathrm{MWh}) \\
\text { during certain hours }\end{array}$ & $\begin{array}{l}\text { Nodal pricing; } \\
\text { Futures market, hourly spot } \\
\text { market, balancing market }\end{array}$ \\
\hline Chile & $\begin{array}{l}\text { Coordinador } \\
\text { Eléctrico } \\
\text { Nacional }\end{array}$ & $\begin{array}{l}24 \text { GW capacity (2019); } \\
74 \text { TWh generated (2016) }\end{array}$ & $\begin{array}{l}\text { Resources declare their marginal } \\
\text { costs to operators, including } \\
\text { opportunity costs for hydro }\end{array}$ & $\begin{array}{l}\text { Merit order clearing; } \\
\text { Generators receive monthly } \\
\text { capacity payments }\end{array}$ & $\begin{array}{l}\text { Node-based pricing; } \\
\text { Real-time 60-minute spot } \\
\text { market }\end{array}$ \\
\hline Europe & $\begin{array}{l}\text { European } \\
\text { Power } \\
\text { Exchanges: } \\
\text { Price Coupling } \\
\text { of Regions }\end{array}$ & $\begin{array}{l}\text { 1000 GW capacity in } \\
\text { ENTSO-E (2017); } \\
\text { Project co-owned by } 8 \text { power } \\
\text { exchanges }\end{array}$ & $\begin{array}{l}\text { Multi-part bidding; } \\
\text { Many types of orders are accepted, } \\
\text { including minimum income orders, } \\
\text { block orders: regular, profile, linked, } \\
\text { exclusive, flexible hourly }\end{array}$ & $\begin{array}{l}\text { Complex pricing algorithm } \\
\text { called EUPHEMIA, includes } \\
\text { integers variables and is } \\
\text { solved using decomposition } \\
\text { into several sub-problems }\end{array}$ & $\begin{array}{l}\text { Zonal pricing, } 1 \text { or more zone } \\
\text { per country; } \\
\text { Day-ahead and intraday } \\
\text { markets, countries have } \\
\text { separate balancing (real-time) } \\
\text { markets }\end{array}$ \\
\hline $\begin{array}{l}\text { Alberta, } \\
\text { Canada }\end{array}$ & $\begin{array}{l}\text { Alberta Electric } \\
\text { System } \\
\text { Operator }\end{array}$ & $\begin{array}{l}18 \text { GW capacity; } \\
82 \text { TWh energy (2017); } \\
4 \text { million customers }\end{array}$ & $\begin{array}{l}\text { Single-part bidding; } \\
\text { Must bid positive values }\end{array}$ & Merit order clearing & $\begin{array}{l}\text { Singe price; } \\
\text { Real-time market, prices } \\
\text { calculated every minute }\end{array}$ \\
\hline $\begin{array}{l}\text { Ontario, } \\
\text { Canada }\end{array}$ & $\begin{array}{l}\text { Independent } \\
\text { Electric System } \\
\text { Operator }\end{array}$ & $\begin{array}{l}37 \text { GW capacity; } \\
137 \text { TWh energy (2018); } \\
4.9 \text { million customers; } \\
\text { Energy-only market }\end{array}$ & $\begin{array}{l}\text { Single-part bidding; } \\
\text { Resources offer between } 2-20 \text { p/q } \\
\text { pairs and fast-start resources include } \\
\text { commitment costs in bids }\end{array}$ & $\begin{array}{l}\text { Two-stage clearing; } \\
\text { Prices reflect commitment } \\
\text { costs for fast-start units }\end{array}$ & $\begin{array}{l}\text { Single price; } \\
\text { Real-time 5-minute spot market }\end{array}$ \\
\hline $\begin{array}{l}\text { South } \\
\text { Korea }\end{array}$ & $\begin{array}{l}\text { Korea Power } \\
\text { Exchange }\end{array}$ & $\begin{array}{l}117 \text { GW capacity }(2017) ; \\
553 \text { TWh generated }(2017)\end{array}$ & $\begin{array}{l}\text { Resources submit their hourly } \\
\text { capacity for energy and ancillary } \\
\text { services; Capital and incremental } \\
\text { costs are evaluated by a third party } \\
\text { monthly; } \\
\text { Single-buyer }\end{array}$ & $\begin{array}{l}\text { Marginal cost pricing, system- } \\
\text { wide, adjusted by transmission } \\
\text { marginal loss factors for all the } \\
\text { generators; } \\
\text { Plants receive capacity } \\
\text { payments and separate } \\
\text { ancillary service fees are paid } \\
\text { to eligible generators }\end{array}$ & $\begin{array}{l}\text { Single price; } \\
\text { Day-ahead market }\end{array}$ \\
\hline
\end{tabular}




\section{Australia}

The Australian energy-only market is operated by the Australian Energy Market Operator. Resources with minimum operating levels self-commit into the market and try to bid into the market reflecting those costs. For instance, a generator can bid quantities below their minimum operating level at the market price floor, which can be -1,000 AUD/MWh. Typically, only fast start resources are committed by the market software due to their inflexibility. For these resources, start-up costs and any no-load costs are part of the single bid. Meaning, if a generator has a 2000 AUD start-up cost and 50 AUD/MWh marginal cost, it can bid 2050 AUD/MWh.

Two recent rulings by the Australian Energy Market Commission consider prices and bidding. First, a December 2015 ruling determined that generators must not submit false or misleading offers, and instead bid in good faith. Second, a November 2017 ruling updated the settlement period for the spot market. In settlements today, 5-minute prices are averaged every 30-minutes (6 periods) for settlement. In 2021, the pricing and settlement will both be every 5 minutes. A final minor note, LMP within the AEMO context refers to a gas pipeline called the Longford to Melbourne Pipeline.

\section{Resources}

- AEMO. 2010. “An Introduction to Australia's National Electricity Market." https://www.abc.net.au/mediawatch/transcripts/1234_aemo2.pdf.

- Australian Energy Market Commission. 2018. "Gaming in Rebidding Assessment.” Final Report. https://www.aemc.gov.au/sites/default/files/2018-10/Final\%20report.pdf

- Australian Energy Market Commission. 2015. "Bidding in Good Faith." Final Rule. https://www.aemc.gov.au/rule-changes/bidding-in-good-faith.

- Australian Energy Market Commission. 2017. "Five Minute Settlement." Final Rule. https://www.aemc.gov.au/rule-changes/five-minute-settlement.

- AEMO. "Fact Sheet: The National Electricity Market." https://www.aemo.com.au//media/Files/Electricity/NEM/National-Electricity-Market-Fact-Sheet.pdf.

- AEMO. 2018. "AEMO Annual Report: Leading the Transformation." http://www.aemo.com.au/About-AEMO/Annual-report.

- Thorpe, G.H. 2015. "Comparison of NZEM and Australian NEM" prepared for Electricity Authority of New Zealand by Oakley Greenwood. https://www.ea.govt.nz/dmsdocument/19226-appendix-b-report-from-oakley-greenwood.

- F. Billimoria and R. Poudineh. 2018. "Electricity Sector Transition in the National Electricity Market of Australia: Managing Reliability and Security in an Energy-Only Market." Oxford Institute for Energy Studies Paper. EL 31. https://www.oxfordenergy.org/wpcms/wp-content/uploads/2018/11/Electricity-SectorTransition-in-the-National-Electricity-Market-of-Australia-Managing-Reliability-andSecurity-in-an-Energy-Only-Market-EL-31.pdf.

\section{New Zealand}

The New Zealand market is operated under the Electricity Authority, and the transmission system is operated by the state-run Transpower. Market participants use the wholesale information and trading system (WITS) to submit bids and offers into the real-time 30-minute market. There is no forward market, but there are opportunities to hedge congestion risk. 
Energy and reserve offers are co-optimized in the real-time market. The minimum price bid allowed is $\$ 0 / \mathrm{MWh}$ NZD, while there is no maximum (functionally, it is $\$ 999,999.99 / \mathrm{MWh}$ NZD). Similar to U.S. ISOs, New Zealand uses nodal pricing, with clearing similar to the Traditional LMP described in Section 2.2. Unlike the United States, start-up and no-load costs are not part of the bid structure.

\section{Resources}

- Electricity Authority. 2018. "Electricity in New Zealand.” https://www.ea.govt.nz/aboutus/media-and-publications/electricity-nz/.

- Electricity Authority. 2017. "Electricity Authority Wholesale Information and Trading System Functional Specification." https://www.ea.govt.nz/operations/market-operation-service-providers/wits-manager/.

- Electricity Authority. 2019. "Electricity Industry Participation Code 2010, Part 13 Trading Arrangements." https://www.ea.govt.nz/code-and-compliance/the-code/part-13trading-arrangements/.

- Philpott, Andy, G. Read, S. Batstone, and A. Miller. 2019. "The New Zealand Electricity Market: Challenges of a Renewable Energy System." IEEE Power and Energy Society Magazine, 17 (1).

\section{Argentina}

The wholesale energy market (MEM) in Argentina is operated by the Compañía Administradora del Mercado Mayorista Eléctrico (CAMMESA). CAMMESA is owned by five entities equally: generation, large users, distributors, transmission companies, and the Secretary of Energy. CAMMESA clears the market based on marginal cost pricing, with a central 'market' node in the System Load Center. Locational congestion components are then added relative to delivery to that node.

Bids can include commitment costs, such as start-up costs, but they are not used in determining price. Generators will recover these fixed costs through a capacity charge added to the marginal price if they operate during certain hours. Determined in 1994, the charge was fixed to \$10/MWh USD. Bids are also limited to $115 \%$ of fuel costs; contracts for fuel are reviewed by the operator.

\section{Resources}

- Vagliasindi, M. and J. Besant-Jones. 2013. "Chapter 2 Argentina.” Power Market Structure: Revisiting Policy Options. The World Bank. Washington, D.C. http://documents.worldbank.org/curated/en/795791468314701057/pdf/Power-marketstructure-revisiting-policy-options.pdf.

- Pollitt, Michael. 2008. "Electricity Reform in Argentina: Lessons for Developing Countries," Energy Economics. 30: 1536-1567.

- Sijm, J.P.M. 2015. "The Governance Model of Power Transmission in Argentina." ECN Report E--15-063. https://publicaties.ecn.nl/PdfFetch.aspx?nr=ECN-E--15-063.

- Ferreira, P.J.A. 2002. "On the Efficiency of the Argentinean Electricity Wholesale Market," Department of Economics, University of Chicago.

- Nunez-Luna, A. and E.J. Woodhouse. 2005. "The IPP Investment Experience in Argentina." Working Paper \#44, The Program on Energy and Sustainable Development at Stanford University. 


\section{Chile}

The two largest networks in Chile, SIC and SING, are now part of a single large network named Sistema Eléctrico Nacional (SEN), operated by the Coordinador Eléctrico Nacional (CEN). Generators are dispatched according to their declared actual expected energy costs (fuel and maintenance), which are sometimes audited. The regulator optimizes the use of water in large hydroelectric power plants using a stochastic program. The resulting value of water is used for dispatch and pricing of the resource in the short-term.

The market is a cost-based market, sometimes called a "simulated spot market." Pricing is based on the marginal generator in the system. The marginal resource is often a hydro unit, which sets its marginal cost to the opportunity cost of water in the system. Prices can also reflect shortages in the system, including predicted water shortages. Unlike full nodal pricing in U.S. markets, the node price reflects system losses; it should also be noted that the Chilean system is mostly radial. Customers pay a price that includes a semiannually fixed node price determined by the regulator, Comisión Nacional de Energía.

\section{Resources}

- Pollitt, Michael. 2004. Electricity Reform in Chile: Lessons for Developing Countries. Working Paper. Development Research Group, World Bank.

- Galetovic, Alexander, Cristián M. Muñoz, and Frank A. Wolak. 2015. "Capacity Payments in a Cost-Based Wholesale Electricity Market: The Case of Chile." The Electricity Journal 28 (10): 80-96. https://doi.org/10.1016/j.tej.2015.10.011.

- Comisión Nacional de Energía. "Pricing: Electricity" and "Statistics: Electricity." https://www.cne.cl/en/tarificacion/electrica/

- Coordinador Eléctrico Nacional. 2019. "Objetivos y funciones." https://www.coordinador.cl/nosotros/objetivos-y-funciones/

- Central Energía. "Regulation.” http://www.centralenergia.cl/en/electric-market$\underline{\text { regulation-chile/ }}$

- Munoz, Francisco D., Sonja Wogrin, Shmuel S. Oren and Benjamin F. Hobbs. "Economic Inefficiencies of Cost-based Electricity Market Designs." The Energy Journal. 39 (3). https://doi.org/10.5547/01956574.39.3.fmun

\section{Europe}

European markets and grid operations vary significantly by country. Day-ahead and intraday markets are operated by power exchanges, and bulk system operations are managed by transmission system operators (TSOs). This section focuses on the European-wide organizations rather than individual operations within a country. Among the European wide organizations is the Association of European Energy Exchanges, or Europex. Their 26 member exchanges can be contained within or span several countries. Another large organization is the European Network of Transmission System Operators (ENTSO-E). Individually, TSOs are responsible for operating the bulk power system within their region and they allow market participants access to the grid; 43 TSOs from 36 countries are organized under ENTSO-E. The TSOs run the real-time or balancing markets and reserve auctions in control areas, which are different from market zones. While separate from day-ahead and intraday auctions, volumes can be significant in the balancing markets. 
In order to harmonize European day-ahead electricity markets, eight exchanges operate a Price Coupling of Regions project, which is co-owned and co-operated by the members. The countries within the project include Austria, Belgium, Czech Republic, Croatia, Denmark, Estonia, Finland, France, Germany, Hungary, Italy, Ireland, Latvia, Lithuania, Luxembourg, the Netherlands, Norway, Poland, Portugal, Romania, Slovakia, Slovenia, Spain, Sweden and the United Kingdom. The market coupling process is coordinated by nominated electricity market operators (NEMOs) and the NEMO Committee.

An algorithm was developed to complete the difficult project task of coupling day-ahead markets across Europe, called EUPHEMIA. The process considers supply and demand from across the exchanges and maximizes social welfare. The bid and offer structure is complex, with many order types and rules, including offers that add integer variables to the model. The Balance Responsible Parties, or market participant responsible for imbalances in real-time, bid their portfolio positions then nominate their production schedule to the TSOs in advance, which means they do not need to bid their marginal costs.

The clearing problem is similarly complex, a mixed integer quadratic program, which must be decomposed into smaller problems to solve: one master and three interdependent sub-problems. The master problem maximizes market surplus and includes network constraints reflecting cross border Net Transfer Capacities calculated using flow based coupling; intra-zonal congestion is not modeled. One sub-problem determines prices for each bidding zone, the second solves prices for a type of demand merit order (called PUN), and the third considers curtailment following volume indeterminacy rules. Due to the complexity of the bidding structure and the additional sub-problems that must be solved to determine prices, it is difficult to directly compare the algorithm with other methods discussed in this paper.

\section{Resources}

- NEMO Committee. 2019. "EUPHEMIA Public Description Single Price Coupling Algorithm." https://www.nordpoolspot.com/globalassets/download-center/pcr/euphemiapublic-description.pdf

- NEMO Committee. "All NEMOs.” https://www.europex.org/all-nemos/all-nemos/

- PCR PXs. 2018. "EUPHEMIA Public Description PCR Market Coupling Algorithm." http://www.enexgroup.gr/fileadmin/groups/PCR/Euphemia_Public_Description.pdf

- EPEX Spot. 2019. "Market Coupling, PCR: Price Coupling of Regions." https://www.epexspot.com/en/market-coupling/pcr

- ENSTO-E. 2016. "Governance of the Market Coupling Operation Functions Transmission: System Operators' Perspective." https://docstore.entsoe.eu/Documents/Publications/Position\%20papers\%20and\%20report s/entsoe pp MCO web\%20(002).pdf

- ENTOS-E. 2019. "Power Statistics.” https://www.entsoe.eu/data/power-stats/

\section{Alberta, Canada}

Alberta Electric System Operator (AESO) was established by the Province of Alberta to operate and manage the bulk power system. AESO takes in supply offers and demand bids, and dispatches lower cost resources first (merit order dispatch). Offers and bids must be $\$ 0 / \mathrm{MWh}$ or greater, meaning they are not allowed to bid negative values. The dispatch instructions are 
updated as it gets closer to real-time on an as needed basis depending on shifts in demand. The price, called the System Marginal Price, is then determined every minute based on the dispatched resourced with the highest marginal cost at that moment. Financial settlement uses the pool price, or the hourly average of the minute-by-minute System Marginal Price.

While the Alberta market is currently an energy-only market, plans are developing for a capacity market. Many designs have been considered with a goal implementation date of 2021.

\section{Resources}

- AESO. 2018. "Overview of the Alberta Capacity Market: Comprehensive Market Design Final proposal.” https://www.aeso.ca/market/capacity-market-transition/comprehensivemarket-design/.

- AESO. 2018. "Determining the Wholesale Market Price for Electricity." https://www.aeso.ca/market/understanding-the-market/.

- AESO. 2018. “Annual market statistics reports.” https://www.aeso.ca/market/marketand-system-reporting/annual-market-statistic-reports/.

- AESO. 2018. "Electricity in Alberta." https://www.aeso.ca/aeso/electricity-in-alberta/.

\section{Ontario, Canada}

The Independent Electric System Operator (IESO) runs the market for Ontario. The pricing method is a "two-schedule" system that first dispatches the system considering network constraints and participant bids and offers. The price is then calculated ignoring network effects, and any generators that do not recover costs are made whole using a side payment that includes lost cost and lost opportunity. Generators additionally receive a global adjustment payment made by loads meant to fund generator procurement contracts and conservation programs. The payment can often be a significant part of the revenue received from the market.

Generators that are dispatchable and are not considered to be a quick-start facility are guaranteed cost recovery; they provide the start-up and no-load costs, minimum operating level, and minimum generation block run-time to IESO. Generators that qualify as a quick-start facility can include all commitment and start-up costs in their energy bid. Their minimum operating level is relaxed to zero during the pricing run, which results in prices that reflect both incremental, startup, and commitment costs. Additionally, generators that have longer minimum run times are relaxed to zero for the pricing run. Although the minimum is relaxed, prices only reflect incremental costs.

IESO is evaluating different options to update several aspects of their market design, called market renewal. Among the considerations is moving to a single-schedule dispatch and pricing system, which is similar to U.S. ISO LMP pricing that considers congestion. The high-level design was completed in August 2019 and can be found on the IESO website. A second relevant change is the move to a day-ahead market. While resources are currently committed day-ahead to meet reliability needs, settlement occurs in real-time. This change would implement a dispatch and pricing auction day-ahead. 


\section{Resources}

- Independent Electricity System Operator. 2018. "IESO 2017 Annual Report." http://www.ieso.ca/-/media/Files/IESO/Document-Library/annual-reports/ieso2017annualreport.pdf

- Independent Electricity System Operator. 2018. "Chapter 7 System Operations and Physical Markets." Market Rules for the Ontario Electricity Market. http://www.ieso.ca/Sector-Participants/Market-Operations/Market-Rules-And-ManualsLibrary.

- Independent Electricity System Operator. "Year-End Electricity Data." http://www.ieso.ca/en/Corporate-IESO/Media/Year-End-Data.

- Market Surveillance Panel. 2018. "Monitoring Report on the IESO-Administered Electricity Markets.” https://www.oeb.ca/sites/default/files/msp-monitoring-report20180322.pdf.

\section{South Korea}

The Korea Power Exchange was established in 2001 as a pool-based market for generators and load. In South Korea there is a single buyer for electricity, Korea Electric Power Corporation (KEPCO), who also operates the transmission and distribution system. Generation includes some independent power producers along with KEPCO owned generation subsidiaries.

All generators submit capacity for energy and ancillary services to the market. At the same time, the market evaluates costs of capital (construction) annually and incremental fuel costs monthly. The price, called the System Marginal Price, is determined from a separate Price Settling Schedule for energy only. The schedule excludes some generator and all transmission constraints and therefore will not reflect congestion. The determinization includes start-up and incremental fuel costs, and results in a price that reflects the highest cost unit in the Price Settling Schedule (marginal cost pricing). In addition to the System Marginal Price, generators receive capacity payments regardless of their dispatch as well as ancillary service fees.

\section{Resources}

- Korea Power Exchange. 2015. "Market Price Determination." https://www.kpx.or.kr/eng/contents.do?key=302

- Korea Electric Power Corporation. 2013. "Overview of Korea's Electric Power Industry." http://home.kepco.co.kr/kepco/EN/B/htmlView/ENBAHP001.do?menuCd=EN020101

- Park, Jung-Yeon, Nam-sung Ahn, Yong-Beum Yoon, Kyung-ho Koh, and Derek W. Bunn. 2007. "Investment Incentives in the Korean Electricity Market." Energy Policy 35 (11): 5819-5828. http://dx.doi.org/10.1016/j.enpol.2007.06.025.

- U.S Energy Information Administration. 2018. "Country Analysis Brief: South Korea." https://www.eia.gov/beta/international/analysis.php?iso=KOR.

- Kim, Young-Chang and Konstantin Petrov. 2012. "Recent Development of Restructuring of the Korean Power Sector.” KEMA Report. https://www.nbr.org/wpcontent/uploads/pdfs/programs/PES 2012_Young-Chang_KimConstantin Petrov handout.pdf

- Tsai, Chung Min. 2016. "The Political Economy of Restructuring the Electricity Sector in South Korea." Issues \& Studies: A Social Science Quarterly on China, Taiwan, and East Asian Affairs 52 (1). https://doi.org/10.1142/S1013251116500041. 


\section{Appendix B: Price Duration Curves}

This section provides additional price duration curve figures related to the pricing outcomes described in Section 4.1. The price duration curves shown in Figure 5 begin the $y$-axis at \$200/MWh to focus on the "elbow" of each curve, which is difficult to see in the full version, shown in Figure B-1. Values above \$1,000/MWh are periods where multiple violations occurred, causing additional penalties. These violations include ramping, congestion, and reserve shortages for the day-ahead market.

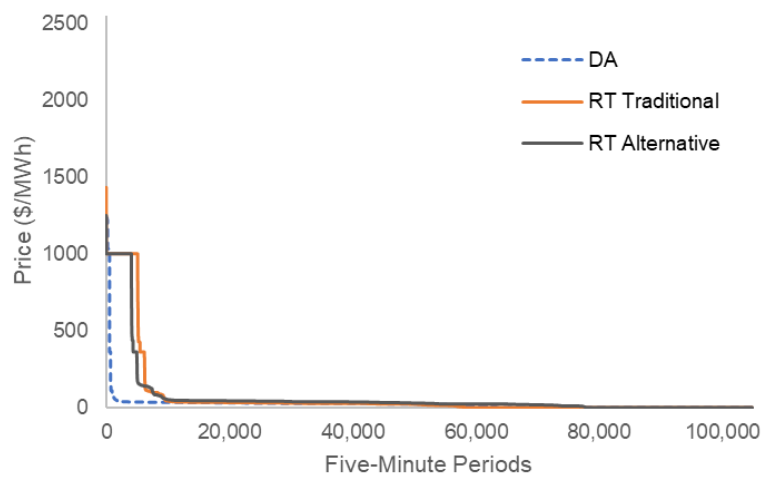

a)

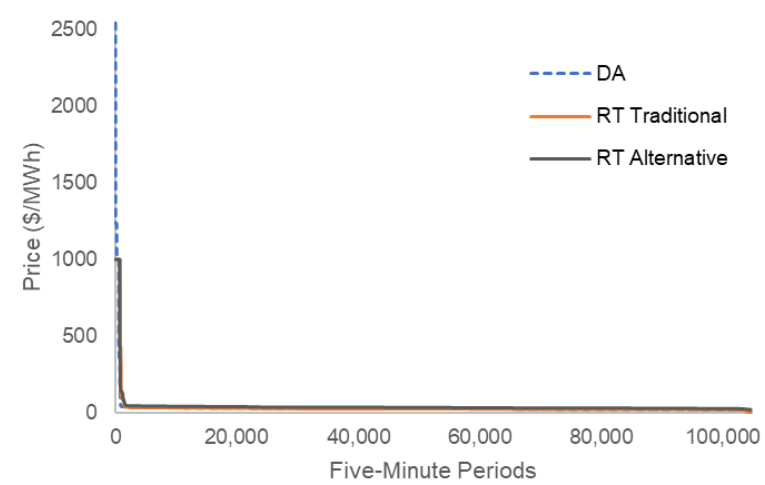

c)

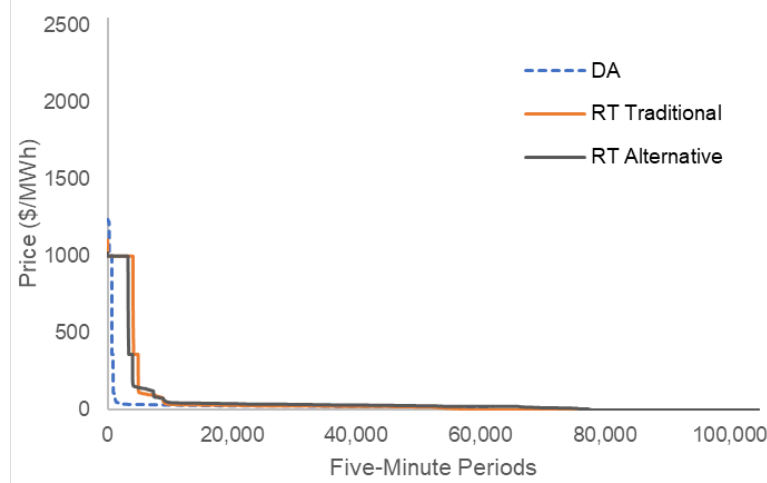

b)

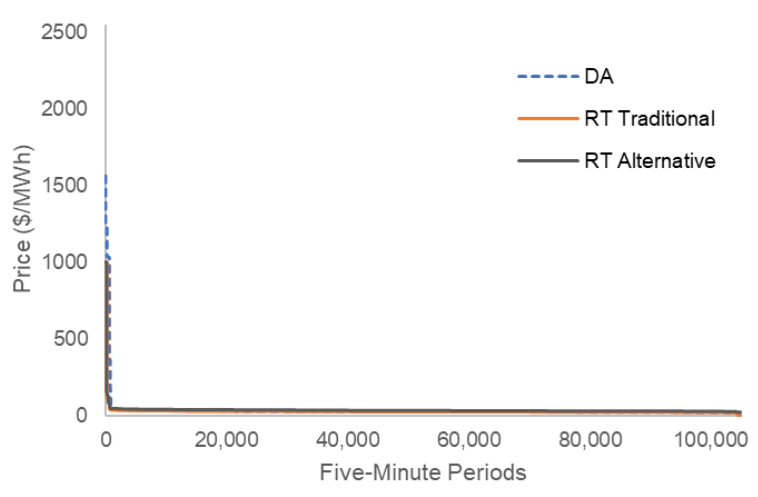

d)

Figure B-1. Price duration curves for (a) high/adjusted, (b) high/unadjusted, (c) low/adjusted, (d) low/unadjusted scenarios 


\section{Appendix C: Heat Maps}

This section shows heat maps related to the pricing outcomes described in Section 4.1. The additional heatmaps from the unadjusted cases are shown in Tables $\mathrm{C}-1$ through $\mathrm{C}-4$, which show the same trends as the adjusted cases.

Table C-1. Heat Map of Traditional Average Real-Time Prices for the High/Unadjusted Scenario over the Course of a Day (24 hours) for Each Month of the Year in \$/MWh

$\begin{array}{lrrrrrrrrrrrrrrrrrrrrrrrrrrrrrr}\text { Hour } & 1 & 2 & 3 & 4 & 5 & 6 & 7 & 8 & 9 & 10 & 11 & 12 & 13 & 14 & 15 & 16 & 17 & 18 & 19 & 20 & 21 & 22 & 23 & 24 \\ \text { Jan } & 17 & 16 & 45 & 39 & 58 & 117 & 399 & 18 & 0 & 0 & 0 & 0 & 0 & 0 & 0 & 0 & 36 & 171 & 74 & 52 & 53 & 31 & 86 & 44 \\ \text { Feb } & 41 & 47 & 30 & 25 & 128 & 257 & 454 & 7 & 0 & 0 & 0 & 0 & 0 & 9 & 4 & 4 & 10 & 178 & 109 & 39 & 92 & 35 & 120 & 61 \\ \text { Mar } & 90 & 71 & 39 & 71 & 152 & 504 & 128 & 5 & 0 & 0 & 0 & 0 & 0 & 3 & 2 & 13 & 4 & 137 & 166 & 38 & 49 & 54 & 53 & 93 \\ \text { Apr } & 88 & 105 & 110 & 128 & 347 & 450 & 9 & 1 & 4 & 1 & 1 & 1 & 0 & 0 & 0 & 0 & 2 & 114 & 183 & 168 & 45 & 39 & 57 & 119 \\ \text { May } & 72 & 34 & 77 & 98 & 379 & 57 & 5 & 0 & 0 & 0 & 0 & 0 & 0 & 0 & 1 & 1 & 3 & 32 & 83 & 106 & 35 & 27 & 22 & 94 \\ \text { Jun } & 35 & 51 & 32 & 120 & 442 & 16 & 5 & 3 & 1 & 0 & 1 & 2 & 3 & 8 & 37 & 30 & 9 & 19 & 73 & 58 & 40 & 29 & 26 & 157 \\ \text { Jul } & 38 & 90 & 73 & 147 & 458 & 32 & 12 & 3 & 0 & 0 & 0 & 3 & 6 & 8 & 9 & 11 & 15 & 24 & 111 & 58 & 30 & 28 & 68 & 201 \\ \text { Aug } & 50 & 26 & 41 & 36 & 29 & 206 & 14 & 2 & 0 & 0 & 0 & 0 & 2 & 4 & 7 & 8 & 12 & 25 & 32 & 30 & 28 & 29 & 53 & 57 \\ \text { Sep } & 32 & 36 & 58 & 73 & 81 & 551 & 9 & 0 & 0 & 0 & 0 & 0 & 0 & 1 & 2 & 3 & 11 & 40 & 62 & 32 & 25 & 26 & 67 & 79 \\ \text { Oct } & 29 & 38 & 35 & 39 & 110 & 488 & 18 & 1 & 0 & 0 & 0 & 0 & 0 & 0 & 0 & 0 & 43 & 41 & 29 & 73 & 50 & 21 & 44 & 51 \\ \text { Nov } & 57 & 42 & 55 & 17 & 125 & 24 & 159 & 0 & 0 & 0 & 0 & 0 & 0 & 0 & 0 & 0 & 147 & 109 & 26 & 25 & 17 & 22 & 83 & 50 \\ \text { Dec } & 29 & 53 & 27 & 89 & 135 & 19 & 49 & 33 & 0 & 0 & 0 & 0 & 1 & 15 & 3 & 2 & 170 & 196 & 39 & 73 & 63 & 49 & 114 & 67\end{array}$

Table C-2. Heat Map of Relaxed Minimum Average Real-Time Prices for the High/Unadjusted Scenario in \$/MWh

\begin{tabular}{|c|c|c|c|c|c|c|c|c|c|c|c|c|c|c|c|c|c|c|c|c|c|c|c|c|}
\hline 10ui & & & & & & & & & 9 & & & & & 4 & 15 & 16 & 17 & 18 & 19 & 20 & 21 & 22 & 23 & 24 \\
\hline & 34 & 29 & & 54 & & 11 & 24 & & & 0 & 0 & & 0 & 0 & 0 & 1 & & & 82 & 2 & 1 & & 92 & 42 \\
\hline & & & & 37 & & 88 & & & & 1 & 0 & 0 & & & 6 & 4 & & & & & & & & \\
\hline & & & & 66 & & & & 13 & & ? & & & & 3 & 5 & 15 & & & & & & & & \\
\hline & 81 & & 106 & 114 & & & & 1 & & 0 & 1 & 1 & 1 & 1 & 2 & 4 & 12 & & & & 57 & 47 & & 1 \\
\hline & & & & & & & & 5 & & 0 & I & 1 & 2 & 1 & 1 & 9 & & & 107 & & 46 & 35 & & 88 \\
\hline & & & & & & & 15 & & & $t$ & 0 & $y$ & 11 & 15 & 46 & 39 & & & 90 & & 50 & 36 & 34 & \\
\hline & & & & & & & 25 & 16 & & & & 16 & 19 & 20 & 21 & 22 & & & 118 & 69 & 40 & 37 & 38 & 104 \\
\hline & 57 & & & & & & 24 & 15 & 11 & 11 & 11 & 12 & 14 & 17 & 20 & 20 & & 35 & 43 & 40 & 37 & 35 & 38 & 41 \\
\hline & 42 & & & & 70 & 483 & 22 & 8 & & 4 & 3 & 4 & 6 & 9 & 11 & 14 & 23 & 59 & 71 & 41 & 35 & 33 & 00 & 70 \\
\hline & 34 & 47 & & 47 & 111 & 412 & 32 & 6 & 1 & 0 & 0 & 1 & 1 & 3 & 4 & 10 & 108 & 64 & 38 & 64 & 59 & 31 & 46 & 52 \\
\hline & 46 & 47 & & 29 & & & 120 & 4 & & 0 & 0 & 0 & U & 0 & 0 & 3 & 257 & 118 & 38 & 38 & 30 & 33 & 78 & 59 \\
\hline & 39 & & & 95 & 126 & 175 & 413 & 45 & 3 & 2 & 2 & 2 & 2 & 14 & 5 & 5 & 219 & 190 & 53 & 77 & 66 & 53 & 77 & 80 \\
\hline
\end{tabular}


Table C-3. Heat Map of Traditional Average Real-Time Prices for the Low/Unadjusted Scenario in $\$ / M W h$

$\begin{array}{llllllllllllllllllllllllllll}\text { Hour } & 1 & 2 & 3 & 4 & 5 & 6 & 7 & 8 & 9 & 10 & 11 & 12 & 13 & 14 & 15 & 16 & 17 & 18 & 19 & 20 & 21 & 22 & 23 & 24 \\ \text { Jan } & 23 & 23 & 23 & 23 & 23 & 25 & 30 & 27 & 23 & 22 & 21 & 21 & 21 & 21 & 21 & 21 & 24 & 37 & 31 & 35 & 27 & 29 & 27 & 24 \\ \text { Feb } & 24 & 23 & 23 & 23 & 23 & 25 & 34 & 24 & 22 & 22 & 22 & 22 & 21 & 21 & 22 & 22 & 23 & 27 & 39 & 30 & 32 & 31 & 27 & 26 \\ \text { Mar } & 23 & 23 & 23 & 23 & 24 & 25 & 25 & 23 & 22 & 22 & 21 & 21 & 21 & 21 & 21 & 22 & 22 & 25 & 69 & 35 & 47 & 27 & 25 & 24 \\ \text { Apr } & 24 & 24 & 24 & 26 & 48 & 37 & 22 & 21 & 21 & 20 & 20 & 20 & 20 & 20 & 21 & 22 & 22 & 23 & 75 & 132 & 50 & 38 & 44 & 29 \\ \text { May } & 24 & 23 & 23 & 22 & 22 & 22 & 21 & 21 & 21 & 22 & 23 & 23 & 24 & 24 & 25 & 25 & 26 & 27 & 27 & 40 & 30 & 47 & 41 & 28 \\ \text { Jun } & 24 & 23 & 23 & 23 & 23 & 22 & 22 & 23 & 24 & 25 & 25 & 26 & 26 & 27 & 28 & 29 & 29 & 29 & 28 & 28 & 31 & 29 & 57 & 31 \\ \text { Jul } & 26 & 24 & 23 & 23 & 23 & 23 & 23 & 24 & 25 & 26 & 26 & 27 & 28 & 28 & 32 & 33 & 31 & 30 & 30 & 30 & 29 & 32 & 33 & 31 \\ \text { Aug } & 25 & 24 & 24 & 24 & 24 & 24 & 24 & 24 & 25 & 25 & 26 & 27 & 27 & 28 & 50 & 30 & 40 & 29 & 29 & 29 & 29 & 38 & 29 & 27 \\ \text { Sep } & 24 & 23 & 23 & 23 & 24 & 52 & 24 & 24 & 24 & 24 & 25 & 25 & 25 & 26 & 26 & 27 & 28 & 29 & 30 & 34 & 29 & 28 & 47 & 27 \\ \text { Oct } & 23 & 23 & 23 & 23 & 23 & 25 & 24 & 22 & 22 & 22 & 23 & 23 & 23 & 23 & 23 & 23 & 25 & 46 & 28 & 59 & 37 & 28 & 41 & 26 \\ \text { Nov } & 23 & 23 & 22 & 22 & 23 & 55 & 42 & 23 & 22 & 21 & 22 & 21 & 21 & 21 & 22 & 22 & 25 & 29 & 28 & 27 & 26 & 25 & 25 & 24 \\ \text { Dec } & 23 & 23 & 23 & 23 & 24 & 27 & 32 & 25 & 23 & 22 & 21 & 20 & 19 & 20 & 20 & 22 & 24 & 27 & 28 & 28 & 27 & 26 & 25 & 24\end{array}$

Table C-4. Heat Map of Relaxed Minimum Average Real-Time Prices for the Low/Unadjusted Scenario in $\$ / M W h$

$\begin{array}{lllllllllllllllllllllllllll}\text { Hour } & 1 & 2 & 3 & 4 & 5 & 6 & 7 & 8 & 9 & 10 & 11 & 12 & 13 & 14 & 15 & 16 & 17 & 18 & 19 & 20 & 21 & 22 & 23 & 24 \\ \text { Jan } & 31 & 31 & 31 & 31 & 32 & 34 & 40 & 36 & 31 & 30 & 29 & 29 & 29 & 29 & 29 & 29 & 32 & 44 & 43 & 43 & 36 & 35 & 36 & 32 \\ \text { Feb } & 33 & 31 & 31 & 31 & 31 & 34 & 43 & 32 & 30 & 29 & 29 & 29 & 29 & 29 & 29 & 29 & 31 & 37 & 48 & 39 & 39 & 37 & 41 & 38 \\ \text { Mar } & 32 & 31 & 31 & 31 & 32 & 34 & 34 & 31 & 30 & 29 & 29 & 29 & 28 & 28 & 29 & 29 & 30 & 34 & 75 & 45 & 38 & 36 & 33 & 32 \\ \text { Apr } & 32 & 32 & 31 & 34 & 53 & 46 & 30 & 29 & 29 & 29 & 29 & 29 & 29 & 29 & 29 & 30 & 30 & 32 & 81 & 141 & 37 & 42 & 51 & 37 \\ \text { May } & 32 & 31 & 30 & 30 & 30 & 30 & 29 & 29 & 30 & 30 & 31 & 32 & 32 & 33 & 33 & 34 & 35 & 36 & 37 & 49 & 36 & 36 & 45 & 39 \\ \text { Jun } & 33 & 32 & 31 & 30 & 30 & 30 & 30 & 31 & 32 & 33 & 34 & 35 & 35 & 36 & 38 & 39 & 39 & 39 & 39 & 38 & 38 & 38 & 44 & 44 \\ \text { Jul } & 35 & 33 & 32 & 31 & 31 & 31 & 31 & 32 & 34 & 35 & 36 & 37 & 38 & 39 & 40 & 43 & 41 & 41 & 40 & 40 & 39 & 39 & 41 & 41 \\ \text { Aug } & 34 & 33 & 32 & 32 & 33 & 33 & 32 & 33 & 34 & 34 & 35 & 36 & 37 & 38 & 60 & 41 & 51 & 40 & 40 & 40 & 39 & 47 & 39 & 37 \\ \text { Sep } & 32 & 31 & 31 & 31 & 32 & 61 & 33 & 32 & 32 & 33 & 33 & 34 & 34 & 35 & 36 & 37 & 38 & 39 & 40 & 39 & 38 & 37 & 46 & 36 \\ \text { Oct } & 31 & 30 & 30 & 31 & 31 & 33 & 32 & 30 & 30 & 30 & 31 & 31 & 31 & 32 & 31 & 32 & 34 & 56 & 38 & 50 & 41 & 36 & 45 & 36 \\ \text { Nov } & 31 & 30 & 30 & 30 & 31 & 61 & 53 & 31 & 29 & 29 & 29 & 29 & 29 & 29 & 30 & 30 & 34 & 38 & 37 & 36 & 35 & 34 & 33 & 32 \\ \text { Dec } & 32 & 31 & 31 & 31 & 32 & 36 & 40 & 34 & 30 & 29 & 29 & 28 & 28 & 28 & 28 & 29 & 33 & 36 & 37 & 37 & 37 & 36 & 34 & 33\end{array}$

